\title{
Macrophage stimulating protein (MSP) in the metabolic syndrome
}

\author{
Citation for published version (APA):
}

Li, J. (2017). Macrophage stimulating protein (MSP) in the metabolic syndrome. [Doctoral Thesis, Maastricht University]. Maastricht University. https://doi.org/10.26481/dis.20170908jl

Document status and date:

Published: 01/01/2017

DOI:

10.26481/dis.20170908jl

Document Version:

Publisher's PDF, also known as Version of record

\section{Please check the document version of this publication:}

- A submitted manuscript is the version of the article upon submission and before peer-review. There can be important differences between the submitted version and the official published version of record.

People interested in the research are advised to contact the author for the final version of the publication, or visit the DOI to the publisher's website.

- The final author version and the galley proof are versions of the publication after peer review.

- The final published version features the final layout of the paper including the volume, issue and page numbers.

Link to publication

\footnotetext{
General rights rights.

- You may freely distribute the URL identifying the publication in the public portal. please follow below link for the End User Agreement:

www.umlib.nl/taverne-license

Take down policy

If you believe that this document breaches copyright please contact us at:

repository@maastrichtuniversity.nl

providing details and we will investigate your claim.
}

Copyright and moral rights for the publications made accessible in the public portal are retained by the authors and/or other copyright owners and it is a condition of accessing publications that users recognise and abide by the legal requirements associated with these

- Users may download and print one copy of any publication from the public portal for the purpose of private study or research.

- You may not further distribute the material or use it for any profit-making activity or commercial gain

If the publication is distributed under the terms of Article $25 \mathrm{fa}$ of the Dutch Copyright Act, indicated by the "Taverne" license above, 
Macrophage stimulating protein (MSP) in the metabolic syndrome 
(C) Jieyi Li, 2017. For all articles published, the copyright has been transferred to the respective publisher. No part of this publication may be reproduced, stored in a retrieval system or transmitted in any form by any means, without prior written permission from the author, or when appropriate, from the publisher.

Cover design and layout by: Tomasz Karawajczyk Cover photography by: Junfang Zhao

Printed by: LT Imprenta, Rijswijk

ISBN: 978-90-9030501-1 


\title{
Macrophage stimulating protein (MSP) in the metabolic syndrome
}

\author{
PROEFSCHRIFT
}

ter verkrijging van de graad van doctor aan de Universiteit Maastricht, op gezag van de Rector Magnificus, Prof. Dr. Rianne M. Letschert volgens het besluit van het College van Decanen, in het openbaar te verdedigen vrijdag, 8 september 2017 om 10:00 uur

door

Jieyi Li

Geboren op 19 augustus 1988 te Henan China 


\section{Promotores}

Prof. dr. R. Shiri-Sverdlov

Prof. dr. J.F.C. Glatz

\section{Co-promotor}

Dr. D. Neumann

\section{Beoordelingscommissie}

Prof. dr. M.K.C. Hesselink (voorzitter)

Prof. dr. J.M. Dekker (Vrije Universiteit Medical Center, Netherlands)

Dr. G.H. Koek

Prof. dr. D. Lütjohann (University of Bonn, Germany) 


\section{Contents}

$\begin{array}{lll}\text { Chapter } 1 & \text { General Introduction } & 7\end{array}$

Chapter 2 MSP: an emerging player in metabolic syndrome

Chapter 3 MSP is a negative regulator of inflammation and lipogenesis in ex vivo models of NASH

Chapter 4 Macrophage stimulating protein enhances hepatic inflammation in a NASH model

Chapter 5 Macrophage stimulating protein (MSP) is inversely associated with fasting plasma glucose: The CODAM Study.

Chapter 6 General Discussion

\section{Appendices}

Summary

Samenvatting

Valorization

Curriculum vitae

Acknowledgments 

Chapter 1

General Introduction 


\section{Metabolic syndrome}

Metabolic syndrome (MetS) is a group of health conditions which is associated with an increased risk for heart disease, stroke, type 2 diabetes (T2DM) and fatty liver disease. The driving forces behind MetS can be attributed to both environmental and genetic factors. Physical inactivity, sedentary lifestyle, overnutrition of low-fiber, fatty and highcaloric foods, and smoking all play an important role on the development of MetS [1]. The underlying pathogenesis of MetS is generally considered as multifactorial: obesity, insulin resistance are acknowledged as important causative factors, while the other factors like hepatic metabolism, immune factors, pro-inflammatory state and hormonal changes are considered as contributors as well [2]. According to the International Diabetes Foundation (IDF), MetS refers to a cluster of conditions: central obesity, high triglyceride levels, low high-density lipoprotein (HDL) cholesterol levels, hypertension, and above-normal blood glucose levels. Individuals with central obesity, plus two additional risk conditions that are mentioned above can be classified as having MetS. Based on these criteria, approximately one quarter of the adult world population have MetS. Despite the availability of a number of treatment options that ameliorate specific aspects of MetS, their overall curative effect is unsatisfactory. Moreover, public prevention programs largely failed their targets. Consequently, the prevalence of MetS is still increasing and it has become a worldwide health threat. Thus, a comprehensive understanding of the pathogenesis and possible new treatment options of MetS are crucial in order to effectively counter this epidemic.

\section{Type 2 Diabetes Mellitus (T2DM)}

The MetS is referred to be a significant predictor of T2DM - a metabolic disorder characterized by chronic hyperglycemia with disturbed carbohydrate, fat and protein metabolism, which results from the body's ineffective use of insulin termed 'insulin resistance'. T2DM is the most common form of diabetes mellitus and is largely driven by obesity and physical inactivity. Individuals with high fasting plasma glucose levels ( $\geq 7.0$ $\mathrm{mmol} / \mathrm{L}$ ) and/or high 2-h postload glucose levels ( $\geq 11.1 \mathrm{mmol} / \mathrm{L}$ ) are classified as having T2DM. So far, T2DM is on the rise worldwide. The World Health Organization (WHO) reports that the number of people with T2DM has risen to 380 million in 2014. Over time, T2DM can damage the heart, blood vessels, eyes, kidneys, nerves, and makes a tremendous difference in the quality of life. There is clearly a need for newer targets acting through novel mechanisms which could be used to replace or support the current antidiabetic therapies. 
Non-alcoholic steatohepatitis (NASH)

In addition to the strong correlation with T2DM to MetS, clinical and epidemiologic studies have associated non-alcoholic fatty liver disease (NAFLD) with the MetS. The term NAFLD describes a variety of steatosis-induced liver pathologies in the absence of significant alcohol consumption. It comprises a wide spectrum of liver damage, ranging from simple steatosis to steatohepatitis, fibrosis and cirrhosis [3,4]. Non-alcoholic steatohepatitis (NASH) represents the stage that is composed of steatosis and hepatic inflammation, and is regarded as the hepatic equivalent of the metabolic syndrome. Although the simple steatosis seen in NAFLD does not correlate with increased shortterm morbidity or mortality, the presence of inflammation is detrimental, as it may cause irreversible liver damage and sets the stage for further liver injury, like cirrhosis and liver cancer [5]. Currently, as liver biopsy is required to make a definitive diagnosis of $\mathrm{NASH}$, the accurately-defined prevalence of NASH remains largely unknown. The estimates from biopsy series indicate that the prevalence of NASH in the US general population is between $3 \%$ and $5 \%$ [6]. In the subpopulation with abnormal liver enzyme levels that were selected for liver biopsy, the detection rate of NASH is around $34 \%-40 \%$ $[7,8]$, suggesting NASH as one of the leading causes of liver injury. Currently, NASH has become a major public-health challenge worldwide, however, the mechanisms that trigger inflammation are lacking and no effective therapeutic options are available for $\mathrm{NASH}$ yet.

\section{Macrophage stimulating protein (MSP)}

Macrophage stimulating protein (MSP) is an $80 \mathrm{kDa}$ serum protein which belongs to the plasminogen-related kringle domain protein family [9]. It is secreted mainly by hepatocytes, and released into the circulation as a biologically inactive single-chain precursor (pro-MSP) [10]. Biological activity of pro-MSP requires proteolytic conversion of the precursor into a double-chain form, the active MSP, catalyzed by certain proteases [11-16]. After cleavage, active MSP mediates its effects by binding to the receptor tyrosine kinase Recepteur d'Origine Nantais (RON). Binding of active MSP to RON triggers intracellular tyrosine kinase activation leading to downstream effects [17].

\section{Roles of MSP in inflammation and glucose-lipid metabolism}

The role of MSP in inflammation has been investigated for decades since its discovery in 1976. It has been documented that MSP-RON signaling plays negative regulatory role in exogenous toxicant-induced inflammation [18-22]. Notably, MSP has been revealed as an endogenous AMP-activated protein kinase (AMPK) activator. It has been shown that MSP activates AMPK, and subsequently induces small heterodimer partner (SHP) expression in primary hepatocytes and bone marrow derived macrophages (BMDMs) 
$[21,23]$. Of note, SHP was identified as an inhibitor of Toll-like receptor (TLR) signaling [21], and AMPK itself is also known to suppress inflammation [24-26]. Therefore, it appears that MSP-AMPK-SHP signaling pathway is very likely to contribute to the antiinflammatory effects of MSP.

An emerging role of MSP in glucose and lipid metabolism has been indicated. Studies showed that homozygous MSP knockout mice (MSP-/- mice) developed hepatic steatosis even when fed a normal chow diet [27]. A previous study also demonstrated that MSP regulates hepatic gluconeogenesis via the MSP-AMPK-SHP pathway [23]. In a more recent mouse study, loss of MSP-RON signaling led to impaired glucose tolerance, much higher levels of blood sugar, and a disturbed lipid profile in mice fed with high-fat diet [28]. Furthermore, as a homolog to MSP, hepatocyte growth factor (HGF) - a secreted factor belonging to the same growth factor family as MSP- has been demonstrated to be beneficial in obesity, insulin resistance and metabolism syndrome [29-32]. By homology, MSP could be predicted to elicit similar effects as HGF. Relevantly, since AMPK is a wellknown master regulator in cellular response acting on both inflammation and metabolic deregulations [24,33], the participation of AMPK in MSP signaling strongly point towards the research value of MSP in MetS. Overall, it is suggested that MSP participates in glucose and lipid metabolism, however its precise role and the relevant mechanism still need further investigation.

Given to the fact that MSP play roles in both inflammation and glucose-lipid metabolism, it is worthwhile to explore the mechanism of action and treatment potential of MSP in the context of MetS.

\section{Thesis aim and outline}

In the current thesis, we aimed to explore the role of MSP, as a novel factor, in the field of MetS, specifically in the context of NASH and T2DM. Different methods, including in vitro, in vivo and clinical investigation, were used to explore the effects and acting mechanism of MSP under metabolic stress condition, test the novel treatment potential of MSP in NASH, and provide new evidence about the associations of MSP with metabolic profiles in human.

Chapter 2 provides a detailed overview of MSP as a key player in inflammation and metabolic homeostasis, bringing forward its possible therapeutic potential in MetS. To investigate whether MSP participates in inflammation and lipid metabolism in metabolically challenging conditions, an in vitro study which mimicked NASH conditions was implemented in Chapter 3. In Chapter 4, an in vivo study using low density lipoprotein receptor knock out (/d/r-/-) mice, an established NASH mouse model, was performed to test the systemic therapeutic effects of MSP in NASH. In Chapter 5, the associations of 
plasma MSP with metabolic profiles, as well as with glucose tolerance and incidence of T2DM was explored by using a prospective human cohort - the Cohort on Diabetes and Atherosclerosis Maastricht (CODAM). Finally, in Chapter 6, several controversial issues relating to MSP in the context of MetS are discussed and open questions that could be addressed in future research are formulated. 


\section{References}

1. Sarafidis, P. A., and Nilsson, P. M. (2006) The metabolic syndrome: a glance at its history. J Hypertens 24, 621-626

2. Grundy, S. M., Brewer, H. B., Jr., Cleeman, J. I., Smith, S. C., Jr., and Lenfant, C. (2004) Definition of metabolic syndrome: Report of the National Heart, Lung, and Blood Institute/American Heart Association conference on scientific issues related to definition. Circulation 109, 433438

3. Chalasani, N., Younossi, Z., Lavine, J. E., Diehl, A. M., Brunt, E. M., Cusi, K., Charlton, M., and Sanyal, A. J. (2012) The diagnosis and management of non-alcoholic fatty liver disease: practice Guideline by the American Association for the Study of Liver Diseases, American College of Gastroenterology, and the American Gastroenterological Association. Hepatology (Baltimore, Md.) 55, 2005-2023

4. Farrell, G. C., van Rooyen, D., Gan, L., and Chitturi, S. (2012) NASH is an Inflammatory Disorder: Pathogenic, Prognostic and Therapeutic Implications. Gut and liver 6, 149-171

5. LaBrecque, D. R., Abbas, Z., Anania, F., Ferenci, P., Khan, A. G., Goh, K. L., Hamid, S. S., Isakov, V., Lizarzabal, M., Penaranda, M. M., Ramos, J. F., Sarin, S., Stimac, D., Thomson, A. B., Umar, M., Krabshuis, J., and LeMair, A. (2014) World Gastroenterology Organisation global guidelines: Nonalcoholic fatty liver disease and nonalcoholic steatohepatitis. J Clin Gastroenterol 48, 467-473

6. Vernon, G., Baranova, A., and Younossi, Z. M. (2011) Systematic review: the epidemiology and natural history of non-alcoholic fatty liver disease and non-alcoholic steatohepatitis in adults. Aliment Pharmacol Ther 34, 274-285

7. Daniel, S., Ben-Menachem, T., Vasudevan, G., Ma, C. K., and Blumenkehl, M. (1999) Prospective evaluation of unexplained chronic liver transaminase abnormalities in asymptomatic and symptomatic patients. Am J Gastroenterol 94, 3010-3014

8. Skelly, M. M., James, P. D., and Ryder, S. D. (2001) Findings on liver biopsy to investigate abnormal liver function tests in the absence of diagnostic serology. Journal of hepatology 35, 195-199

9. Donate, L. E., Gherardi, E., Srinivasan, N., Sowdhamini, R., Aparicio, S., and Blundell, T. L. (1994) Molecular evolution and domain structure of plasminogen-related growth factors (HGF/SF and HGF1/MSP). Protein science: a publication of the Protein Society 3, 2378-2394
10. Wang, M. H., Skeel, A., and Leonard, E. J. (1996) Proteolytic cleavage and activation of pro-macrophage-stimulating protein by resident peritoneal macrophage membrane proteases. J Clin Invest 97, 720-727

11. Orikawa, H., Kawaguchi, M., Baba, T., Yorita, K., Sakoda, S., and Kataoka, H. (2012) Activation of macrophage-stimulating protein by human airway trypsin-like protease. FEBS letters 586, 217 221

12. Ganesan, R., Kolumam, G. A., Lin, S. J., Xie, M. H., Santell, L., Wu, T. D., Lazarus, R. A., Chaudhuri, A., and Kirchhofer, D. (2011) Proteolytic activation of pro-macrophage-stimulating protein by hepsin. Molecular cancer research: MCR 9, 1175-1186

13. Kawaguchi, M., Orikawa, H., Baba, T., Fukushima, T., and Kataoka, H. (2009) Hepatocyte growth factor activator is a serum activator of single-chain precursor macrophage-stimulating protein. The FEBS journal 276, 3481-3490

14. Bhatt, A. S., Welm, A., Farady, C. J., Vasquez, M., Wilson, K., and Craik, C. S. (2007) Coordinate expression and functional profiling identify an extracellular proteolytic signaling pathway. Proceedings of the National Academy of Sciences of the United States of America 104, 5771-5776

15. Wang, M. H., Yoshimura, T., Skeel, A., and Leonard, E. J. (1994) Proteolytic conversion of single chain precursor macrophage-stimulating protein to a biologically active heterodimer by contact enzymes of the coagulation cascade. The Journal of biological chemistry 269, 3436-3440

16. Wang, M. H., Gonias, S. L., Skeel, A., Wolf, B. B., Yoshimura, T., and Leonard, E. J. (1994) Proteolytic activation of single-chain precursor macrophage-stimulating protein by nerve growth factor-gamma and epidermal growth factor-binding protein, members of the kallikrein family. The Journal of biological chemistry 269, 13806 13810

17. Waltz, S. E. (1997) Functional Characterization of Domains Contained in Hepatocyte Growth Factor-like Protein. Journal of Biological Chemistry 272, 30526-30537

18. Wang, M. H., Cox, G. W., Yoshimura, T., Sheffler, L. A., Skeel, A., and Leonard, E. J. (1994) Macrophage-stimulating protein inhibits induction of nitric oxide production by endotoxin- or cytokine-stimulated mouse macrophages. The Journal of biological chemistry 269, 14027-14031

19. Zhou, Y. Q., Chen, Y. Q., Fisher, J. H., and Wang, M. H. (2002) Activation of the RON receptor tyrosine kinase by macrophage-stimulating pro- 
tein inhibits inducible cyclooxygenase-2 expression in murine macrophages. The Journal of biological chemistry 277, 38104-38110

20. Morrison, A. C., Wilson, C. B., Ray, M., and Correll, P. H. (2004) Macrophage-stimulating protein, the ligand for the stem cell-derived tyrosine kinase/RON receptor tyrosine kinase, inhibits IL-12 production by primary peritoneal macrophages stimulated with IFN-gamma and lipopolysaccharide. J Immunol 172, 1825-1832

21. Yuk, J. M., Shin, D. M., Lee, H. M., Kim, J. J., Kim, S. W., Jin, H. S., Yang, C. S., Park, K. A., Chanda, D., Kim, D. K., Huang, S. M., Lee, S. K., Lee, C. H., Kim, J. M., Song, C. H., Lee, S. Y., Hur, G. M., Moore, D. D., Choi, H. S., and Jo, E. K. (2011) The orphan nuclear receptor SHP acts as a negative regulator in inflammatory signaling triggered by Toll-like receptors. Nature immunology 12, 742751

22. Liu, Q. P., Fruit, K., Ward, J., and Correll, P. H. (1999) Negative regulation of macrophage activation in response to IFN-gamma and lipopolysaccharide by the STK/RON receptor tyrosine kinase. J Immunol 163, 6606-6613

23. Chanda, D., Li, T., Song, K. H., Kim, Y. H., Sim, J., Lee, C. H., Chiang, J. Y., and Choi, H. S. (2009) Hepatocyte growth factor family negatively regulates hepatic gluconeogenesis via induction of orphan nuclear receptor small heterodimer partner in primary hepatocytes. The Journal of biological chemistry 284, 28510-28521

24. O'Neill, L. A., and Hardie, D. G. (2013) Metabolism of inflammation limited by AMPK and pseudo-starvation. Nature 493, 346-355

25. Salminen, A., Hyttinen, J. M., and Kaarniranta, K. (2011) AMP-activated protein kinase inhibits NF-kappaB signaling and inflammation: impact on healthspan and lifespan. Journal of molecular medicine (Berlin, Germany) 89, 667-676

26. Sag, D., Carling, D., Stout, R. D., and Suttles, J. (2008) Adenosine 5'-monophosphate-activated protein kinase promotes macrophage polarization to an anti-inflammatory functional phenotype. Journal of immunology (Baltimore, Md.: 1950) $181,8633-8641$

27. Bezerra, J. A., Carrick, T. L., Degen, J. L., Witte, D., and Degen, S. J. (1998) Biological effects of targeted inactivation of hepatocyte growth factor-like protein in mice. J Clin Invest 101, 11751183

28. Yu, S., Allen, J. N., Dey, A., Zhang, L., Balandaram, G., Kennett, M. J., Xia, M., Xiong, N., Peters, J. M., Patterson, A., and Hankey-Giblin, P. A. (2016) The Ron Receptor Tyrosine Kinase Regulates Macrophage Heterogeneity and Plays a Protective Role in Diet-Induced Obesity, Atherosclerosis, and Hepatosteatosis. Journal of immu- nology (Baltimore, Md.: 1950) 197, 256-265

29. Hiratsuka, A., Adachi, H., Fujiura, Y., Yamagishi, S., Hirai, Y., Enomoto, M., Satoh, A., Hino, A., Furuki, K., and Imaizumi, T. (2005) Strong association between serum hepatocyte growth factor and metabolic syndrome. The Journal of clinical endocrinology and metabolism 90, 2927-2931

30. Fafalios, A., Ma, J., Tan, X., Stoops, J., Luo, J., Defrances, M. C., and Zarnegar, R. (2011) A hepatocyte growth factor receptor (Met)-insulin receptor hybrid governs hepatic glucose metabolism. Nature medicine 17, 1577-1584

31. Tsukagawa, E., Adachi, H., Hirai, Y., Enomoto, M., Fukami, A., Ogata, K., Kasahara, A., Yokoi, K., and Imaizumi, T. (2013) Independent association of elevated serum hepatocyte growth factor levels with development of insulin resistance in a 10-year prospective study. Clinical endocrinology 79, 43-48

32. Faber, D. R., van der Graaf, Y., Westerink, J., Kanhai, D. A., Monajemi, H., and Visseren, F. L. (2013) Hepatocyte growth factor and interferon-gamma inducible protein-10 are related to visceral adiposity. European journal of clinical investigation 43, 369-378

33. Zhang, B. B., Zhou, G., and Li, C. (2009) AMPK: an emerging drug target for diabetes and the metabolic syndrome. Cell metabolism 9, 407-41 



\title{
Chapter 2
}

MSP: an emerging player in metabolic syndrome

\author{
Jieyi Li \#, Dipanjan Chanda \#, Ronit Shiri-Sverdlov *, Dietbert Neumann* \\ $\#,{ }^{*}$ Authors equally contributed
}

Cytokine \& growth factor reviews 26 (2015), 75-82. 


\section{Abstract}

MSP (Macrophage Stimulating Protein; also known as Hepatocyte Growth Factor-like protein (HGFL) and MST1) is a secreted protein and the ligand for transmembrane receptor tyrosine kinase Recepteur d'Origine Nantais (RON; also known as MST1R). Since its discovery, MSP has been demonstrated to play a key role in regulating inflammation in the peripheral tissues of multiple disease models. Recent evidences also point towards a beneficial role of MSP in the regulation of hepatic lipid and glucose metabolism, thereby implicating MSP as a crucial regulator in maintaining metabolic homeostasis while simultaneously suppressing inflammatory processes. In this review, we discuss the recent advances that demonstrate the significance of MSP in metabolic syndrome and build a strong case supporting its therapeutic potential. 


\section{Introduction}

Macrophage stimulating protein (MSP) was firstly discovered in 1976 as a serum protein which could stimulate the chemotactic response, migration and spreading of mouse peritoneal resident macrophages [1]. MSP was later shown to be involved in inflammatory responses and following studies demonstrated MSP to be a crucial regulator of inflammation in multiple animal disease models of the liver, kidney, lung, gut and other organs [2-5]. Studies showed that homozygous MSP knockout mice (MSP-/- mice) were viable without any obvious abnormalities, however they developed hepatic steatosis even fed on normal chow diet [6]. Recent evidences also demonstrate that MSP regulates hepatic gluconeogenesis [7]. Overall, these findings strongly indicate MSP's involvement in hepatic lipid and glucose metabolism. Furthermore, hepatocyte growth factor (HGF), a secreted factor belonging to the same growth factor family as MSP, has been demonstrated to be beneficial in obesity, insulin resistance and metabolism syndrome. By homology, MSP could be predicted to elicit similar effects as HGF. This current review discusses the evidences indicating MSP as a key player in inflammation and metabolic homeostasis, and builds up a strong case for considering MSP to be a potential therapeutic target to ameliorate metabolic syndrome.

\section{MSP and its receptor-RON}

Macrophage stimulating protein (MSP) is an $80 \mathrm{kDa}$ serum protein which belongs to a plasminogen-related kringle protein family [8]. It is also known as hepatocyte growth like factor (HGFL) because of its high homology to $\operatorname{HGF}[9,10]$. The primary domain structure of MSP is identical to HGF: one $\alpha$ chain which includes an N-terminal hairpin loop domain corresponding to the plasminogen pre-activation peptide, four kringles; one $\beta$ chain which includes the serine protease-like domain without enzymatic activity due to catalytic triad mutations [8,11]. The mRNA of MSP is primarily detected in liver and to a lower level in kidney and pancreas $[10,12]$. Hepatocytes are the major source of MSP, which is constitutively transcribed and then secreted into the circulation as a biologically inactive single-chain precursor (pro-MSP) [13]. Biological activity of proMSP requires proteolytic conversion of the precursor into a double-chain $(\alpha / \beta)$ form, the mature MSP, catalyzed by certain proteases [14-19]. The cleavage has been detected during blood coagulation [13], tissue injury and local inflammation [20]. So far, a number of proteases within different tissue distribution have been found to cleave pro-MSP, such as kallikrein, coagulation factor XII and XI [14], nerve growth factor- $\gamma$ (NGF- $\gamma$ ) and epidermal growth factor-binding protein (EGF-BP) [15], hepatocyte growth factor activator (HGFA) [16], hepsin [17], human airway trypsin-like protease (HAT) [18] and membrane type serine protease 1(MT-SP1) [19]. The conversion to mature MSP could 
also be mediated by proteolytic enzymes associated with the cell membrane from resident or exudate peritoneal macrophages [13].

After cleavage, active MSP mediates its effects by binding to the receptor tyrosine kinase Recepteur d'Origine Nantais (receptor tyrosine kinase RON). RON is constitutively transcribed and expressed in different type of cells, mainly of epithelial origins, which has been detected in liver, lung, gut, kidney, brain, bone, adrenal gland, and skin [21,22]. RON is a transmembrane receptor with its short chain and N-terminal region of long chain presented on the cell surface, and the remaining part of the long chain containing tyrosine kinase and phosphorylation sites located intracellularly [23]. Binding of active MSP to RON triggers receptor autophosphorylation, leading to tyrosine kinase activation and consequent downstream signaling events [24,25].

Since the discovery of RON and its ligand MSP, this secreted factor and dedicated receptor kinase pair have been reported to exert multiple effects in the context of cancer and inflammation [26,27]. So far reviews are mainly focus on the correlation between MSP and cancer, discussed evidences that MSP-RON activation can promote cancer progression, angiogenesis and metastasis $[26,28]$. In this current review, we will focus on the other aspects of MSP, such as representing new evidences to support its anti-inflammatory property, and bringing up its potential to play positive roles in the stage of metabolic syndrome.

\section{Role of MSP in inflammation}

\section{Mechanisms of action}

Over the past 20 years, a growing number of studies have demonstrated that MSP plays a key role in regulating the immune system. In the early 1990s, MSP-RON was found to directly act in the innate-immune responses by inducing phagocytosis of c3bi (complement component C3 fragment)-coated erythrocytes-which is an important protective mechanism in innate-immunity $[29,30]$. MSP also acts as an activator of chemotaxis [29]- an essential step in the immune defense system. Studies showed that MSP could promote C5a (complement component C5 fragment)-mediated chemotaxis effectively [29,31]. In addition to assisting in activating chemotaxis, MSP itself could function as a chemoattractant in the activation of macrophages, hence overcoming the need for any other stimulus [29].

Several studies have revealed the direct participation of MSP in inflammatory responses. It was first demonstrated in the mid-90s that MSP could block the inducible nitric oxide synthase (iNOS) mRNA increase in macrophages in response to endotoxin and interferon- $\gamma$ (IFN- $\gamma$ ), thus reducing the nitric oxide (NO) production [32], which is a key 
pro-inflammatory mediator that induces inflammation due to its overproduction in pathologic situations. Furthermore, homozygous RON knockout mice (RON-/- mice) exhibit an elevated NO level in serum and more severe inflammation after stimulation with IFN- $\gamma$, also reflected by higher susceptibility to endotoxic shock $[33,34]$. In addition, it was reported that LPS induced pro-inflammatory enzyme Cyclooxygenase-2 (Cox-2) and its product prostaglandin E2 (PGE2) could be suppressed by MSP [35]. The antiinflammatory action of MSP-RON via suppression of nuclear factor kappa B (NF-kB) signaling resulted in reduced iNOS and Cox-2 expression at both mRNA and protein levels $[35,36]$. When challenged with IFN- $\gamma$ and Lipopolysaccharide (LPS), the nuclear translocation of NF-KB was decreased in presence of MSP whereas other regulators of iNOS, such as IFN- $\gamma$ receptor, signal transducer and activator of transcription 1 (STAT-1) and IFN response factor-1 remained unaltered [36]. Furthermore, MSP activation could reduce LPS induced IKB $\alpha$ (nuclear factor of kappa light polypeptide gene enhancer in B-cells inhibitor, alpha) degradation, as well as the IKK- $\beta$ (inhibitor of nuclear factor

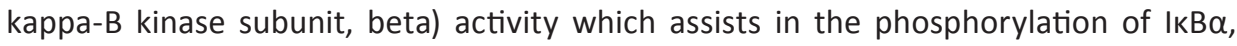
therefore inhibiting NF-KB pathway $[35,37]$. Additionally, MSP-RON signaling reduced NF- $\mathrm{kB}$ activity at the transcriptional level by inhibiting serine phosphorylation of $\mathrm{p} 65$, after stimulation with LPS $[37,38]$. Studies further showed that treatment with MSP in murine peritoneal macrophages leads to up-regulation of mRNA and protein expression of arginase, an enzyme that competes with iNOS for the substrate-L arginine, therefore yielding inhibition of NO production [39]. In short, regulating of NO production via NF$\mathrm{KB}$ pathway is one of the major mechanisms through which MSP exerts anti-inflammatory effects.

PI3-Kinase has been reported previously to be a mediator of MSP-RON signaling. It has been demonstrated that MSP activated PI3-Kinase through tyrosine phosphorylation of PI3-Kinase p85 subunit [40], and PI3-Kinase activation subsequently reduced iNOS transcription [41,42]. Using Wortmannin (a PI3-Kinase inhibitor) and dominant-inhibitory p85 subunit of PI3-Kinase, the inhibitory effect of MSP on iNOS was prevented [40]. However, by using the similar experimental approach, it turned out that PI3-kinase does not participate in MSP induced Cox-2 inhibition [35], which indicates that MSP regulates iNOS and Cox-2 expression via different mechanisms.

Interleukin 12 (IL-12) plays important roles in immunity by mediating enhancement of the cytotoxic activity of T lymphocytes and natural killer cell (NK cells), as well as stimulating the production of IFN- $\gamma$ and tumor necrosis factor-alpha (TNF- $\alpha$ ) from T lymphocytes and NK cells. It was found that pretreatment of macrophages with MSP before IFN- $\gamma$ and LPS resulted in complete inhibition of IL-12 production through suppression of $\mathrm{p} 40$ expression [43]. In support of this data, RON-/-mice exhibit increased 
IL12p40 level in response to LPS, accompanied with elevated IFN- $\gamma$ level [44]. Moreover, MSP inhibited the expression of $І \kappa B \zeta$-a nuclear $1 \kappa B$ family member which is upregulated by LPS stimulation, a positive regulator for IL-12 p40 [38]. These results indicate that the anti-inflammatory effects of MSP are supported by its ability to down-regulate IL-12 expression levels.

Recently, small heterodimer partner (SHP) was discovered as an important molecule involved in MSP-RON signaling. MSP initially activates AMPK (AMP-activated protein kinase) in a LKB1 (liver kinase B1)-dependent way, then downstream AMPK activation induces $\mathrm{mRNA}$ and protein expression of SHP in primary hepatocytes and bone marrow derived macrophages (BMDMs) [7,37]. Importantly, in BMDMs, SHP was identified as an inhibitor of LPS induced Toll-like receptors (TLR) signaling by negatively regulating the polyubiquitination of TNF receptor associated factor 6 (TRAF6), which is an essential transducer for TLR signaling activation. SHP physically interacts with the RING domain of TRAF6 -the domain which is required for polyubiquitination and possible downstream activation of TRAF6, therefore interfering its role in TLR signaling [37]. Besides, MSPinduced SHP overexpression not only inhibited TRAF6 polyubiquitination, but also reduced nuclear translocation of p65 and its recruitment to the proximal enhancer region of the TNF- $\alpha$ promoter, thereby repressing LPS-TLR-induced inflammation [37]. Furthermore, AMPK is also known to suppress inflammation [45-47]. Therefore, it appears that both AMPK and SHP contribute to the anti-inflammatory effect of MSP. The discussed pathways downstream of MSP-RON activation affecting intracellular signalling events are visualized in Fig. 1.

Taken together, MSP exerts anti-inflammatory actions, in part by suppressing several pro-inflammatory pathways and activating the AMPK-SHP axis.

\section{MSP regulates inflammatory processes in vivo}

Several studies revealed MSP-mediated anti-inflammatory effects in multiple peripheral tissues of animal models. In rodent models, the expression of MSP was dramatically upregulated at transcript level during inflammation, as well as liver regeneration induced by hepatectomy or chemical treatment [48], while in patients with fulminant hepatic failure, MSP levels have been shown to decrease significantly [49]. A possible explanation is that elevated MSP is part of a compensatory mechanism, and this could be exhausted when the liver is seriously damaged. RON-/- mice with LPS-induced acute endotoxemia exhibited lowered anti-inflammatory cytokine-Interleukin 10 (IL-10) mRNA expression in the liver compared with wild-type mice, accompanied with deceased level of superoxide dismutase (SOD), an important antioxidant enzyme that works against oxidative stress in 


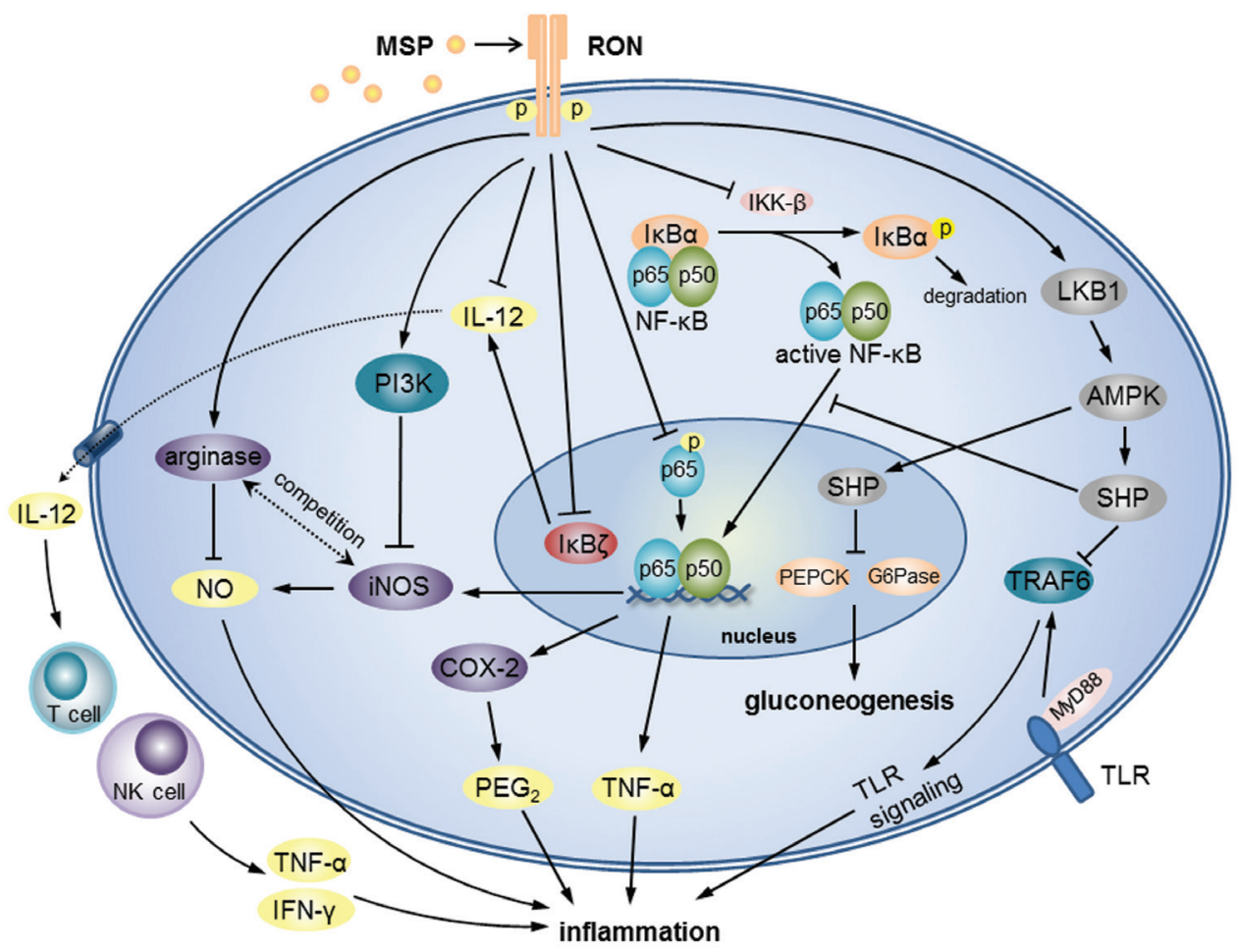

Figure 1. Mode of action- roles of MSP in inhibiting inflammation and gluconeogenesis.

MSP-induced anti-inflammatory action is mediated by several molecular mechanisms: 1) MSP negatively regulates iNOS and NO production through suppression of NF-kB pathway, activation of PI3K pathway, and up-regulation of the competitor-arginase; 2) MSP inhibits IL-12 production which can be mediated by IKB $\mathrm{K}$ inhibition, consequently reduces TNF- $\alpha$ and IFN- $\gamma$; 3) MSP activates SHP through AMPK and consequently inhibits TRAF6 polyubiquitination and TLR signaling; SHP activation also reduces $\mathrm{p} 65$ translocation and suppresses NF-KB pathway.

MSP down-regulates gluconeogenesis via activation of LKB1/AMPK/SHP, followed by inhibition of PEPCK and G6Pase, two hepatic gluconeogenic enzymes.

liver [50]. To block the intracellular signaling of MSP-RON, mice with deletion of tyrosine kinase domain of RON (RON TK-/- mice) were used in several studies [2,51,52]. In a model of acute liver failure, it was shown that RON TK-/- mice were more prone to severe inflammation showing an increased TNF- $\alpha$ level and a decreased IL-10 level in serum, in response to LPS and galactosamine (GaIN). Surprisingly, contrary to the inflamed status in plasma, a relatively normal histology in the liver, as well as lesser serum aminotransferase elevation, were observed in these RON TK-/- mice in comparison to the wild-type mice [52]. It is possible that those contradictory results are due to different target cells in the liver. This view is supported by a follow-up study by Stuart et al., which used Kupffer cells and hepatocytes from RON TK-/- mice and demonstrated that RON TK-/- Kupffer cells 
treated with LPS lead to remarkable up-regulation of serum TNF- $\alpha$ level, whereas RON TK-/- hepatocytes exhibited an increased resistance to inflammatory factors and cell death in comparison with normal genotypic hepatocytes [2]. Mechanisms behind the opposing MSP effects in hepatocytes and Kupffer cells are not clarified yet, however, it was suggested that the hepatocyte-protective effect may come from the early increase of TNF- $\alpha$, since the TNF- $\alpha$ increase in early stage actually could be beneficial to hepatocytes [52]. Besides, the MSP-regulated change of pro-inflammatory cytokines may reduce the sensitization of hepatocytes and thereby attenuate hepatocyte damage [52]. Taken together, these studies explicitly indicate that MSP-RON signaling plays an inhibitory role in regulating pro-inflammatory cytokines production in liver, mainly by exerting its effects on Kupffer cells, while the effects of MSP-RON activation on other cell types in liver including hepatocytes still need further investigation. Since these listed data are all based on disrupted MSP-RON signaling, further studies utilizing enhancement of MSP-RON activity are very much needed offering complementary understanding of MSP effects in liver disorders.

Involvement of MSP in the pathogenesis of inflammatory bowel disease (IBD), a group of inflammatory conditions of the colon and small intestine, has been reported. In a positional candidate gene association study of IBD patients, a non- synonymous variant (rs3197999) in macrophage stimulating 1 (MST1) gene - the gene encoding MSP protein - was linked to IBD, which included both Crohn's disease and ulcerative colitis [4]. This variant in MST1 gene gives rise to a mutant MSP which has a R689C substitution in its $\beta$ chain. At present the causal role of the R689C variant remains unclear, although several studies provided evidences for this MSP mutant to increase susceptibility for IBD. In one study the R689C mutant MSP showed impaired affinity to RON [53]. Since MSP-RON regulates innate and adaptive immune responses, logically the mutant MSP would cause increased susceptibility to IBD. However in another study, the same $689 \mathrm{C}$ polymorphism reportedly did not change the ability of MSP to bind or activate RON, but instead caused a lowered amount of circulating MSP [54]. In addition, R689C mutant MSP protein was thermally less stable than wild-type MSP [53]. Despite some discrepancy, all these studies point to decreased anti-inflammatory potential of R689C mutant MSP, indicating that the physiological action of MSP is needed to the counter the development of IBD. In further support of this notion, RON TK-/- mice developed more severe colitis compared with wild-type mice, following by the administration of dextran sulfate sodium, a chemical used to induce chronic colitis in mice model. These animals showed more serious symptoms with increased inflammation and more pronounced histological changes in the colonic epithelium [51]. In summary, these evidences indicate that MSPRON signaling participates in the anti-inflammation processes in gut. 
In the acute lung injury (ALI) rodent models induced by either nickel or LPS, RON TK-/mice showed enhanced sensitivity to the challenge compared with wild-type mice. These changes were associated with significantly raised serum inflammatory factors, earlier and more serious pulmonary disease $[3,55]$, indicating MSP-RON signaling might be preventive in the pathogenesis of acute lung inflammation. The role of MSP-RON signaling specifically in alveolar macrophages has also been investigated. Ron f/f Lys-cre mice devoid of RON signaling selectively in myeloid cells exhibit increased lung injury following intranasal administration of LPS, manifesting as increased TNF- $\alpha$ production, ensuing neutrophil accumulation and worsening lung histopathology [56]. Similar findings were obtained in intranasal LPS-treated RON knockout mice [55], which indicates that MSP-RON negatively regulates acute lung inflammation primarily through the immune components. However, in a study involving humans, results showed that recombinant MSP promoted inflammatory cytokines release in alveolar macrophages of patients with pulmonary sarcoidosis [57], a type of inflammatory disorder related to immunologic abnormalities. Recombinant MSP treatment was found to activate NF-KB pathway in alveolar macrophages of these patients [57], which is in apparent contrast to MSP-mediated suppression of the LPS-induced NF-KB pathway [35,37]. The reason for this discrepancy is not clear. However, sarcoidosis is considered by most viewpoints as an immune inflammatory disease (a dysfunction of the immune system causing enhanced inflammation), as opposed to LPS-TLR induced inflammation (a normal/functional immune response). Notably, MSP levels in the bronchoalveolar lavage fluid correlated with the disease course of sarcoidosis patients, i.e. showing significantly higher MSP levels in advanced cases that required treatment [58]. These evidences point towards the involvement of MSP in disease development, but could also be interpreted as the body's attempt to limit the inflammatory response. More data are certainly needed to explain the exact role of MSP in sarcoidosis.

MSP expression is up-regulated in patients either with acute renal failure or after renal transplantation surgery, as well as in rat model with renal tubular inflammation $[59,60]$. Importantly, with MSP treatment, the gentamicin-induced renal inflammation could be attenuated [59]. In a rodent model with anti-Thy 1 nephritis - a well-established experimental model of mesangial proliferative nephritis, neutralization of MSP by using anti-MSP antibody, however, results in attenuated infiltration of the inflammatory cells, decreased plasma creatinine and proteinuria, and eventually protects glomerular from injury [5]. It is noteworthy that this nephritis is most commonly caused by autoimmunedisorders. Therefore, similar to sarcoidosis (see paragraph above), MSP could affect the inflammatory responses context-dependently. MSP also has proliferative effects. Accordingly, neutralization of MSP could relieve the observed proliferation of glomerular 
cells in nephritis [5], thus partly protecting the glomerulus from damage. Moreover, MSP is reported to participate in the pathological processes of rheumatoid arthritis [61] and peritonitis [62], where MSP showed disease-inhibiting action in both. Taken together, MSP has been established as a crucial negative regulator of exogenous substancesinduced inflammation at cellular and whole body level, but further look into specific immune diseases is required for a more comprehensive understanding.

\section{Emerging role of MSP in metabolic syndrome}

\section{MSP takes part in hepatic lipid and glucose regulation}

As early as 1998, Jorge et al. [6] generated the homozygous MSP knockout mice (MSP-/mice), fed them normal diet and compared with wild type mice, mainly to learn about MSP features during the process of growth. Results showed that MSP-/- mice grew to adulthood without any obvious difference compared with wild-type mice, except for accumulation of lipid-containing cytoplasmic vacuoles in hepatocytes throughout the liver lobules [6]. Although the mechanisms behind this observation are still unclear, the phenomenon strongly indicated a key role of MSP in hepatic lipid metabolism. A more recent study revealed the potential of MSP in regulating hepatic glucose metabolism [7]. Primary rat hepatocytes and primary human hepatocytes were pre-treated with recombinant MSP, followed by stimulation with CAMP/dexamethasone (Dex), and then hepatic gluconeogenesis was assessed. It turned out that MSP treatment dramatically suppressed the CAMP/ Dex-mediated glucose production and negatively regulated the gene promoter activities and expression levels of key hepatic gluconeogenic enzyme genes, i.e. phosphoenolpyruvate carboxykinase (PEPCK) and glucose-6-phosphatase (Glc-6-Pase), in a dose-dependent manner. Results also demonstrated that these effects are mediated by MSP-AMPK-SHP signaling: recombinant MSP activated AMPK signaling consequently driving the SHP gene promoter and up-regulating SHP at both MRNA and protein levels [7]. AMPK is proven to be one essential mediator in this signaling. Utilization of compound C -an AMPK inhibitor- markedly abolished the MSP-induced SHP activation as well as PEPCK and Glc-6-Pase inhibition, whereas Wortmannin, and SP600125 -a c-Jun N-terminal kinases (JNK) inhibitor- showed no effects on SHP expression [7]. Another study confirmed the AMPK-SHP pathway by using macrophages transduced by adenoviruses carrying dominant negative AMPK, and found dramatically suppressed SHP mRNA expression [37]. Similarly, after SHP-knock down was performed in primary hepatocytes, the effects of MSP in inhibiting PEPCK and Glc-6-Pase were also prominently eliminated [7]. It is particularly worth mentioning that the activation of AMPK is involved in MSP-mediated mechanisms. Since AMPK is a well-known master regulator in cellular response acting on both inflammation and metabolic deregulations $[45,63]$, the participation of AMPK in MSP-RON signaling in hepatocytes strongly points 


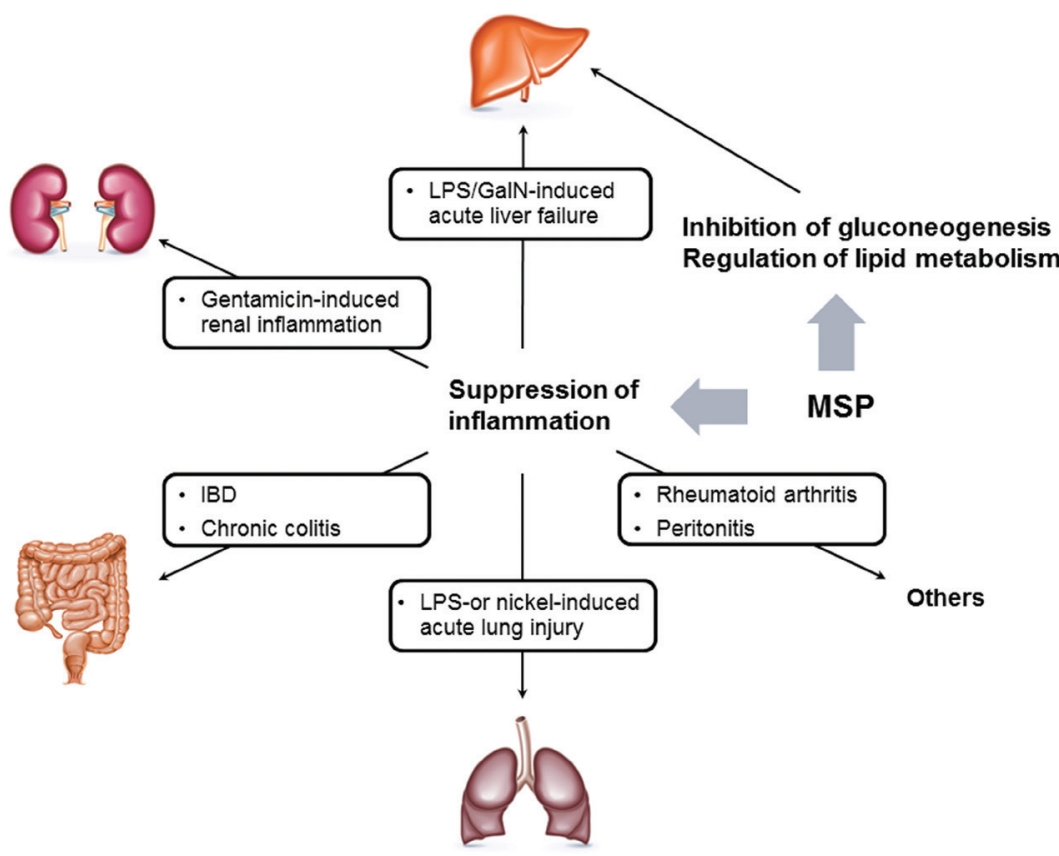

Figure 2. Actions of MSP and target tissues.

The anti-inflammatory effects of MSP have been investigated in liver, gut, lung, kindey and other tissues through different model. The role of MSP in lipid and glucose metabolism is currently focused on liver.

towards the research value of MSP in liver and systemic metabolism. Fig. 2 depicts established actions of MSP in several target tissues.

Role of HGF, a MSP homolog in the metabolic syndrome

Both MSP and HGF belong to the plasminogen-related growth factor family and interact with their specific transmembrane receptor tyrosine kinases (RTKs)-RON and mesenchymal-epithelial transition factor (c-Met) [64], respectively. Unlike MSP, that is mainly secreted from hepatocytes, HGF is synthesized by the nonparenchymal cells in liver, as well as many different types of cells including adipocytes, fibroblasts, vascular smooth muscle cells $[65,66]$. The HGF receptor c-Met is mainly expressed in cells of epithelial organs [67]. HGF and MSP display high homology in their primary functional domain structure [8], and research studies suggest they have common range of effects $[26,27,67,68]$. HGF-c-Met and MSP-RON both show proliferative and mitogenic effects, and participate in promoting cancer progression, angiogenesis and metastasis mainly through the aberrant activation of receptors $[26,67]$. Similar to MSP, HGF has been demonstrated to exert inhibitory effects on inflammation in several studies [69-72]. More importantly, HGF has been identified as a key regulator in metabolic diseases such 
as obesity, type 2 diabetes mellitus (T2DM), and metabolic syndrome. Several clinical studies revealed elevated HGF in metabolic syndrome with serum levels correlating to important parameters such as waist circumference, triglycerides, blood pressure and fasting blood glucose [73], also the development of insulin resistance [65] and presence of T2DM [74]. Although these strong correlations have been demonstrated decades ago, the mechanisms leading to elevation of HGF level remains unclear. Since HGF exerts several protective responses in metabolic disorders, HGF up-regulation could be interpreted as a compensatory response. Namely, studies showed that HGF up-regulates glucose transporters in intestinal epithelia [75], adipocytes [76], pancreatic $\beta$ cells [7779]. Moreover, HGF also increases glucose transporters 1 and 4 (Glut-1 and Glut-4) levels in $\mathrm{L} 6$ myotubes, and directly promotes glucose uptake in mouse skeletal muscle ex vivo [80]. HGF also inhibits hepatic gluconeogenesis through the activation of HGF-AMPKSHP signaling pathway [7]. Moreover, the receptor of HGF-c-Met can cooperate with insulin receptor (INSR) and forms a hybrid complex, which provides an optimal hepatic insulin response and lead to robust insulin signaling [81]. c-Met knock down mice showed distinct hyperglycemia and impaired response to insulin, supporting that HGF-cMet is strongly involved in hepatic glucose homeostasis and insulin sensitivity [81]. HGF is also essential for $\beta$-cell proliferation and regeneration [82], and protects $\beta$-cells from damage and death $[83,84]$. Besides, it was observed that HGF-c-Met have a regulatory role in lipid metabolism. The mRNA and protein expression of c-Met was found downregulated in fatty liver [85] and HGF treatment dramatically suppressed hepatic lipid accumulation and ameliorated steatosis [86]. Hepatocyte-specific c-Met knockout mice fed on methionine-choline deficient (MCD) diet displayed severe steatosis accompanied with disturbed $\beta$-oxidation of free fatty acids, and manifested a severe phenotype of non-alcoholic steatohepatitis (NASH), which is a metabolic disorder composed of steatosis and inflammation, and considered as the hepatic equivalent of metabolic syndrome [87]. Hence, HGF has been investigated for decades for its beneficial effects in metabolic diseases, while fewer studies addressed the metabolic functions of MSP. Since MSP has cut a figure as one player in the stage of lipid-glucose metabolism, it's worthy of further exploration. Furthermore, while MSP and HGF show extensive similarities, MSP is not just a simple replica of HGF. Notably, both also have their own unique features, such as the specificity of receptor, the distinctiveness of expression patterns [88] and domain function [25]. Therefore, exploring novel MSP functions in the metabolic field is going well beyond reconfirming the already known HGF-attributed roles for MSP. 


\section{Future perspectives}

As an endogenous factor which is constitutively generated in the body, MSP has great advantages to be implemented in clinical application compared to synthetic drugs by virtue of its safe and stable nature. In view of the combined involvements in both suppression of inflammation and amelioration of lipid-glucose metabolism, MSP holds important research value and may provide novel therapeutic options in the field of metabolic syndrome.

Firstly, given MSP serves as an endogenous activator of AMPK in the liver, plus the fact that liver is the main source of MSP, exploring the effects of MSP in hepatic metabolic disease may be worthwhile. In particular, as MSP suppresses hepatic inflammation and controls lipid metabolism, MSP treatment could turn out effective against NASH. In addition, since MSP, as well as HGF, has been found to inhibit gluconeogenesis, the better understanding of underlying mechanisms will offer new opportunities to treat metabolic diseases. Investigating the metabolic effects of MSP will be helpful to get a better and more integrated understanding of MSP, since as mentioned earlier, MSP acts as a "two-faced" factor in different pathological processes such as cancer and inflammation. In general, there are lots of studies investigating the mechanisms of cancer-promoting and inflammation-inhibiting effects respectively, but no clear explanation about the connection of these "good and evil" effects has been found. Hence, a more comprehensive understanding of the functions of MSP and its mode of actions will definitely provide with better insight in this focus area of research.

Taken together, the current evidences highlight the need for further investigation of MSP in the field of metabolic syndrome. 


\section{References}

1. Leonard, E. J., and Skeel, A. (1976) A serum protein that stimulates macrophage movement, chemotaxis and spreading. Experimental cell research 102, 434-438

2. Stuart, W. D., Kulkarni, R. M., Gray, J. K., Vasiliauskas, J., Leonis, M. A., and Waltz, S. E. (2011) Ron receptor regulates Kupffer cell-dependent cytokine production and hepatocyte survival following endotoxin exposure in mice. Hepatology (Baltimore, Md.) 53, 1618-1628

3. McDowell, S. A., Mallakin, A., Bachurski, C. J., Toney-Earley, K., Prows, D. R., Bruno, T., Kaestner, K. H., Witte, D. P., Melin-Aldana, H., Degen, S. J., Leikauf, G. D., and Waltz, S. E. (2002) The role of the receptor tyrosine kinase Ron in nickel-induced acute lung injury. Am J Respir Cell Mol Biol 26, 99-104

4. Goyette, P., Lefebvre, C., Ng, A., Brant, S. R., Cho, J. H., Duerr, R. H., Silverberg, M. S., Taylor, K. D., Latiano, A., Aumais, G., Deslandres, C., Jobin, G., Annese, V., Daly, M. J., Xavier, R. J., and Rioux, J. D. (2008) Gene-centric association mapping of chromosome 3p implicates MST1 in IBD pathogenesis. Mucosal immunology 1, 131-138

5. Rampino, T., Soccio, G., Gregorini, M., Guidetti, C., Marasa, M., Maggio, M., Panichi, V., Migliori, M., Libetta, C., and Dal Canton, A. (2007) Neutralization of macrophage-stimulating protein ameliorates renal injury in anti-thy 1 glomerulonephritis. Journal of the American Society of Nephrology: JASN 18, 1486-1496

6. Bezerra, J. A., Carrick, T. L., Degen, J. L., Witte, D., and Degen, S. J. (1998) Biological effects of targeted inactivation of hepatocyte growth factor-like protein in mice. J Clin Invest 101, 11751183

7. Chanda, D., Li, T., Song, K. H., Kim, Y. H., Sim, J., Lee, C. H., Chiang, J. Y., and Choi, H. S. (2009) Hepatocyte growth factor family negatively regulates hepatic gluconeogenesis via induction of orphan nuclear receptor small heterodimer partner in primary hepatocytes. The Journal of biological chemistry 284, 28510-28521

8. Donate, L. E., Gherardi, E., Srinivasan, N., Sowdhamini, R., Aparicio, S., and Blundell, T. L. (1994) Molecular evolution and domain structure of plasminogen-related growth factors (HGF/SF and HGF1/MSP). Protein science: a publication of the Protein Society 3, 2378-2394

9. Han, S., Stuart, L. A., and Degen, S. J. (1991) Characterization of the DNF15S2 locus on human chromosome 3: identification of a gene coding for four kringle domains with homology to hepatocyte growth factor. Biochemistry $\mathbf{3 0}$, 9768-9780
10. Yoshimura, T., Yuhki, N., Wang, M. H., Skeel, A., and Leonard, E. J. (1993) Cloning, sequencing, and expression of human macrophage stimulating protein (MSP, MST1) confirms MSP as a member of the family of kringle proteins and locates the MSP gene on chromosome 3. The Journal of biological chemistry 268, 1546115468

11. Danilkovitch, A., Miller, M., and Leonard, E. J. (1999) Interaction of macrophage-stimulating protein with its receptor. Residues critical for beta chain binding and evidence for independent alpha chain binding. The Journal of biological chemistry 274, 29937-29943

12. Rampino, T., Collesi, C., Gregorini, M., Maggio, M., Soccio, G., Guallini, P., and Dal Canton, A. (2002) Macrophage-stimulating protein is produced by tubular cells and activates mesangial cells. Journal of the American Society of $\mathrm{Ne}$ phrology: JASN 13, 649-657

13. Wang, M. H., Skeel, A., and Leonard, E. J. (1996) Proteolytic cleavage and activation of pro-macrophage-stimulating protein by resident peritoneal macrophage membrane proteases. J Clin Invest 97, 720-727

14. Wang, M. H., Yoshimura, T., Skeel, A., and Leonard, E. J. (1994) Proteolytic conversion of single chain precursor macrophage-stimulating protein to a biologically active heterodimer by contact enzymes of the coagulation cascade. The Journal of biological chemistry 269, 3436-3440

15. Wang, M. H., Gonias, S. L., Skeel, A., Wolf, B. B., Yoshimura, T., and Leonard, E. J. (1994) Proteolytic activation of single-chain precursor macrophage-stimulating protein by nerve growth factor-gamma and epidermal growth factor-binding protein, members of the kallikrein family. The Journal of biological chemistry 269, 13806 13810

16. Kawaguchi, M., Orikawa, H., Baba, T., Fukushima, T., and Kataoka, H. (2009) Hepatocyte growth factor activator is a serum activator of single-chain precursor macrophage-stimulating protein. The FEBS journal 276, 3481-3490

17. Ganesan, R., Kolumam, G. A., Lin, S. J., Xie, M. H., Santell, L., Wu, T. D., Lazarus, R. A., Chaudhuri, A., and Kirchhofer, D. (2011) Proteolytic activation of pro-macrophage-stimulating protein by hepsin. Molecular cancer research: MCR 9, 1175-1186

18. Orikawa, H., Kawaguchi, M., Baba, T., Yorita, K., Sakoda, S., and Kataoka, H. (2012) Activation of macrophage-stimulating protein by human airway trypsin-like protease. FEBS letters 586, 217 221 
19. Bhatt, A. S., Welm, A., Farady, C. J., Vasquez, M. Wilson, K., and Craik, C. S. (2007) Coordinate expression and functional profiling identify an extracellular proteolytic signaling pathway. Proceedings of the National Academy of Sciences of the United States of America 104, 5771-5776

20. Nanney, L. B., Skeel, A., Luan, J., Polis, S., Richmond, A., Wang, M. H., and Leonard, E. J. (1998) Proteolytic cleavage and activation of pro-macrophage-stimulating protein and upregulation of its receptor in tissue injury. The Journal of investigative dermatology 111, 573-581

21. Quantin, B., Schuhbaur, B., Gesnel, M. C., Doll'e, P., and Breathnach, R. (1995) Restricted expression of the ron gene encoding the macrophage stimulating protein receptor during mouse development. Developmental dynamics: an official publication of the American Association of Anatomists 204, 383-390

22. Gaudino, G., Avantaggiato, V., Follenzi, A., Acampora, D., Simeone, A., and Comoglio, P. M. (1995) The proto-oncogene RON is involved in development of epithelial, bone and neuro-endocrine tissues. Oncogene 11, 2627-2637

23. Ronsin, C., Muscatelli, F., Mattei, M. G., and Breathnach, R. (1993) A novel putative receptor protein tyrosine kinase of the met family. Oncogene 8, 1195-1202

24. Wang, J., Steinbacher, S., Augustin, M., Schreiner, P., Epstein, D., Mulvihill, M. J., and Crew, A. P. (2010) The crystal structure of a constitutively active mutant RON kinase suggests an intramolecular autophosphorylation hypothesis. Biochemistry 49, 7972-7974

25. Waltz, S. E. (1997) Functional Characterization of Domains Contained in Hepatocyte Growth Factor-like Protein. Journal of Biological Chemistry 272, 30526-30537

26. Yao, H. P., Zhou, Y. Q., Zhang, R., and Wang, M. H. (2013) MSP-RON signalling in cancer: pathogenesis and therapeutic potential. Nature reviews. Cancer 13, 466-481

27. Wang, M. H., Zhou, Y. Q., and Chen, Y. Q. (2002) Macrophage-stimulating protein and RON receptor tyrosine kinase: potential regulators of macrophage inflammatory activities. Scand J Immunol 56, 545-553

28. Wang, M. H., Zhang, R., Zhou, Y. Q., and Yao, H. P. (2013) Pathogenesis of RON receptor tyrosine kinase in cancer cells: activation mechanism, functional crosstalk, and signaling addiction. Journal of biomedical research 27, 345-356

29. Skeel, A., and Leonard, E. J. (1994) Action and target cell specificity of human macrophagestimulating protein (MSP). I Immunol 152, 4618-4623
30. Lutz, M. A., and Correll, P. H. (2003) Activation of CR3-mediated phagocytosis by MSP requires the RON receptor, tyrosine kinase activity, phosphatidylinositol 3-kinase, and protein kinase C zeta. Journal of leukocyte biology 73, 802-814

31. Skeel, A., Yoshimura, T., Showalter, S. D., Tanaka, S., Appella, E., and Leonard, E. J. (1991) Macrophage stimulating protein: purification, partial amino acid sequence, and cellular activity. The Journal of experimental medicine 173, 12271234

32. Wang, M. H., Cox, G. W., Yoshimura, T., Sheffler, L. A., Skeel, A., and Leonard, E. J. (1994) Macrophage-stimulating protein inhibits induction of nitric oxide production by endotoxin- or cytokine-stimulated mouse macrophages. The Journal of biological chemistry 269, 14027-14031

33. Correll, P. H., Iwama, A., Tondat, S., Mayrhofer, G., Suda, T., and Bernstein, A. (1997) Deregulated inflammatory response in mice lacking the STK/RON receptor tyrosine kinase. Genes Funct 1, 69-83

34. Waltz, S. E., Eaton, L., Toney-Earley, K., Hess, K. A., Peace, B. E., Ihlendorf, J. R., Wang, M. H., Kaestner, K. H., and Degen, S. J. (2001) Ron-mediated cytoplasmic signaling is dispensable for viability but is required to limit inflammatory responses. J Clin Invest 108, 567-576

35. Zhou, Y. Q., Chen, Y. Q., Fisher, J. H., and Wang, M. H. (2002) Activation of the RON receptor tyrosine kinase by macrophage-stimulating protein inhibits inducible cyclooxygenase- 2 expression in murine macrophages. The Journal of biological chemistry 277, 38104-38110

36. Liu, Q. P., Fruit, K., Ward, J., and Correll, P. H. (1999) Negative regulation of macrophage activation in response to IFN-gamma and lipopolysaccharide by the STK/RON receptor tyrosine kinase. J Immunol 163, 6606-6613

37. Yuk, J. M., Shin, D. M., Lee, H. M., Kim, J. J., Kim, S. W., Jin, H. S., Yang, C. S., Park, K. A., Chanda, D., Kim, D. K., Huang, S. M., Lee, S. K., Lee, C. H., Kim, J. M., Song, C. H., Lee, S. Y., Hur, G. M., Moore, D. D., Choi, H. S., and Jo, E. K. (2011) The orphan nuclear receptor SHP acts as a negative regulator in inflammatory signaling triggered by Toll-like receptors. Nature immunology 12, 742751 
38. Ray, M., Yu, S., Sharda, D. R., Wilson, C. B., Liu, Q., Kaushal, N., Prabhu, K. S., and Hankey, P. A. (2010) Inhibition of TLR4-induced IkappaB kinase activity by the RON receptor tyrosine kinase and its ligand, macrophage-stimulating protein. J Immunol 185, 7309-7316

39. Morrison, A. C., and Correll, P. H. (2002) Activation of the stem cell-derived tyrosine kinase/ RON receptor tyrosine kinase by macrophagestimulating protein results in the induction of arginase activity in murine peritoneal macrophages. J Immunol 168, 853-860

40. Chen, Y. Q., Fisher, J. H., and Wang, M. H. (1998) Activation of the RON receptor tyrosine kinase inhibits inducible nitric oxide synthase (iNOS) expression by murine peritoneal exudate macrophages: phosphatidylinositol-3 kinase is required for RON-mediated inhibition of iNOS expression. J Immunol 161, 4950-4959

41. Wright, K., Ward, S. G., Kolios, G., and Westwick, J. (1997) Activation of phosphatidylinositol 3-kinase by interleukin-13. An inhibitory signal for inducible nitric-oxide synthase expression in epithelial cell line HT-29. The Journal of biological chemistry 272, 12626-12633

42. Park, Y. C., Lee, C. H., Kang, H. S., Chung, H. T., and Kim, H. D. (1997) Wortmannin, a specific inhibitor of phosphatidylinositol-3-kinase, enhances LPS-induced NO production from murine peritoneal macrophages. Biochem Biophys Res Commun 240, 692-696

43. Morrison, A. C., Wilson, C. B., Ray, M., and Correll, P. H. (2004) Macrophage-stimulating protein, the ligand for the stem cell-derived tyrosine kinase/RON receptor tyrosine kinase, inhibits IL-12 production by primary peritoneal macrophages stimulated with IFN-gamma and lipopolysaccharide. J Immunol 172, 1825-1832

44. Wilson, C. B., Ray, M., Lutz, M., Sharda, D., Xu, J., and Hankey, P. A. (2008) The RON receptor tyrosine kinase regulates IFN-gamma production and responses in innate immunity. J Immunol $181,2303-2310$

45. O'Neill, L. A., and Hardie, D. G. (2013) Metabolism of inflammation limited by AMPK and pseudo-starvation. Nature 493, 346-355

46. Salminen, A., Hyttinen, J. M., and Kaarniranta, K. (2011) AMP-activated protein kinase inhibits NF-kappaB signaling and inflammation: impact on healthspan and lifespan. Journal of molecular medicine (Berlin, Germany) 89, 667-676

47. Sag, D., Carling, D., Stout, R. D., and Suttles, J. (2008) Adenosine 5'-monophosphate-activated protein kinase promotes macrophage polarization to an anti-inflammatory functional phenotype. Journal of immunology (Baltimore, Md.: 1950) $181,8633-8641$
48. Bezerra, J. A., Laney, D. W., Jr., and Degen, S. J. (1994) Increased expression of mRNA for hepatocyte growth factor-like protein during liver regeneration and inflammation. Biochem Biophys Res Commun 203, 666-673

49. Harrison, P., Degen, S. J., Williams, R., and Farzaneh, F. (1994) Hepatic expression of hepatocyte-growth-factor-like/macrophage-stimulating protein mRNA in fulminant hepatic failure. Lancet 344, 27-29

50. Laskin, D. L., Chen, L., Hankey, P. A., and Laskin, J. D. (2010) Role of STK in mouse liver macrophage and endothelial cell responsiveness during acute endotoxemia. Journal of leukocyte biology 88, 373-382

51. Kulkarni, R. M., Stuart, W. D., Gurusamy, D., and Waltz, S. E. (2014) Ron receptor signaling is protective against DSS-induced colitis in mice. American journal of physiology. Gastrointestinal and liver physiology 306, G1065-1074

52. Leonis, M. A., Toney-Earley, K., Degen, S. J., and Waltz, S. E. (2002) Deletion of the Ron receptor tyrosine kinase domain in mice provides protection from endotoxin-induced acute liver failure. Hepatology (Baltimore, Md.) 36, 1053-1060

53. Gorlatova, N., Chao, K., Pal, L. R., Araj, R. H., Galkin, A., Turko, I., Moult, J., and Herzberg, $\mathrm{O}$ (2011) Protein characterization of a candidate mechanism SNP for Crohn's disease: the macrophage stimulating protein R689C substitution. PloS one 6, e27269

54. Kauder, S. E., Santell, L., Mai, E., Wright, L. Y., Luis, E., N'Diaye, E. N., Lutman, J., Ratti, N., Sa, S. M., Maun, H. R., Stefanich, E., Gonzalez, L. C., Graham, R. R., Diehl, L., Faubion, W. A., Jr., Keir, M. E., Young, J., Chaudhuri, A., Lazarus, R. A., and Egen, J. G. (2013) Functional consequences of the macrophage stimulating protein $689 \mathrm{C}$ inflammatory bowel disease risk allele. PloS one 8, e83958

55. Lentsch, A. B., Pathrose, P., Kader, S., Kuboki, S., Collins, M. H., and Waltz, S. E. (2007) The Ron receptor tyrosine kinase regulates acute lung injury and suppresses nuclear factor kappaB activation. Shock 27, 274-280

56. Nikolaidis, N. M., Kulkarni, R. M., Gray, J. K., Collins, M. H., and Waltz, S. E. (2011) Ron receptor deficient alveolar myeloid cells exacerbate LPSinduced acute lung injury in the murine lung. Innate immunity 17, 499-507

57. Gunella, G., Bardelli, C., Amoruso, A., Viano, I., Balbo, P., and Brunelleschi, S. (2006) Macrophage-stimulating protein differently affects human alveolar macrophages from smoker and non-smoker patients: evaluation of respiratory burst, cytokine release and NF-kappaB pathway. British journal of pharmacology 148, 478-489 
58. Arakelyan, A., Kriegova, E., Kubištova, Z., Mrazek, F., Kverka, M., Du Bois, R. M., Kolek, V., and Petrek, M. (2009) Protein levels of CC chemokine ligand (CCL)15, CCL16 and macrophage stimulating protein in patients with sarcoidosis. Clinical \& Experimental Immunology 155, 457465

59. Lee, K. E., Kim, E. Y., Kim, C. S., Choi, J. S., Bae, E. H., Ma, S. K., Kim, K. K., Lee, J. U., and Kim, S. W. (2013) Macrophage-stimulating protein attenuates gentamicin-induced inflammation and apoptosis in human renal proximal tubular epithelial cells. Biochem Biophys Res Commun 434, 527-533

60. Cantaluppi, V., Biancone, L., Romanazzi, G. M., Figliolini, F., Beltramo, S., Galimi, F., Camboni, M. G., Deriu, E., Conaldi, P., Bottelli, A., Orlandi, V., Herrera, M. B., Pacitti, A., Segoloni, G. P., and Camussi, G. (2008) Macrophage stimulating protein may promote tubular regeneration after acute injury. Journal of the American Society of Nephrology: JASN 19, 1904-1918

61. Tong, X. M., Wang, J. C., Shen, Y., Xie, J. J., Zhang, J. Y., and Jin, J. (2011) Inhibition of inflammatory mediators and related signaling pathways by macrophage-stimulating protein in rheumatoid arthritis synovial fibroblasts. Inflamm Res 60, 823-829

62. Caldwell, C. C., Martignoni, A., Leonis, M. A., Ondiveeran, H. K., Fox-Robichaud, A. E., and Waltz, S. E. (2008) Ron receptor tyrosine kinasedependent hepatic neutrophil recruitment and survival benefit in a murine model of bacterial peritonitis. Critical care medicine 36, 1585-1593

63. Zhang, B. B., Zhou, G., and Li, C. (2009) AMPK: an emerging drug target for diabetes and the metabolic syndrome. Cell metabolism 9, 407416

64. Bottaro, D. P., Rubin, J. S., Faletto, D. L., Chan, A. M., Kmiecik, T. E., Vande Woude, G. F., and Aaronson, S. A. (1991) Identification of the hepatocyte growth factor receptor as the c-met protooncogene product. Science (New York, N.Y.) 251, 802-804

65. Tsukagawa, E., Adachi, H., Hirai, Y., Enomoto, M., Fukami, A., Ogata, K., Kasahara, A., Yokoi, K., and Imaizumi, T. (2013) Independent association of elevated serum hepatocyte growth factor levels with development of insulin resistance in a 10-year prospective study. Clinical endocrinology 79, 43-48

66. Boros, P., and Miller, C. M. (1995) Hepatocyte growth factor: a multifunctional cytokine. Lancet 345, 293-295

67. Gentile, A., Trusolino, L., and Comoglio, P. M. (2008) The Met tyrosine kinase receptor in development and cancer. Cancer metastasis reviews $\mathbf{2 7}, 85-94$
68. Nakamura, T., Sakai, K., Nakamura, T., and Matsumoto, K. (2011) Hepatocyte growth factor twenty years on: Much more than a growth factor. Journal of gastroenterology and hepatology 26 Suppl 1, 188-202

69. Giebeler, A., Boekschoten, M. V., Klein, C., Borowiak, M., Birchmeier, C., Gassler, N., Wasmuth, H. E., Muller, M., Trautwein, C., and Streetz, K. L. (2009) c-Met confers protection against chronic liver tissue damage and fibrosis progression after bile duct ligation in mice. Gastroenterology 137, 297-308, 308 e291-294

70. Gong, R., Rifai, A., and Dworkin, L. D. (2006) Anti-inflammatory effect of hepatocyte growth factor in chronic kidney disease: targeting the inflamed vascular endothelium. Journal of the American Society of Nephrology: JASN 17, 24642473

71. Gong, R., Rifai, A., and Dworkin, L. D. (2006) Hepatocyte growth factor suppresses acute renal inflammation by inhibition of endothelial E-selectin. Kidney international 69, 1166-1174

72. Kusunoki, H., Taniyama, Y., Otsu, R., Rakugi, H., and Morishita, R. (2014) Anti-inflammatory effects of hepatocyte growth factor on the vicious cycle of macrophages and adipocytes. Hypertension research: official journal of the Japanese Society of Hypertension 37, 500-506

73. Hiratsuka, A., Adachi, H., Fujiura, Y., Yamagishi, S., Hirai, Y., Enomoto, M., Satoh, A., Hino, A., Furuki, K., and Imaizumi, T. (2005) Strong association between serum hepatocyte growth factor and metabolic syndrome. The Journal of clinical endocrinology and metabolism 90, 2927-2931

74. Rajpathak, S. N., Wassertheil-Smoller, S., Crandall, J., Liu, S., and Ho, G. Y. (2010) Hepatocyte growth factor and clinical diabetes in postmenopausal women. Diabetes care 33, 20132015

75. Kato, Y., Yu, D., and Schwartz, M. Z. (1998) Hepatocyte growth factor up-regulates SGLT1 and GLUT5 gene expression after massive small bowel resection. Journal of pediatric surgery 33, 13-15

76. Bertola, A., Bonnafous, S., Cormont, M., Anty, R., Tanti, J. F., Tran, A., Le Marchand-Brustel, Y., and Gual, P. (2007) Hepatocyte growth factor induces glucose uptake in 3T3-L1 adipocytes through A Gab1/phosphatidylinositol 3-kinase/ Glut4 pathway. The Journal of biological chemistry 282, 10325-10332 
77. Garcia-Ocana, A., Vasavada, R. C., Cebrian, A., Reddy, V., Takane, K. K., Lopez-Talavera, J. C., and Stewart, A. F. (2001) Transgenic overexpression of hepatocyte growth factor in the beta-cell markedly improves islet function and islet transplant outcomes in mice. Diabetes 50, 27522762

78. Roccisana, J., Reddy, V., Vasavada, R. C., Gonzalez-Pertusa, J. A., Magnuson, M. A., and GarciaOcana, A. (2005) Targeted inactivation of hepatocyte growth factor receptor c-met in betacells leads to defective insulin secretion and GLUT-2 downregulation without alteration of beta-cell mass. Diabetes 54, 2090-2102

79. Demirci, C., Ernst, S., Alvarez-Perez, J. C., Rosa, T., Valle, S., Shridhar, V., Casinelli, G. P., Alonso, L. C., Vasavada, R. C., and Garcia-Ocana, A. (2012) Loss of HGF/c-Met signaling in pancreatic beta-cells leads to incomplete maternal betacell adaptation and gestational diabetes mellitus. Diabetes 61, 1143-1152

80. Perdomo, G., Martinez-Brocca, M. A., Bhatt, B. A., Brown, N. F., O'Doherty, R. M., and GarciaOcana, A. (2008) Hepatocyte growth factor is a novel stimulator of glucose uptake and metabolism in skeletal muscle cells. The Journal of biological chemistry 283, 13700-13706

81. Fafalios, A., Ma, J., Tan, X., Stoops, J., Luo, J., Defrances, M. C., and Zarnegar, R. (2011) A hepatocyte growth factor receptor (Met)-insulin receptor hybrid governs hepatic glucose metabolism. Nature medicine 17, 1577-1584

82. Alvarez-Perez, J. C., Ernst, S., Demirci, C., Casinelli, G. P., Mellado-Gil, J. M., Rausell-Palamos, F., Vasavada, R. C., and Garcia-Ocana, A. (2014) Hepatocyte growth factor/c-Met signaling is required for beta-cell regeneration. Diabetes 63, 216-223

83. Mellado-Gil, J., Rosa, T. C., Demirci, C., Gonzalez-Pertusa, J. A., Velazquez-Garcia, S., Ernst, S., Valle, S., Vasavada, R. C., Stewart, A. F., Alonso, L. C., and Garcia-Ocana, A. (2011) Disruption of hepatocyte growth factor/c-Met signaling enhances pancreatic beta-cell death and accelerates the onset of diabetes. Diabetes 60, 525536
84. Park, M. K., Kim, D. K., and Lee, H. J. (2003) Adenoviral mediated hepatocyte growth factor gene attenuates hyperglycemia and beta cell destruction in overt diabetic mice. Experimental \& molecular medicine 35, 494-500

85. Tomita, K., Azuma, T., Kitamura, N., Nishida, J., Tamiya, G., Oka, A., Inokuchi, S., Nishimura, T., Suematsu, M., and Ishii, H. (2004) Pioglitazone prevents alcohol-induced fatty liver in rats through up-regulation of c-Met. Gastroenterology 126, 873-885

86. Kosone, T., Takagi, H., Horiguchi, N., Ariyama, Y., Otsuka, T., Sohara, N., Kakizaki, S., Sato, K., and Mori, M. (2007) HGF ameliorates a high-fat dietinduced fatty liver. American journal of physiology. Gastrointestinal and liver physiology 293, G204-210

87. Kroy, D. C., Schumacher, F., Ramadori, P., Hatting, M., Bergheim, I., Gassler, N., Boekschoten, M. V., Muller, M., Streetz, K. L., and Trautwein, C. (2014) Hepatocyte specific deletion of c-Met leads to the development of severe non-alcoholic-steatohepatitis in mice. Journal of hepatology

88. Bezerra, J. A., Witte, D. P., Aronow, B. J., and Degen, S. J. (1993) Hepatocyte-specific expression of the mouse hepatocyte growth factor-like protein. Hepatology (Baltimore, Md.) 18, 394-3 




\section{Chapter 3}

\section{MSP is a negative regulator of inflammation and lipogenesis in ex vivo models of non-alcoholic steatohepatitis}

Dipanjan Chanda \#, Jieyi Li \#, Yvonne Oligschlaeger, Mike L. J. Jeurissen, Tom Houben, Sofie M. A. Walenbergh, Ronit Shiri-Sverdlov, Dietbert Neumann

${ }^{\text {\#} A u t h o r s ~ e q u a l l y ~ c o n t r i b u t e d ~}$ Experimental \& molecular medicine 48 (2016), e258. 


\begin{abstract}
Non-alcoholic steatohepatitis (NASH), a metabolic disorder cosisting of steatosis and inflammation, is considered the hepatic equivalent of metabolic syndrome and can result in irreversible liver damage. Macrophage stimulating protein (MSP) is a hepatokine that potentially has a beneficial role in hepatic lipid and glucose metabolism via the activation of AMP-activated protein kinase (AMPK). In the current study, we investigated the regulatory role of MSP in the development of inflammation and lipid metabolism in various NASH models, both in vitro and ex vivo. We observed that MSP treatment activated the AMPK signaling pathway and inhibited lipopolysaccharide (LPS)- and palmitic acid (PA)-induced gene expression of pro-inflammatory cytokines in primary mouse hepatocytes. In addition, MSP treatment resulted in a significant reduction in PAinduced lipid accumulation and inhibited the gene expression of key lipogenic enzymes in HepG2 cells. Upon short hairpin RNA-induced knockdown of RON (the membranebound receptor for MSP), the anti-inflammatory and anti-lipogenic effects of MSP were markedly ablated. Finally, to mimic NASH ex vivo, we challenged bone marrow-derived macrophages with oxidized low- density lipoprotein (oxLDL) in combination with LPS. OxLDL+LPS exposure led to a marked inhibition of AMPK activity and a robust increase in inflammation. MSP treatment significantly reversed these effects by restoring AMPK activity and by suppressing pro-inflammatory cytokine gene expression and secretion under this condition. Taken together, these data suggest that MSP is an effective inhibitor of inflammation and lipid accumulation in stressed liver, thereby indicating that MSP has a key regulatory role in NASH.
\end{abstract}




\section{Introduction}

Non-alcoholic steatohepatitis (NASH) is characterized by excessive hepatic lipid accumulation (steatosis) in addition to inflammation (hepatitis). The transition from steatosis to NASH initiates further severe liver damage and thus represents a crucial step in the pathogenesis of NASH [1]. Thus far, the triggers for the inflammatory response in the liver are poorly understood. Recent findings suggest that visceral adipose tissue and its secretory products (adipocytokines) are major contributors to inflammation. Increased lipid content in visceral adipose tissue enhances free fatty acid delivery from the adipocytes into the liver, thereby increasing hepatic lipid content and initiating inflammation and insulin resistance [2]. Recent evidence also indicates that elevated levels of plasma lipopolysaccharide (LPS) secreted from gut microbiota during obesity are a source for liver inflammation [3]. An increasing number of studies show the involvement of oxidized low-density lipoproteins (oxLDL) in hepatic inflammation, and LPS has been shown to synergize oxLDL uptake in macrophages [4]. Although the underlying molecular mechanism is currently unclear, oxLDL has emerged as a new risk factor for hepatic inflammation.

Macrophage stimulating protein (MSP) is constitutively secreted by the liver into the circulating blood as a single chain, biologically inactive pro-MSP. Mature MSP is generated through proteolytic cleavage by trypsin-like serine proteases at extravascular sites and targets macrophages and other cell types. MSP is a ligand for the Recepteur d'origine nantais (RON) receptor tyrosine kinase, which is expressed in several tissues, including the liver and brain [5-7]. The MSP-RON pair has inhibitory roles in inflammatory responses, such as the production of nitric oxide by stimulated macrophages. Remarkably, MSP-deficient mice on a normal diet develop steatosis. Furthermore, MSP is both necessary and sufficient to induce macrophage polarization into the anti-inflammatory M2 phenotype (as opposed to the pro-inflammatory M1 activation), which assists in attenuation of inflammation [5,6]. Previously, we have demonstrated that MSP inhibits gluconeogenesis [8] and Toll-like receptor signaling [9] via the activation of AMPactivated protein kinase (AMPK) signaling. AMPK is an important integrator of signals that coordinates energy balance and acts as a protective response to energy stress during metabolic deregulation [10]. However, an obvious link connecting MSP with inflammation is understudied, and the potential implication of the MSP-RON-AMPK axis in NASH has not been investigated.

In current study, we investigated the role of the MSP-RON-mediated activation of AMPK in the context of inflammation and NASH. We challenged primary mouse hepatocytes, HepG2 cells and bone marrow-derived macrophages (BMDMs) with different triggers for 
inflammation and NASH. To elucidate the involvement of the MSP signaling pathway under these patho-physiological conditions, we analyzed changes in cell signaling, lipid accumulation and gene expression of inflammatory cytokines and lipogenic enzymes. Our data strongly suggest that MSP, via its receptor RON, activates the downstream AMPK signaling pathway, in turn inhibiting inflammation and excessive lipid accumulation and, thereby, having a crucial role in countering NASH.

\section{Materials and Methods}

\section{Materials}

Recombinant human MSP (MSP), LPS, and oxLDL were purchased from R\&D systems. Palmitic acid (PA) was purchased from Sigma-Aldrich (St Louis, MO, USA).

\section{Cell culture, mice, BMDMs and primary mouse hepatocytes}

HepG2 cells (ATCC, Manassas, VA, USA) and age-matched wild-type C57BI/6J mice were used for the various experiments. Mice were housed under standard conditions and provided with unlimited access to food and water. Experiments were performed according to Dutch regulations and approved by the Committee for Animal Welfare of Maastricht University. Primary mouse hepatocytes were isolated from C57BL/6 mice using the collagenase method as previously described [8].

HepG2 cells and primary mouse hepatocytes were incubated for $24 \mathrm{~h}$ with PA (0.5 mM) or for $4 \mathrm{~h}$ with LPS $(100 \mathrm{ng} / \mathrm{ml})$ in the absence or presence of MSP $(100 \mathrm{ng} / \mathrm{ml})$ or 5-aminoimidazole-4carboxamide ribonucleotide (AICAR) $(0.5 \mathrm{mM})$, as indicated. For treatments involving AMPK inhibitor Compound C (Comp. C, $10 \mu \mathrm{M})$, primary mouse hepatocytes were pretreated with Comp. C for $1 \mathrm{~h}$ preceding incubation with PA or LPS in the absence or presence of MSP or AICAR, as indicated in the figures.

BMDMs were isolated from the tibiae and femurs of C57BL/6 mice as previously described $[9,11]$. After attachment, macrophages were incubated with oxLDL $(25 \mu \mathrm{g} / \mathrm{ml})$ for $24 \mathrm{~h}$. Then, the cells were washed and stimulated with LPS in the absence or presence of MSP for $4 \mathrm{~h}$.

Collection of media for ELISA analysis, immunoprecipitation and western blotting, RNA isolation, complementary DNA synthesis and real-time quantitative PCR were performed as previously described $[8,9,11]$.

\section{Oil Red-O staining}

Oil Red-O staining was performed as previously described [12]. Images acquisition was performed using a bright-field light microscope, and image quantification was performd using ImageJ program (http://rsbweb.nih.gov/ij/). 


\section{Lentiviral infection}

pLKO.1 puro was a gift from Bob Weinberg (Addgene plasmid \# 8453). HEK-293T cells were co-transfected with psPAX2 and pMD2.G lentivirus packaging vectors with pLKO.1 scramble (shScr) or pLKO.1 RON $\alpha$ (shRON $\alpha$ ) using Lipofectamine ${ }^{\mathrm{TM}} 2000$ (Invitrogen, Carlsbad, CA, USA) according to the manufacturer's protocol. After a $48 \mathrm{~h}$ infection, the lentivirus particles were collected from the HEK-293T cells, and HepG2 cells were infected with these particles. Infected cells were selected for puromycin resistance $(4 \mu \mathrm{g} /$ $\mathrm{ml}$ ) for 5 days, and western blotting analysis was performed to determine knockdown efficiency.

\section{Statistical analysis}

The data were analyzed using Graphpad Prism 4.0.3 (GraphPad Software, Inc., La Jolla, CA, USA). Unpaired Student's $t$-tests were performed, and data are expressed as means \pm SEM. The level of significance was set at $p<0.05$.

\section{Results}

MSP inhibits PA- and LPS- induced inflammation via the activation of the AMPK signaling pathway

Previously, we demonstrated that MSP activates AMPK signaling in the human hepatoma cell line HepG2 and in primary rat hepatocytes [8]. In primary mouse hepatocytes, we confirmed that 5 to $60 \mathrm{~min}$ incubations with MSP $(100 \mathrm{ng} / \mathrm{ml})$ enhanced the phosphorylation of AMPK and of the downstream AMPK target acetyl CoA carboxylase (ACC) via the phosphorylation and activation of the RON receptor (Fig. 1A). Previous studies have demonstrated that both PA (the predominant free fatty acid in circulation) and LPS induce an inflammatory response in hepatocytes $[3,13]$. Conversely, AMPK activation is considered to have potential therapeutic benefits owing to the antiinflammatory properties of AMPK $[9,14-16]$. Thus, primary hepatocytes were challenged with PA or LPS in the absence or presence of MSP or a well-established AMPK activator, AICAR (Fig. 1B-E and Fig. 2). In addition, to reconfirm MSP-induced activation of the AMPK signaling pathway, hepatocytes were pretreated with the AMPK inhibitor Compound C (Comp. C) in the presence of MSP and AICAR. Both MSP and AICAR increased the phosphorylation levels of AMPK and ACC in PA- (Fig. 1B) and LPS- (Fig. 2A) challenged hepatocytes. However, this effect was significantly attenuated upon pretreatment with Comp. C. PA- (Fig. 1C) and LPS- (Fig. 2B) challenged hepatocytes demonstrated a marked increase in the gene expression of key pro-inflammatory markers, tumor necrosis factor $\alpha(\operatorname{Tn} f \alpha)$, interleukin $6(/ / 6)$ and monocyte chemoattractant protein-1 (Mcp-1). This increase in pro-inflammatory marker gene expression was 
A
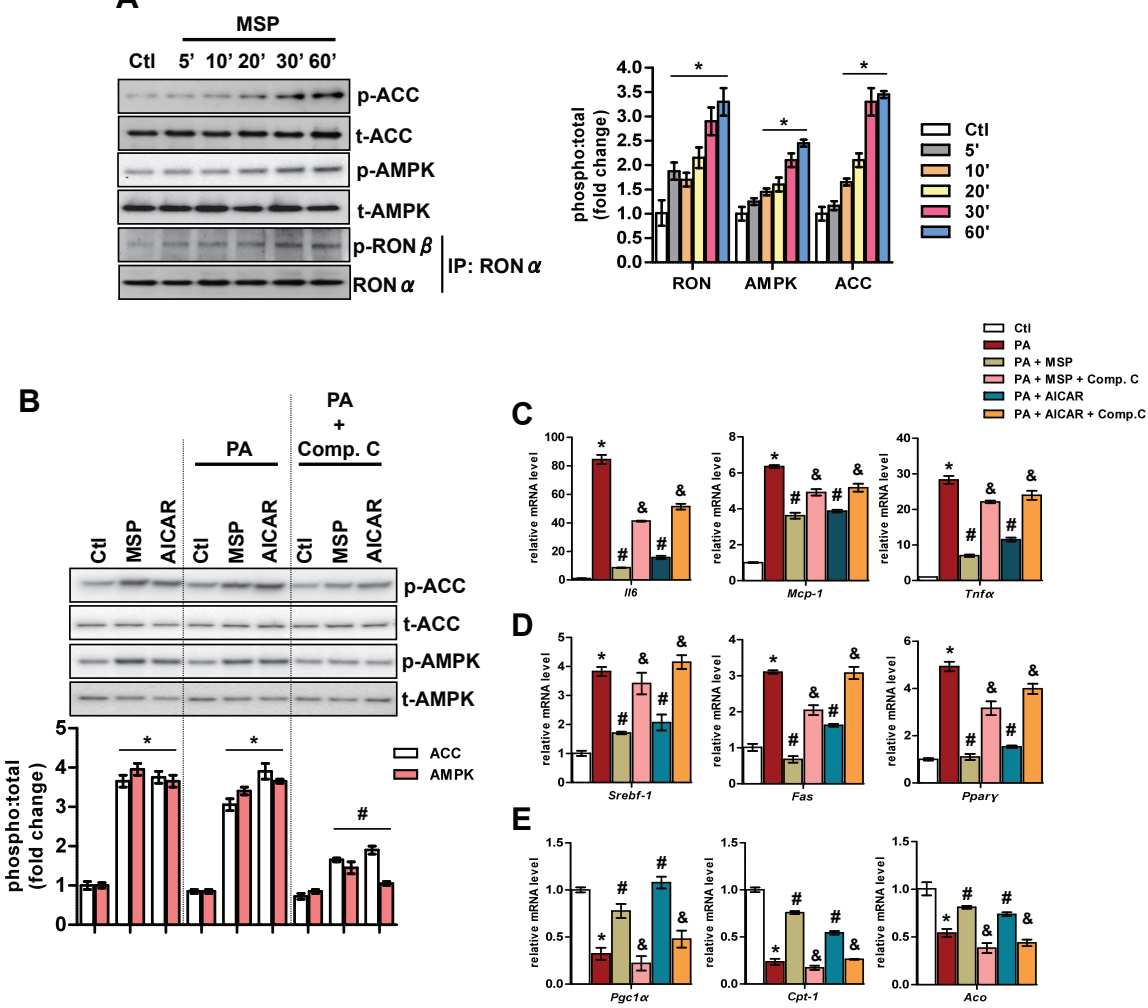

Figure 1. MSP alleviates PA-induced inflammation in primary mouse hepatocytes.

(A) Representative western blot analysis (left) and quantification of the fold change relative to vehicle control (right) of RON, AMPK and ACC phosphorylation upon MSP treatment for indicated amount of time. Data are means \pm SEM $(n=6) .{ }^{*} p<0.05$ vs. Ctl.

(B) Representative western blot (top) and quantification of the fold change relative to vehicle control (bottom) of AMPK and ACC phosphorylation upon indicated treatments. Data are means \pm SEM $(n=$ 6). ${ }^{*} p<0.05$ vs. Ctl; ${ }^{p} p<0.05$ vs. PA.

(C-E) Real-time qPCR analysis of genes involved in inflammation (C) lipogenesis (D), and fatty acid oxidation (E) from the hepatocytes treated as indicated. Each value indicates the amount of mRNA relative to the vehicle control-treated hepatocytes. Cyclophilin $A$ was used as the invariant control. Data are means $\pm \operatorname{SEM}(n=6) .{ }^{*} p<0.01$ vs. Ctl; ${ }^{*} p<0.05$ vs. PA; ${ }^{*} p<0.05$ vs. PA \pm MSP or PA \pm AICAR.

significantly ablated in the presence of either MSP or AICAR under these conditions. However, consistent with the inhibition of AMPK and ACC phosphorylation, pretreatment of Comp. C markedly reversed the inhibitory effect of either MSP or AICAR on Tnfa, I/6 and $M c p-1$ gene expression levels.

Because it has been well established that peripheral AMPK activation can promote fatty acid oxidation by phosphorylating and inactivating ACC as well as inhibiting fatty acid synthesis [14-16], we determined whether MSP-induced AMPK phosphorylation in these inflammatory-challenged hepatocytes can affect the expression of genes involved in 
lipid metabolism. To test this hypothesis, we investigated the expression of lipogenic genes in PA- and LPS-challenged hepatocytes treated with MSP or AICAR in the absence or presence of AMPK inhibition. As demonstrated, PA- (Fig. 1D) and LPS- (Fig. 2C) challenged hepatocytes demonstrated a marked increase in the expression of key lipogenic genes - sterol regulatory element-binding factor 1 (Srebf-1), fatty acid synthase (Fas) and peroxisome proliferator-activated receptor- $\alpha$ (Ppar- $\alpha$ ). MSP (or AICAR) treatment resulted in a marked reduction of Srebf-1, Fas and Ppar- $\alpha$ expression levels, and this anti-lipogenic effect of MSP (or AICAR) was significantly attenuated upon AMPK inhibition by Comp. C. In contrast, PA- (Fig. 1E) and LPS- (Fig. 2D) induced inhibition of the expression of key fatty acid oxidation genes such as acyl-CoA oxidase (Aco), carnitine palmitoyltransferase I (Cpt-1), and peroxisome proliferator-activated receptor- $\gamma$ (PPAR $\gamma$ ) coactivator-1 $\alpha$ (PgC-1 $\alpha)$, was remarkably reversed with MSP and AICAR treatment. Consistent with previous observations, AMPK inhibition following pretreatment of Comp. $C$ under these conditions reversed the stimulation of fatty acid oxidation observed with either MSP or AICAR treatment. Taken together, these findings suggest that MSP ameliorated ex vivo NASH-mimicking conditions by enhancing fatty acid oxidation and by repressing lipogenesis and inflammatory response via the activation of the AMPK signaling pathway.

\section{MSP inhibits PA-induced lipid accumulation}

Recent studies have demonstrated that an aberrant increase in lipid accumulation is a characteristic of metabolic diseases, such as type 2 diabetes, NASH and metabolic syndrome $[2,12,13]$. Thus, using Oil Red-O staining for lipid droplets, we examined the effect of MSP co-treatment on PA-induced lipid accumulation. PA exposure led to a marked increase in lipid droplets in these cells ( 6-fold compared with the control), suggesting a robust increase in lipid accumulation (Fig. 3). However, co-treatment with MSP significantly reduced lipid accumulation ( 3.5-fold compared with PA-challenged cells), thereby implying that MSP inhibits excessive lipid accumulation, potentially via the enhancement of lipid oxidation and/or inhibition of lipogenesis to counter inflammation. 
A

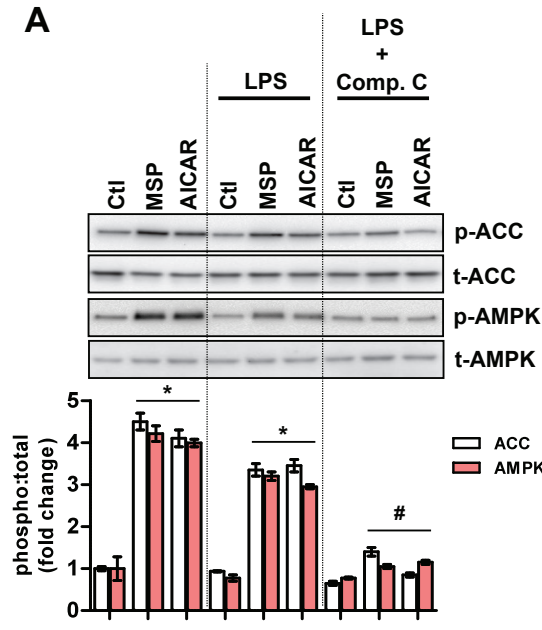

B
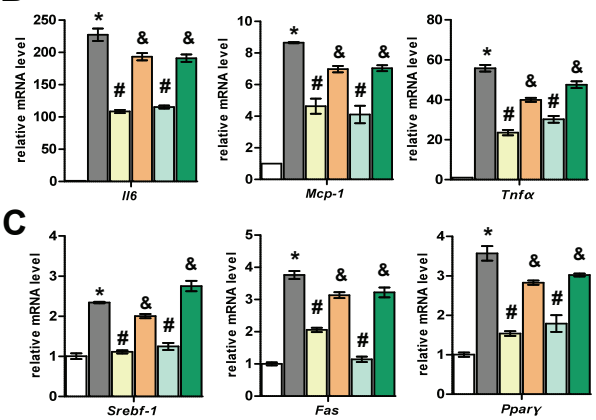

D
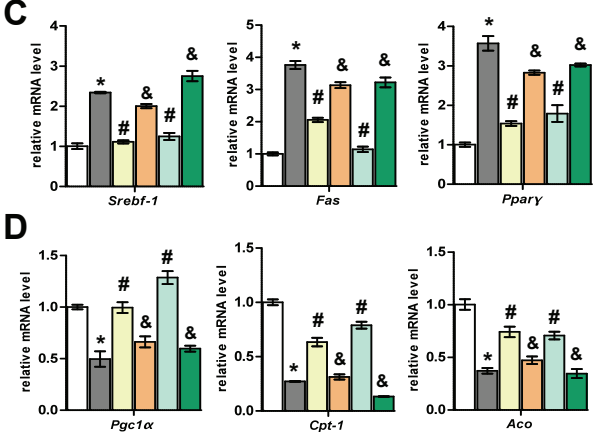

Figure 2. MSP ameliorates LPS-induced inflammation in primary mouse hepatocytes.

(A) Representative western blot (top) and quantification of the fold change relative to vehicle control (bottom) of AMPK and ACC phosphorylation upon indicated treatments. Data are means \pm SEM ( $n=$ 6). ${ }^{*} p<0.05$ vs. Ctl; ${ }^{\#} p<0.05$ vs. LPS.

(B-D) Real-time qPCR analysis of genes involved in inflammation (B) lipogenesis (C), and fatty acid oxidation (D) from the hepatocytes treated as indicated. Each value indicates the amount of mRNA relative to the vehicle control-treated hepatocytes. Cyclophilin $A$ was used as the invariant control. Data are means \pm SEM $(n=6) .{ }^{*} p<0.01$ vs. Ctl; ${ }^{\sharp} p<0.05$ vs. LPS; ${ }^{\&} p<0.05$ vs. LPS \pm MSP or LPS \pm AICAR.

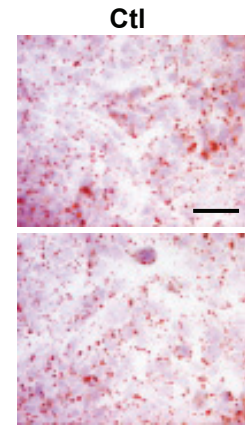

MSP
PA

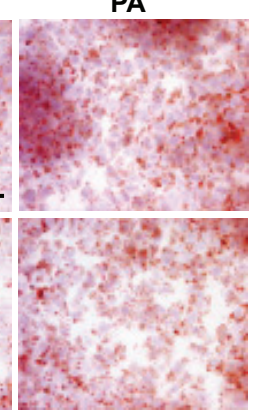

PA + MSP

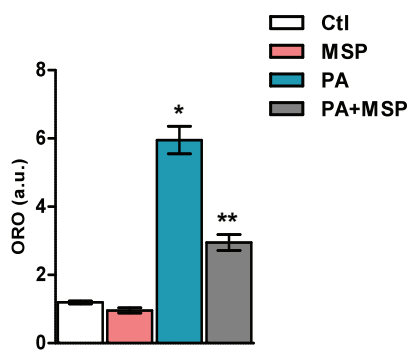

Figure 3. MSP treatment reduces neutral lipid accumulation in HepG2 cells.

Visualization (representative images) and quantification of neutral lipids by ORO analysis in HepG2 cells challenged with PA, in the absence or presence of MSP. Scale bars, $100 \mu \mathrm{m}$; 40X magnification; a.u., arbitrary units. Data are means \pm SEM of three independent experiments. ${ }^{*} p<0.01 \mathrm{vs.} \mathrm{Ctl;}{ }^{* *} p$ $<0.01$ vs. PA 


\section{Anti-inflammatory and anti-lipogenic effect of MSP is reversed upon knockdown of the RON receptor}

Next, to determine whether MSP activates AMPK via its membrane-bound RON receptor and whether MSP exerts anti-inflammatory and anti-lipogenic effects, we employed lentivirus-mediated knockdown of the RON receptor (shRON) in HepG2 cells, which markedly reduced $\mathrm{RON}$ receptor level $(\mathrm{RON} \alpha)$ compared with the scrambled, nonspecific virus-infected cells (shScr) (Fig. 4A). As expected, in shScr-infected cells, MSP treatment led to a significant increase in AMPK and ACC phosphorylation in the absence or presence of PA. However, this activation of the AMPK signaling pathway was significantly diminished in shRON-infected cells, confirming that MSP exerts its effect via its RON receptor (Fig. 4B). In the presence of shScr, MSP co-treatment resulted in a significant reduction in the PA-induced gene expression of pro-inflammatory markers $T N F \alpha$ and $I L-6$, along with the key lipogenic enzymes SREBP-1C and FAS (Fig. 4C). However, in the shRON-infected cells, the anti-lipogenic and anti-inflammatory effect of MSP cotreatment is dramatically abolished, thus confirming that MSP regulates lipogenesis and inflammation via its RON receptor.

\section{MSP inhibits inflammation in an ex vivo model mimicking NASH}

Macrophages have a pivotal role in the hepatic inflammation and in the subsequent development of NASH. Recent data show the involvement and contribution of oxLDL in hepatic inflammation, thus implicating it to be a new risk factor for hepatic inflammation [1]. In addition, it has been shown that LPS augments the uptake of oxLDL in macrophages [4]. Therefore, we examined the effect of MSP in oxLDL+LPS-induced inflammation in BMDMs. BMDMs were treated with oxLDL for $24 \mathrm{~h}$ followed by LPS treatment for $4 \mathrm{~h}$ in the absence or presence of MSP. RON receptor, AMPK and ACC phosphorylation was significantly inhibited by oxLDL+LPS exposure, and upon MSP co-treatment, this inhibitory effect on the activation of RON and the downstream activation of the AMPK signaling pathway was markedly reversed (Fig. 5A). Next, we observed that oxLDL+LPS exposure led to a significant increase in TNF $\alpha$ production and decreased the production of anti-inflammatory cytokine interleukin 10 (IL-10).

MSP co-treatment under this condition resulted in a marked reversal of TNF $\alpha$ production and concomitantly induced the production of IL-10 (Fig. 5B), indicating an antiinflammatory role of MSP. Finally, gene expression analysis demonstrated that MSP cotreatment resulted in a significant reduction in oxLDL+LPS-induced Tnfo, II-6 and Mcp-1 mRNA levels in BMDMs (Fig. 5C). Moreover, as expected from our previous findings [9], MSP treatments led to a strong induction of orphan nuclear receptor small heterodimer partner (Shp; NrOb2) gene expression. Overall, these results suggest that MSP reduces inflammation to alleviate NASH, both in vitro and ex vivo. 
A

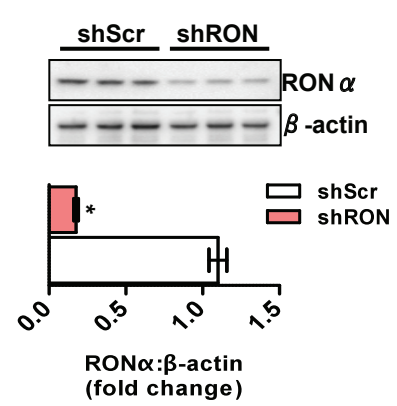

C

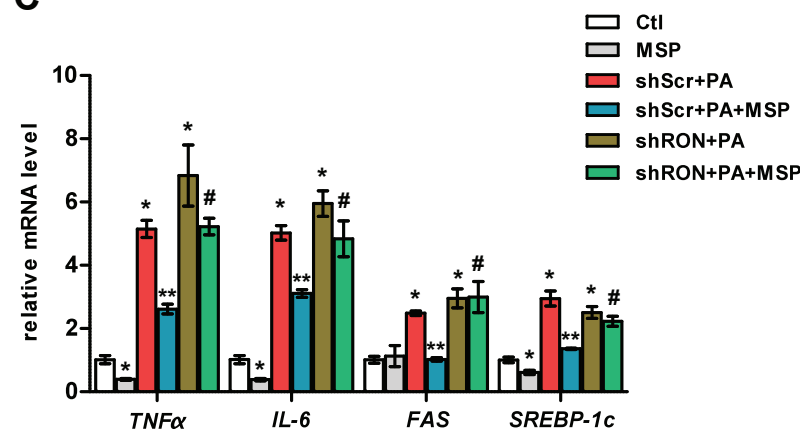

B

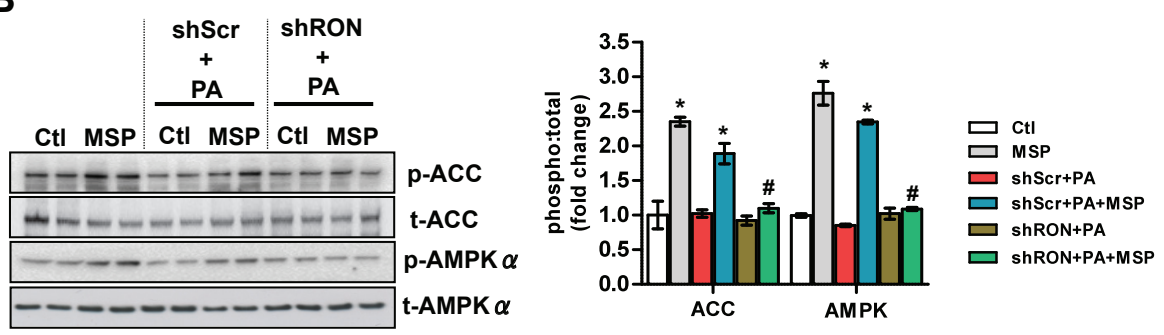

Figure 4. RON receptor relays the downstream effects of MSP in HepG2 cells.

(A) Representative western blot of shRNA-induced knockdown of RON (top) and quantification of the fold change relative to shScr (bottom). Data are means \pm SEM of three independent experiments. ${ }^{*} p$ $<0.01$ vs. shScr.

(B) Representative western blot (left) and quantification of the fold change relative to Ctl (bottom) of AMPK and ACC phosphorylation in cells challenged with PA, in the absence or presence of MSP, in RON knockdown cells. Data are means \pm SEM of three independent experiments. ${ }^{*} p<0.01$ vs. Ctl; ${ }^{*} p$ $<0.05$ vs. shScr+PA+MSP.

(C) Real-time qPCR analysis of genes involved in inflammation (TNFQ, IL-6) and lipogenesis (FAS, $S R E B P-1 C$ ) in cells challenged with $\mathrm{PA}$, in the absence or presence of MSP, in RON knockdown cells. Values are means \pm SEM of three independent experiments. ${ }^{*} p<0.01 \mathrm{vs}$. $\mathrm{Ctl} ;{ }^{* *} p<0.05 \mathrm{vs}$. shScr+PA; ${ }^{\#} p<0.05$ vs. shScr+PA+MSP.

\section{Discussion}

NASH is a feature of the metabolic syndrome, and as such, it is strongly associated with insulin resistance. Hepatic steatosis is characterized by a higher dietary fat intake, increased de novo lipogenesis, and increased lipolysis in adipose tissue, leading to an imbalance between lipid storage and lipid removal. Furthermore, macrophages and other immune cells are recruited to the liver and secrete pro-inflammatory cytokines, perpetuating chronic hepatic inflammation and eventually progressing toward cirrhosis and hepatocellular carcinoma [1-3]. Currently there is no effective treatment for NASH. In the current study, we demonstrated for the first time that MSP acts as a key negative regulator of inflammation and lipogenesis by activating the AMPK signaling pathway in 


\section{A}
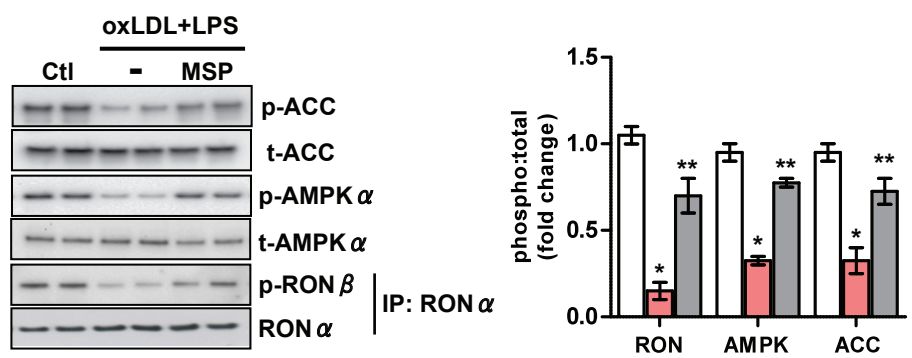

B

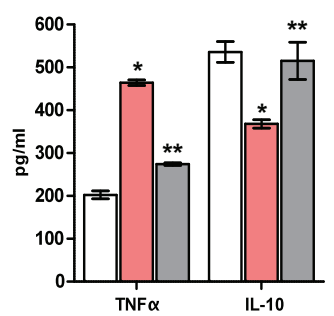

C

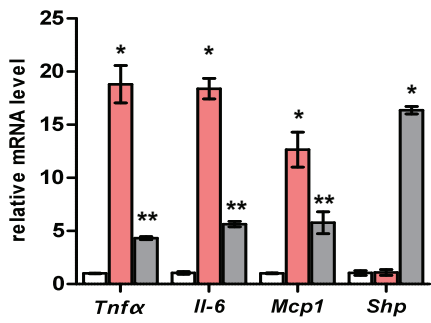

Figure 5. MSP exerts anti-inflammatory effects in BMDMs.

(A) Representative western blot (left) and quantification of the fold change relative to vehicle control (right) of RON, AMPK and ACC phosphorylation (B) ELISA analysis of TNF $\alpha$ and IL-10 production, and (C) Gene expression of pro-inflammatory cytokines Tnfa, II-6, Mcp-1 and orphan nuclear receptor Shp in oxLDL+LPS challenged BMDMs, in the absence or presence of MSP. Values are means \pm SEM, $\mathrm{n}=5$ per group. ${ }^{*} \mathrm{p}<0.01$ vs. $\mathrm{Ctl} ;{ }^{*} \mathrm{p}<0.05$ vs. oxLDL+LPS.

hepatocytes and macrophages. Our data indicate that MSP has anti-inflammatory and anti-lipogenic properties and stimulates fatty acid oxidation under metabolically challenge conditions, suggesting that it plays a beneficial role in countering NASH (Fig. 6).

Previously, we demonstrated that MSP activates the AMPK signaling pathway in primary rat hepatocytes and various hepatic cell lines [8,9]. As a reconfirmation of this phenomenon, we observed a similar effect of MSP on AMPK activation in primary mouse hepatocytes, which is comparable to the well-recognized AMPK activator AICAR. Several previous reports have indicated that MSP has a key role in regulating inflammation $[7,9,17,18]$, particularly during LPS-induced endotoxemia. However, very little is known regarding the regulatory role of MSP in NASH. To address this question, we challenged primary hepatocytes and human hepatoma HepG2 cells, in addition to LPS exposure, with PA. PA is the predominant-free fatty acid in circulation that mimics the diet-induced obesity models in vivo and is an established model to study hepatic inflammation, both in vitro and ex vivo [19]. Our results demonstrate that MSP countered and reversed the 


\section{Inflammatory Stress}

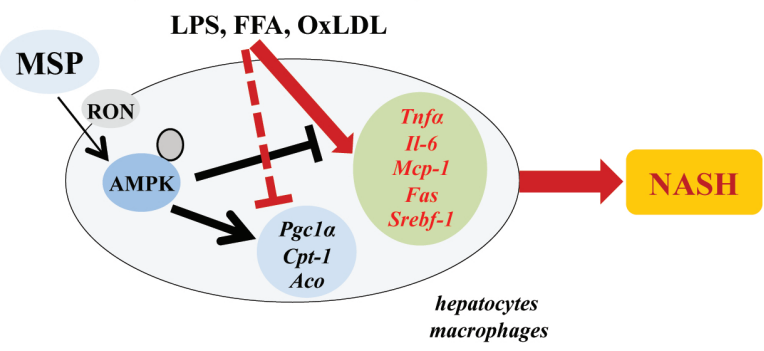

Figure 6. Schematic model representing MSP as a negative regulator of NASH in hepatocytes and macrophages.

Mediators of inflammatory stress- FFA, LPS or OxLDL- induce gene expression of key pro-inflammatory (Tnfa, II-6 and Mcp-1) and lipogenic markers (Srebp-1c and Fas) in hepatocytes and macrophages, precipitating to a pathophysiological condition termed as NASH. MSP, a hepatokine and ligand for RON receptor tyrosine kinase, activates AMPK signaling pathway to stimulate fatty acid oxidation (via upregulation of Pgc1,$C p t-1$ and $A c O)$ and to inhibit inflammation and lipogenesis in ex vivo and in vitro models mimicking NASH.

pro-inflammatory and lipogenic effects of both PA and LPS. On the other hand, MSP reversed the inhibition of fatty acid oxidation upon PA and LPS exposure. Consistent with previous findings implicating that AMPK, which is a key metabolic regulator, has antiinflammatory effects [9,14-16], we observed that activation of AMPK by MSP precedes its anti-inflammatory and anti-lipogenic effects under these conditions. Thus, our findings suggest that MSP-induced activation of AMPK initiates a crucial chain of signaling to reverse hepatic inflammation.

An aberrant increase in lipogenesis and lipid accumulation in hepatocytes is a hallmark of the metabolic syndrome, including NASH $[2,12,13]$. Relevantly, it has been shown that $\mathrm{MSP}^{-/-}$mice develop hepatic steatosis with accumulation of lipid droplets in hepatocytes under normal chow diet [20], pointing to a key role of MSP in regulating hepatic lipid metabolism. However, to the best of our knowledge, the anti-inflammatory aspect of MSP, in the context of NASH, has never been addressed. Our results from neutral lipid staining demonstrated that MSP treatment resulted in a significant reduction in PAinduced lipid accumulation in HepG2 cells. Furthermore, we observed that MSP treatment inhibits PA-induced hepatic lipogenesis via downregulating the gene expression of key lipogenic enzymes, SREBP-1C and FAS. As AMPK is known to inhibit lipogenesis by phosphorylating and downregulating SREBP-1c [21], we anticipated that this anti-lipogenic effect of MSP occurs via the activation of AMPK. Indeed, knockdown of RON, the membrane-bound receptor of MSP, led to a marked decrease in MSPinduced activation of AMPK and significantly reversed the anti-inflammatory and anti- 
lipogenic effect of MSP in PA-challenged cells. Conversely, a recent study using a high-fat diet model demonstrated that Ron ${ }^{-1}$ mice are protected against obesity and steatosis [22]. However, the same authors have previously shown that the Ron receptor deficiency results in potentiation of the inflammatory response and increased mortality resulting from LPS-induced endotoxemia [18], which supports our current findings. Overall, these results indicate that MSP-AMPK axis plays a key role in regulating hepatic lipid metabolism and inflammation in metabolically challenging conditions.

Recent findings based on molecular and clinical approaches suggest that oxLDL plays a critical role in the development of hepatic steatosis and inflammation in macrophages, and the inhibition of the oxLDL effect is expected to be beneficial in NASH $[23,24]$. Moreover, it has been shown that LPS synergizes oxLDL uptake in macrophages to exacerbate inflammation [4]. Previously, we have demonstrated that MSP, via AMPK activation, induces orphan nuclear receptor Shp to inhibit sepsis-induced inflammation in BMDMs, and this effect of MSP was ablated in Shp \% mice [9]. Here, we demonstrate that MSP strongly counteracts oxLDL+LPS induced inflammation in BMDMs by activating the AMPK signaling pathway. Additionally, MSP inhibits the production of proinflammatory cytokine TNF $\alpha$ and induces anti-inflammatory IL-10 production in this condition. These findings are supported by previous reports indicating that RON receptor signaling inhibits macrophage-dependent pro-inflammatory cytokine production during endotoxemia [7,9]. Thus, our results indicate that MSP-AMPK axis exhibits beneficial anti-inflammatory properties and protects macrophages during inflammatory stress conditions.

Taken together, our current findings unraveled a key role for MSP in the context of inflammation and steatosis. Here, we provide novel insight into the role of MSP in regulating lipid metabolism, and using various metabolic challenge models of inflammation, we elucidated the molecular mechanism of MSP action and its beneficial anti-inflammatory effect in NASH, thereby indicating that MSP can be a promising therapeutic option against NASH. 


\section{References}

1. Walenbergh, S. M., Koek, G. H., Bieghs, V., and Shiri-Sverdlov, R. (2013) Non-alcoholic steatohepatitis: the role of oxidized low-density lipoproteins. Journal of hepatology 58, 801-810

2. Fain, J. N., Madan, A. K., Hiler, M. L., Cheema, P., and Bahouth, S. W. (2004) Comparison of the release of adipokines by adipose tissue, adipose tissue matrix, and adipocytes from visceral and subcutaneous abdominal adipose tissues of obese humans. Endocrinology 145, 22732282

3. Brun, P., Castagliuolo, I., Di Leo, V., Buda, A., Pinzani, M., Palu, G., and Martines, D. (2007) Increased intestinal permeability in obese mice: new evidence in the pathogenesis of nonalcoholic steatohepatitis. American journal of physiology. Gastrointestinal and liver physiology 292, G518-525

4. Hossain, E., Ota, A., Karnan, S., Takahashi, M., Mannan, S. B., Konishi, H., and Hosokawa, Y. (2015) Lipopolysaccharide augments the uptake of oxidized LDL by up-regulating lectin-like oxidized LDL receptor-1 in macrophages. Molecular and cellular biochemistry 400, 29-40

5. Leonard, E. J., and Danilkovitch, A. (2000) Macrophage stimulating protein. Advances in cancer research 77, 139-167

6. Li, J., Chanda, D., Shiri-Sverdlov, R., and Neumann, D. (2015) MSP: an emerging player in metabolic syndrome. Cytokine \& growth factor reviews 26, 75-82

7. Lee, E. S., Kalantari, P., Tsutsui Section, S., Klatt, A., Holden, J., Correll, P. H., Power Section, C., and Henderson, A. J. (2004) RON receptor tyrosine kinase, a negative regulator of inflammation, inhibits HIV-1 transcription in monocytes/ macrophages and is decreased in brain tissue from patients with AIDS. J Immunol 173, 68646872

8. Chanda, D., Li, T., Song, K. H., Kim, Y. H., Sim, J., Lee, C. H., Chiang, J. Y., and Choi, H. S. (2009) Hepatocyte growth factor family negatively regulates hepatic gluconeogenesis via induction of orphan nuclear receptor small heterodimer partner in primary hepatocytes. The Journal of biological chemistry 284, 28510-28521

9. Yuk, J. M., Shin, D. M., Lee, H. M., Kim, J. J., Kim, S. W., Jin, H. S., Yang, C. S., Park, K. A., Chanda, D., Kim, D. K., Huang, S. M., Lee, S. K., Lee, C. H., Kim, J. M., Song, C. H., Lee, S. Y., Hur, G. M., Moore, D. D., Choi, H. S., and Jo, E. K. (2011) The orphan nuclear receptor SHP acts as a negative regulator in inflammatory signaling triggered by Toll-like receptors. Nature immunology 12, 742751
10. Hardie, D. G. (2011) AMP-activated protein kinase: an energy sensor that regulates all aspects of cell function. Genes \& development $\mathbf{2 5}$ 1895-1908

11. Hendrikx, T., Jeurissen, M. L., Bieghs, V., Walenbergh, S. M., van Gorp, P. J., Verheyen, F. Houben, T., Guichot, Y. D., Gijbels, M. J., Leitersdorf, E., Hofker, M. H., Lutjohann, D., and ShiriSverdlov, R. (2015) Hematopoietic overexpression of Cyp27a1 reduces hepatic inflammation independently of 27-hydroxycholesterol levels in Ldlr(-/-) mice. Journal of hepatology 62, 430 436

12. Mehlem, A., Hagberg, C. E., Muhl, L., Eriksson, U., and Falkevall, A. (2013) Imaging of neutral lipids by oil red $\mathrm{O}$ for analyzing the metabolic status in health and disease. Nature protocols 8, 1149-1154

13. Alkhouri, N., Dixon, L. J., and Feldstein, A. E. (2009) Lipotoxicity in nonalcoholic fatty liver disease: not all lipids are created equal. Expert review of gastroenterology \& hepatology $\mathbf{3}$ 445-451

14. O'Neill, L. A., and Hardie, D. G. (2013) Metabolism of inflammation limited by AMPK and pseudo-starvation. Nature 493, 346-355

15. Jeong, H. W., Hsu, K. C., Lee, J. W., Ham, M., Huh, J. Y., Shin, H. J., Kim, W. S., and Kim, J. B. (2009) Berberine suppresses proinflammatory responses through AMPK activation in macrophages. American journal of physiology. Endocrinology and metabolism 296, E955-964

16. Kim, W. S., Lee, Y. S., Cha, S. H., Jeong, H. W., Choe, S. S., Lee, M. R., Oh, G. T., Park, H. S., Lee, K. U., Lane, M. D., and Kim, J. B. (2009) Berberine improves lipid dysregulation in obesity by controlling central and peripheral AMPK activity. American journal of physiology. Endocrinology and metabolism 296, E812-819

17. Wang, M. H., Zhou, Y. Q., and Chen, Y. Q. (2002) Macrophage-stimulating protein and RON receptor tyrosine kinase: potential regulators of macrophage inflammatory activities. Scand J Immunol 56, 545-553

18. Waltz, S. E., Eaton, L., Toney-Earley, K., Hess, K. A., Peace, B. E., Ihlendorf, J. R., Wang, M. H., Kaestner, K. H., and Degen, S. J. (2001) Ronmediated cytoplasmic signaling is dispensable for viability but is required to limit inflammatory responses. J Clin Invest 108, 567-576

19. Boden, G. (2008) Obesity and free fatty acids. Endocrinology and metabolism clinics of North America 37, 635-646, viii-ix 
20. Bezerra, J. A., Carrick, T. L., Degen, J. L., Witte, D., and Degen, S. J. (1998) Biological effects of targeted inactivation of hepatocyte growth factor-like protein in mice. J Clin Invest 101, 11751183

21. Li, Y., Xu, S., Mihaylova, M. M., Zheng, B., Hou, X., Jiang, B., Park, O., Luo, Z., Lefai, E., Shyy, J. Y., Gao, B., Wierzbicki, M., Verbeuren, T. J., Shaw, R. J., Cohen, R. A., and Zang, M. (2011) AMPK phosphorylates and inhibits SREBP activity to attenuate hepatic steatosis and atherosclerosis in diet-induced insulin-resistant mice. Cell metabolism 13, 376-388

22. Stuart, W. D., Brown, N. E., Paluch, A. M., and Waltz, S. E. (2015) Loss of Ron receptor signaling leads to reduced obesity, diabetic phenotypes and hepatic steatosis in response to highfat diet in mice. American journal of physiology. Endocrinology and metabolism 308, E562-572
23. Bieghs, V., van Gorp, P. J., Walenbergh, S. M., Gijbels, M. J., Verheyen, F., Buurman, W. A., Briles, D. E., Hofker, M. H., Binder, C. J., and Shiri-Sverdlov, R. (2012) Specific immunization strategies against oxidized low-density lipoprotein: a novel way to reduce nonalcoholic steatohepatitis in mice. Hepatology (Baltimore, Md.) 56, 894-903

24. Bieghs, V., Walenbergh, S. M., Hendrikx, T., van Gorp, P. J., Verheyen, F., Olde Damink, S. W. Masclee, A. A., Koek, G. H., Hofker, M. H., Binder, C. J., and Shiri-Sverdlov, R. (2013) Trapping of oxidized LDL in lysosomes of Kupffer cells is a trigger for hepatic inflammation. Liver international : official journal of the International Association for the Study of the Liver 33, 1056-106 



\section{Chapter 4}

\section{Macrophage stimulating protein enhances hepatic inflammation in a NASH model}

Jieyi Li \#, Dipanjan Chanda \#, Patrick J. van Gorp, Mike L.J. Jeurissen, Tom Houben, Sofie M.A. Walenbergh, Jacques Debets, Yvonne Oligschlaeger, Marion J.J. Gijbels, Dietbert Neumann, Ronit Shiri-Sverdlov

\# Authors equally contributed PLoS One 11(2016), e0163843 


\section{Abstract}

Non-alcoholic steatohepatitis (NASH) is a common liver disease characterized by hepatic lipid accumulation (steatosis) and inflammation. Currently, therapeutic options are poor and the long-term burden to society is constantly increasing. Previously, macrophage stimulating protein (MSP) - a serum protein mainly secreted by liver - was shown to inhibit oxidized low-density lipoprotein (OxLDL)/ lipopolysaccharides (LPS)-induced inflammation in mouse macrophages. Additionally, MSP could reduce palmitic acid (PA)induced lipid accumulation and lipogenesis in the HepG2 cell line. Altogether, these data suggest MSP as a suppressor for metabolic inflammation. However, so far the potential of MSP to be used as a treatment for NASH was not investigated. We hypothesized that MSP reduces lipid accumulation and hepatic inflammation. To investigate the effects of MSP in the early stage of NASH, low-density lipoprotein receptor $\left(L d \mid r^{-}\right)$mice were fed either a regular chow or a high fat, high cholesterol (HFC) diet for 7 days. Recombinant MSP or saline (control) was administrated to the mice by utilizing subcutaneouslyimplanted osmotic mini-pumps for the last 4 days. As expected, mice fed an HFC diet showed increased plasma and hepatic lipid accumulation, as well as enhanced hepatic inflammation, compared with chow-fed controls. Upon MSP administration, the rise in cholesterol and triglyceride levels after an HFC diet remained unaltered. Surprisingly, while hepatic macrophage and neutrophil infiltration was similar between the groups, MSP-treated mice showed increased gene expression of pro-inflammatory and proapoptotic mediators in the liver, compared with saline-treated controls. Contrary to our expectations, MSP did not ameliorate NASH. Observed changes in inflammatory gene expression suggest that further research is needed to clarify the long-term effects of MSP. 


\section{Introduction}

Non-alcoholic fatty liver disease (NAFLD) is a metabolic disorder which comprises a wide spectrum of liver damage, ranging from simple steatosis to steatohepatitis, liver fibrosis and cirrhosis. Non-alcoholic steatohepatitis (NASH) represents the stage that is composed of steatosis and hepatic inflammation, and is regarded as the hepatic manifestation of the metabolic syndrome. Although steatosis is considered relatively benign, the presence of inflammation is detrimental, as it may cause irreversible liver damage and sets the stage for further liver injury, like cirrhosis and liver cancer [1]. Currently, the mechanisms that trigger inflammation are unknown. Consequently, therapeutic options of NASH are poor and the long-term burden to society is constantly increasing.

Macrophage stimulating protein (MSP) is a serum protein, which is mainly secreted by hepatocytes [2]. It exerts its biological effects through binding to the receptor tyrosine kinase Recepteur d'Origine Nantais (receptor tyrosine kinase RON) - a transmembrane receptor, which is expressed in epithelial organs, including liver [3]. Since its discovery, the MSP-RON signaling pathway has been documented as a suppressor of exogenous substances (e.g. lipopolysaccharide (LPS) or galactosamine-induced inflammation) in multiple tissues [4-6]. Additionally, evidences point towards a beneficial role of MSP in hepatic lipid and glucose metabolic regulation. Homozygous MSP knockout (MSP-/-) mice were found to develop hepatic steatosis, even when fed regular chow [7]. Furthermore, MSP administration led to inhibition of CAMP/dexamethasone-induced gluconeogenesis in primary hepatocytes of both human and rat [8]. Our previous study showed that MSP could inhibit palmitic acid (PA)- and LPS-induced upregulation of proinflammatory cytokines in mouse primary hepatocytes. MSP was also found to reduce PA-induced lipid accumulation and lipogenesis in the HepG2 cell line [9]. Moreover, when challenged with LPS and oxidized low-density lipoprotein (OxLDL), which can be considered a metabolic hazard for the development of NASH [10], the pro-inflammatory cytokine production was inhibited by MSP in mouse bone marrow-derived macrophages (BMDMs) [9]. These findings suggest that MSP acts as a negative regulator of lipidinduced inflammation in vitro. So far, the systemic effect of MSP in the context of the metabolic syndrome has not been investigated. In the current study, we investigated the role of MSP in a hyperlipidemic mouse model in order to determine its clinical potential in the field of NASH. We hypothesized that MSP leads to a reduction of fat accumulation and hepatic inflammation in vivo.

To test this hypothesis, hyperlipidemic low-density lipoprotein receptor knockout (LdIr

/) mice, fed a high fat, high cholesterol (HFC) diet for 1 week, were used as a mouse 
model for NASH. To elucidate the therapeutic effects of MSP, recombinant MSP was consecutively administered to mice with assistance of a subcutaneously-implanted osmotic mini-pump. We analyzed the changes in lipid accumulation, inflammatory cell infiltration, and relative gene expressions in the liver. Unexpectedly, we found that MSP promoted rather a pro-inflammatory, instead of anti-inflammatory, response as judged by relevant gene expression levels. Therefore, future studies are needed to evaluate the long-term effects of MSP to better understand its role in NASH.

\section{Materials and Methods}

\section{Mice, diet and treatment}

Mice were housed under standard conditions and given unlimited access to food and water. Experiments were performed according to Dutch regulations and approved by the Committee for Animal Welfare of Maastricht University. Female 10-12 week old LdIr' mice were placed on either chow or an HFC diet for 7 days. The HFC diet contained $17 \%$ casein, $0.3 \%$ DL-methionine, 34\% sucrose, $14.5 \%$ cornstarch, $0.2 \%$ cholesterol, $5 \%$ cellulose, 7\% CM 205B, 1\% vit 200, 21\% butter (diet code 1635; Scientific Animal Food and Engineering, Villemoissonsur-Orge, France). After 3 days, mice fed on each diet were administered with either recombinant MSP (500 ng/day, U-Protein Express BV, Utrecht, $N L$ ), or saline for 4 consecutive days (MSP chow: $n=8, H F C$ : $n=8$; saline chow: $n=8$; HFC: $\mathrm{n}=8$ ). Consecutive administration of recombinant MSP or saline was achieved by utilizing the osmotic mini-pumps (Alzet 2001, DURECT Corporation, Cupertino, CA, USA). Osmotic mini-pumps were placed subcutaneously in the back region of the mouse under isoflurane anesthesia. Blood was collected from the tail vein at the end of the experiment and mice were sacrificed afterwards. Liver tissue was harvested and snap-frozen in liquid nitrogen or fixed in $4 \%$ formaldehyde.

\section{Plasma/liver lipid measurements}

Plasma cholesterol and triglycerides were measured via an enzymatic colorimetric assay according to the manufacturer's protocol (Cholesterol Liquicolor CHOD_PAD; Human \#10028, Instruchemie, Delfzijl) (Sigma Triglyceride (GPO Trinder) kit (Sigma Tr0100)). Absorbance was measured with the BioRad Benchmark Plate Reader (170-6750XTU; Bio-Rad, Hercules, CA). To measure liver cholesterol and triglycerides, liver homogenates were made. Approximately 40-50 mg of frozen liver tissue was homogenized in $1 \mathrm{ml}$ SET buffer ( $250 \mathrm{mM}$ Sucrose, 2 mM EDTA, $10 \mathrm{mMTris}$ ) with $1 \mathrm{~mm}$ glass beads (Biospec, art. 11079110) on the maximal setting of the Biospec Mini Bead Beater-1. Afterwards, samples underwent two freeze-thaw cycles for complete cell destruction. To optimize cell destruction, samples were taken through a $25 \mathrm{G} \times 5 / 8$ " needle several times and a final thaw cycle was added. Total protein content was measured via bicinchoninic acid 
(BCA) assay (23225; Pierce, Rockford, IL). Liver cholesterol and triglycerides were measured via the enzymatic colorimetric assay.

\section{Liver histology}

Frozen liver sections $(7 \mu \mathrm{m})$ were fixed in acetone and subsequently blocked for endogenous peroxidase by incubation with $0.25 \%$ of $0.03 \% \mathrm{H}_{2} \mathrm{O}_{2}$ for 5 minutes. Primary antibodies used were against infiltrated macrophages and neutrophils (rat-anti-mouse Mac-1 [M1/70]), and neutrophils (rat-anti-mouse Ly6-C, clone NIMP-R14) (generous gift from Prof Heeringa, Groningen, The Netherlands). 3-Amino-9 ethylcarbazole (AEC) (A85SK-4200.S1; Bio-connect, Huissen, The Netherlands) was applied as color substrate and hematoxylin (4085.9002, Klinipath, Duiven, The Netherlands) was used for nuclear counterstaining. TUNEL staining for apoptosis was performed on frozen liver sections according to the manufacturers' protocol (In situ Cell Death Detection Kit, Roche Applied Science). Sections were enclosed with Faramount aqueous mounting medium (S302580; DAKO, Glostrup, Denmark). For the lipid staining, the neutral lipid marker Oil Red $\mathrm{O}$ (ORO; O0625; Sigma-Aldrich) was used.

Paraffin-embedded liver sections $(4 \mu \mathrm{m})$ were stained with Hematoxylin-Eosin (Eosin, E4382; Sigma-Aldrich). Images were taken with a Nikon digital camera DMX1200 and ACT-1 v2.63 software (Nikon Instruments Europe, Amstelveen, The Netherlands).

\section{RNA isolation and quantitative polymerase chain reaction}

Total RNA was isolated from frozen mouse liver as described previously [11,12]. Firststrand complementary DNA (cDNA) was made from 500 ng total RNA of each mouse according to the manufacturer's protocol (iScript ${ }^{\mathrm{TM}}$ cDNA Synthesis Kit (170-8891), BioRad, Veenendaal, The Netherlands). Using $10 \mathrm{ng}$ of cDNA template, relative quantitative gene expression levels were measured by quantitative PCR on an SDS 7900HT using SensiMix SYBR HIROX (Cat No QT605-05 Bioline, London, United Kingdom). Primers sets were developed with Primer Express version 2.0 (Applied Biosystems) using default settings. Data from qPCR were analyzed using the LinRegPCR software (Version 2015.3) [13-15].

\section{Western blotting}

Approximately 40-50 mg of frozen liver tissue was homogenized in $1 \mathrm{ml}$ RIPA (50 mM Tris-HCL pH 7.5, $150 \mathrm{mM} \mathrm{NaCl}, 0.5 \%$ Sodium deoxycholate, $1 \%$ Triton X-100, 0.1\% SDS) supplemented with protease and phosphatase inhibitor mixture, with $1 \mathrm{~mm}$ glass beads on the maximal setting of the Biospec Mini Bead Beater-1. Equal amounts of protein (20 ug) were loaded onto the gel. After SDS/PAGE, proteins were transferred on nitrocellulose membrane (Bio-Rad). Subsequently, the membrane was blocked with $4 \%$ non-fat dry 
milk for $1 \mathrm{~h}$ at room temperature. For detection, the membrane was incubated with antibodies overnight at $4{ }^{\circ} \mathrm{C}$, followed by incubation with donkey anti-rabbit antibody for $1 \mathrm{~h}$ at room temperature. All antibodies were purchased from Cell Signaling Technology (Danvers, MA, USA). Signal was detected on autoradiograms by enhanced chemoluminescence.

\section{Measuring aminotranferases}

The level of aminotransferases ALT in plasma of each individual mouse was measured using the Reflotron-system (Roche Diagnostics, Almere, The Netherlands), according to the manufacturer's instructions.

\section{Statistical analysis}

Data were analyzed using Graphpad Prism 6.01 (GraphPad Software, Inc., La Jolla, CA, USA). Groups were compared using two-way ANOVA. The data were expressed as the mean and standard error of the mean (SEM) and were considered significantly different at ${ }^{*} \mathrm{p} \leq 0.05 ; * * \mathrm{p}<0.01 ; * * * \mathrm{p}<0.001$.

\section{Results}

\section{No difference in liver and spleen weights upon MSP treatment}

Compared to mice on regular chow diet, the total body weight did not change after one week of HFC diet and remained similar upon 4 days of MSP treatment (Fig. 1A). Further, both mean liver and spleen weights were unaltered among the groups (Fig. 1B), suggesting that neither one week of HFC diet, nor short-term MSP administration is sufficient to affect relative liver or spleen weight.

\section{Hepatic and plasma lipid accumulation upon MSP treatment remains similar}

As expected, compared with chow controls, the levels of total cholesterol (TC) and triglycerides (TG) were significantly elevated in both plasma and liver after one week of HFC diet. However, comparing saline- and MSP-treated mice on a HFC diet, no differences were found in hepatic TC and TG concentrations (Fig. 2A). Similarly, plasma TC and TG levels did also not show differences between saline- and MSP-treated mice on a HFC diet (Fig. 2B). In order to examine whether saline/MSP treatment and body weight (BW) were capable of predicting the plasma TG level in mice on HFC diet, a multiple linear regression was conducted. No significant regression equation was found $(F(2,13)=1.392$, $p=0.283$ ), with an $R^{2}$ of 0.176 . Further, the analysis showed that treatment (Beta $=-0.38$, $\mathrm{t}=-1.49$, ns) and BW (Beta $=0.11, \mathrm{t}=0.41$, ns) did not significantly predict the value of plasma TG. In line with these data, HFC feeding resulted in equal levels of steatosis in the saline- and MSP- treated groups, as indicated by the H\&E staining and Oil-red-O staining 

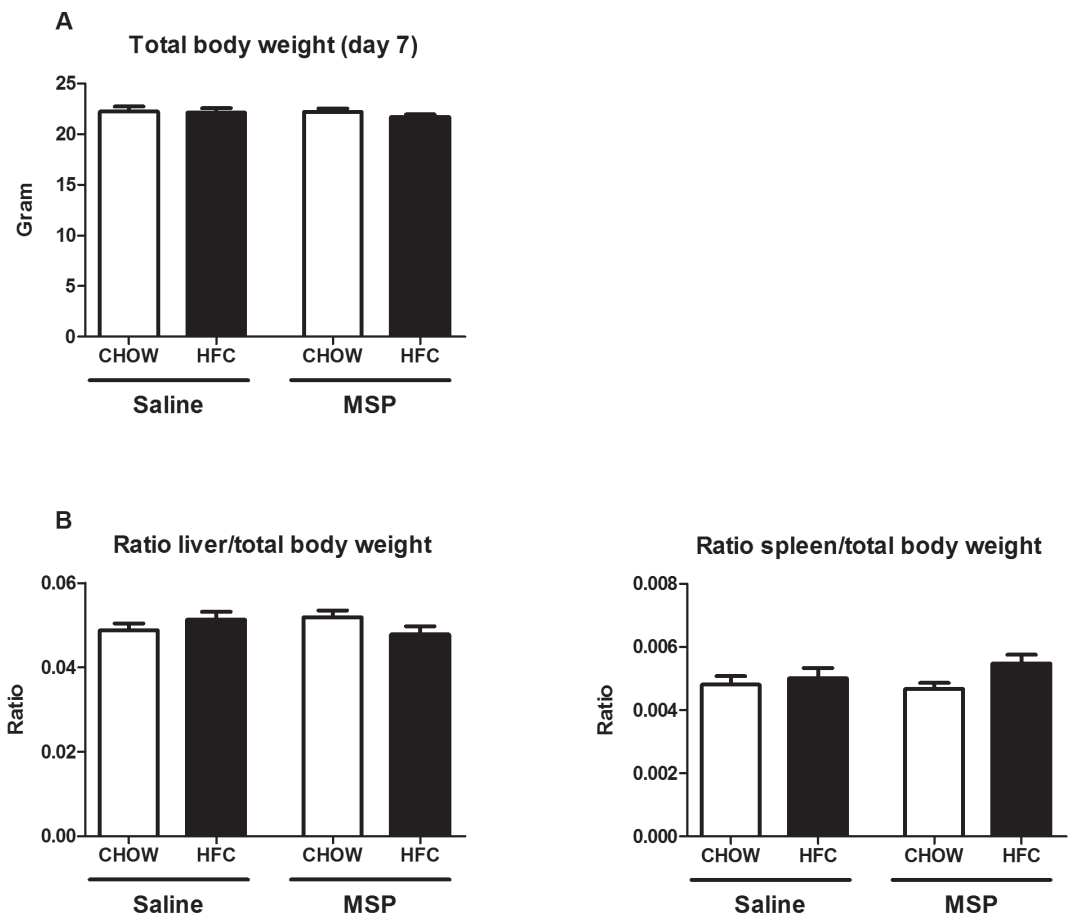

Figure 1. Relative liver and spleen weight.

(A) Body weight after one week of regular chow or HFC diet in $L d / r^{\prime}$ mice with and without MSP treatment. (B) Relative liver and spleen weights after one week of regular chow or HFC diet in Ld/r/ mice with and without MSP treatment. Data are represented as mean \pm SEM.

(Fig. 2C, D), suggesting that short-term administration of MSP does not affect hepatic and plasma lipid concentration.

\section{No difference in hepatic macrophage and neutrophil infiltration upon MSP treatment}

To determine the effect of MSP on hepatic inflammation in the context of NASH, liver sections were stained against Mac1 and NIMP, i.e. markers for infiltrating macrophages and neutrophils, respectively. As expected, scoring of stained sections revealed a higher amount of infiltrating macrophages and neutrophils in the liver of mice fed a HFC diet, compared with chow controls. However, no significant differences in macrophage and neutrophil infiltration were observed between saline- and MSP-treated mice on an HFC diet (Fig. 3A, B). Clustering of macrophages in liver sections did not differ between saline- and MSP-treated mice (Fig. $3 \mathbf{C}$ ). Altogether, these data suggest that MSP treatment does not affect HFC-induced hepatic macrophage and neutrophil infiltration. 

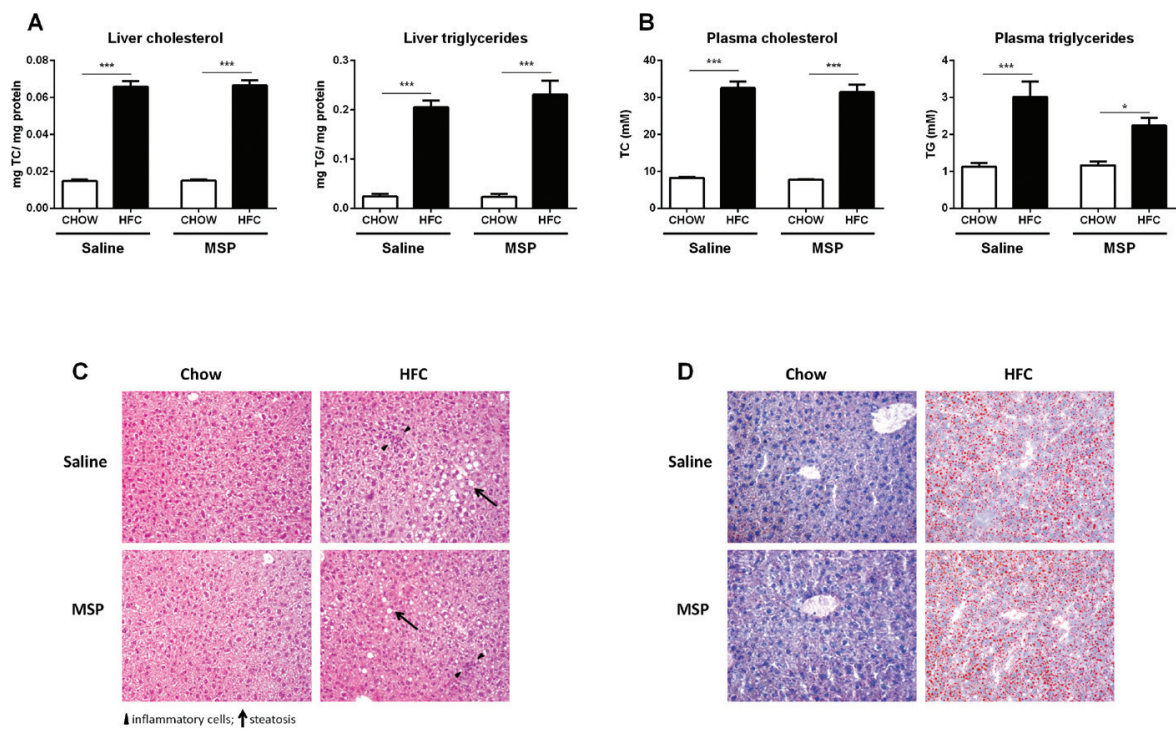

Figure 2. Liver and plasma lipid levels.

(A) Hepatic levels of total cholesterol (TC) and total triglycerides (TG) after one week of regular chow or HFC diet in Ldl/ ${ }^{\prime}$ mice, with and without MSP treatment. (B) Plasma TC and TG levels. (C,D) Representative images (200x magnification) of the H\&E staining and Oil Red O staining of liver sections. Data are represented as mean \pm SEM. ${ }^{*}$ and $* * *$ indicate significant differences between groups, with * $\mathrm{p} \leq 0.05$ and $* * * \mathrm{p}<0.001$.

Hepatic expression of pro-inflammatory and apoptotic genes is increased upon MSP treatment

To further define the effects of MSP on early changes of hepatic inflammation, relative mRNA expression of pro-inflammatory genes in the liver were analyzed. The macrophage markers F4/80 and Cluster of differentiation 68 (Cd68) were upregulated upon HFC diet, but remained similar in saline- and MSP- treated groups. Surprisingly, significantly higher, instead of lower, expression levels of several pro-inflammatory genes in the liver were observed in MSP-treated mice on an HFC diet, compared with controls. This was shown by an increased expression of the following genes: tumor necrosis factor alpha (Tnf $\alpha)$, chemokine ( $\mathrm{C}-\mathrm{C}$ motif) ligand 2 ( $\mathrm{Cc} / 2)$, intercellular adhesion molecule 1 (Icam1), interferon gamma (IfnY), and interleukin 1 beta (IL1B) (Fig. 4A). Moreover, the apoptotic gene expression levels of B-cell lymphoma $2(B C / 2)$ and $B C L 2$-related protein $A 1(B f l 1)$ were also increased upon MSP treatment in mice fed with a HFC diet (Fig. 4B). Despite the fact that there were no histological changes observed in the livers of saline- and MSP-treated groups (Fig. 3 and Supplementary Fig. 4A), the increase in hepatic mRNA levels of multiple inflammatory genes suggest the presence of early increased inflammation in the livers of MSP-treated $L d / r^{\prime}$ - mice. 
A Infiltrated macrophages

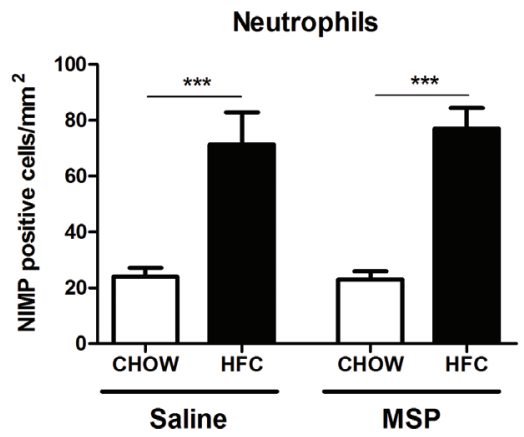

B

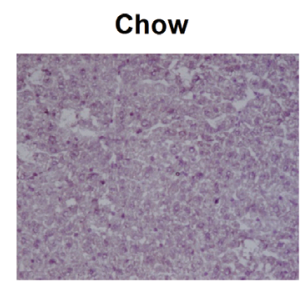

HFC

\section{Saline}
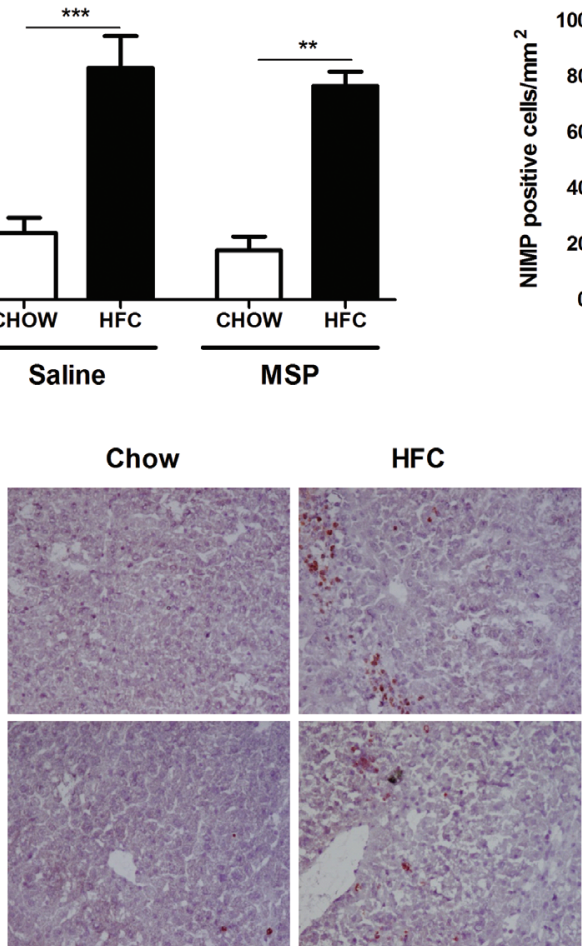

Figure 3. Parameters of macrophage and neutrophil infiltration in the liver.

(A) Liver sections were stained for infiltrating macrophages and neutrophils, respectively. Positive immune cells were counted. (B) Representative images of the Mac1 staining (200x magnification) after one week of regular chow or HFC diet in $\mathrm{Ld} / \mathrm{r}^{\circ}$ - mice, with and without MSP treatment. Data are represented as mean \pm SEM. ${ }^{* *}$ and ${ }^{* * *}$ indicate significant differences between groups, with ${ }^{* *}$ $p<0.01$ and ${ }^{* * *} p<0.001$. 

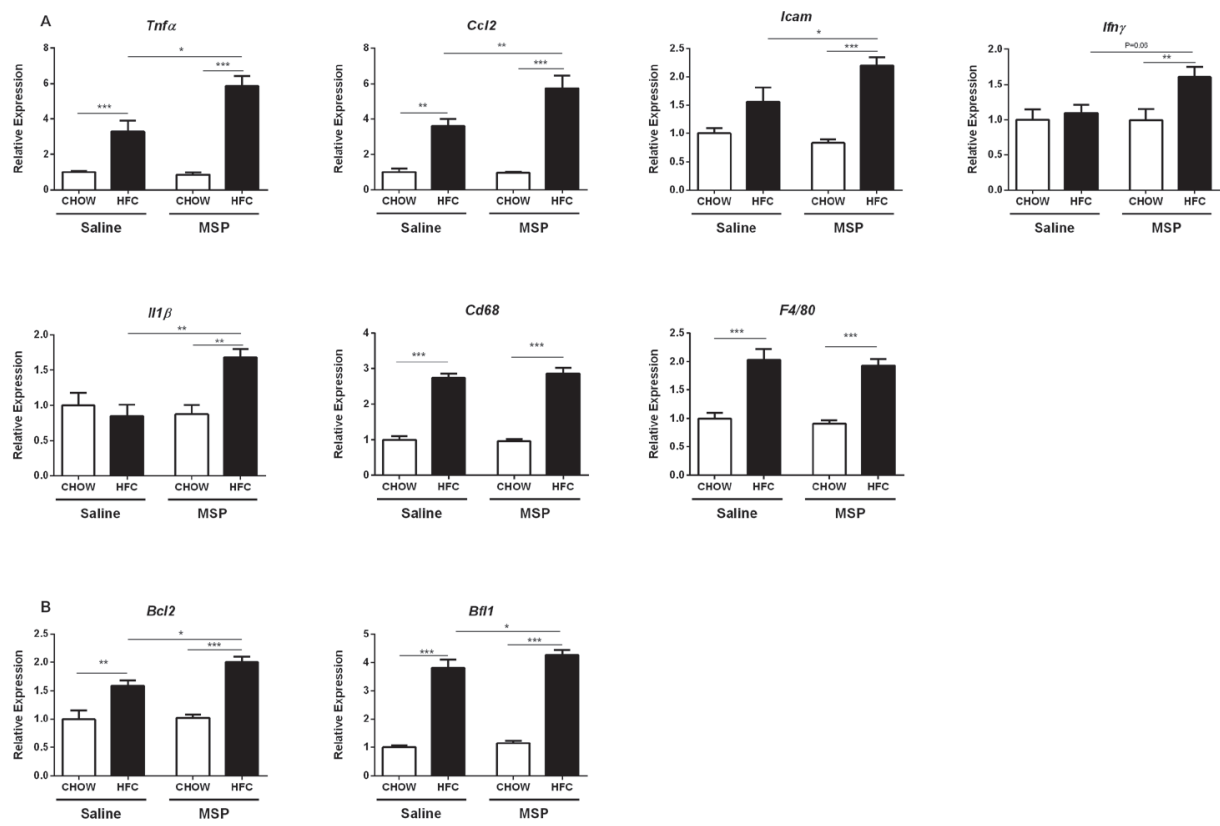

Figure 4. Hepatic expression levels of genes related to inflammation.

(A) Gene expression levels of the pro-inflammatory cytokines, tumor necrosis factor alpha (Tnf $\alpha$ ), chemokine ( $\mathrm{C}-\mathrm{C}$ motif) ligand 2 ( $\mathrm{Cc} / 2$ ), intercellular adhesion molecule 1 (Icam1), interferon gamma (IfnY), interleukin 1 beta (I/16), macrophage markers F4/80 and Cluster of differentiation 68 (Cd68) in the livers of $L d l r^{\prime}$ mice on chow or HFC diet, with or without MSP treatment. (B) Hepatic gene expression levels of B-cell lymphoma $2(B C / 2)$ and $B C L 2$-related protein A1 (Bfl1). Data are represented as mean \pm SEM. ${ }^{*}, * *$ and $* * *$ indicate significant differences between groups, with $* \mathrm{p} \leq 0.05, * *$ $\mathrm{p}<0.01, * * * \mathrm{p}<0.001$.

Hepatic expression of fibrosis- and fatty acid metabolism-related genes is unaltered upon MSP treatment

To investigate the effects of MSP on fibrosis in the context of NASH, gene expression analysis of alpha-smooth muscle actin ( $\alpha S M A)$, collagen 1 type 1 (Col1a1) and TIMP metallopeptidase inhibitor 1 (Timp1) was performed. Whereas the expression levels of these fibrotic genes were increased in the liver of HFC-fed mice, compared with chowfed controls, no differences were found upon short-term treatment with MSP (Fig. 5A), indicating that MSP does not affect the development of fibrosis. In order to investigate whether MSP regulates fatty acid metabolism in the liver, hepatic expression levels of Sterol regulatory element-binding transcription factor 1 (Srebp1), Stearoyl-CoA desaturase-1 (Scd1), Fatty acid synthase (Fasn), and Cluster of differentiation 36 (Cd36) were determined. While we observed an increasing trend of Srebp1, Scd1, Fasn, and Cd36 in the HFC-fed group, no differences were observed between saline- and MSPtreated mice (Fig. 5B), suggesting that liver fatty acid metabolism is not affected by MSP treatment. 

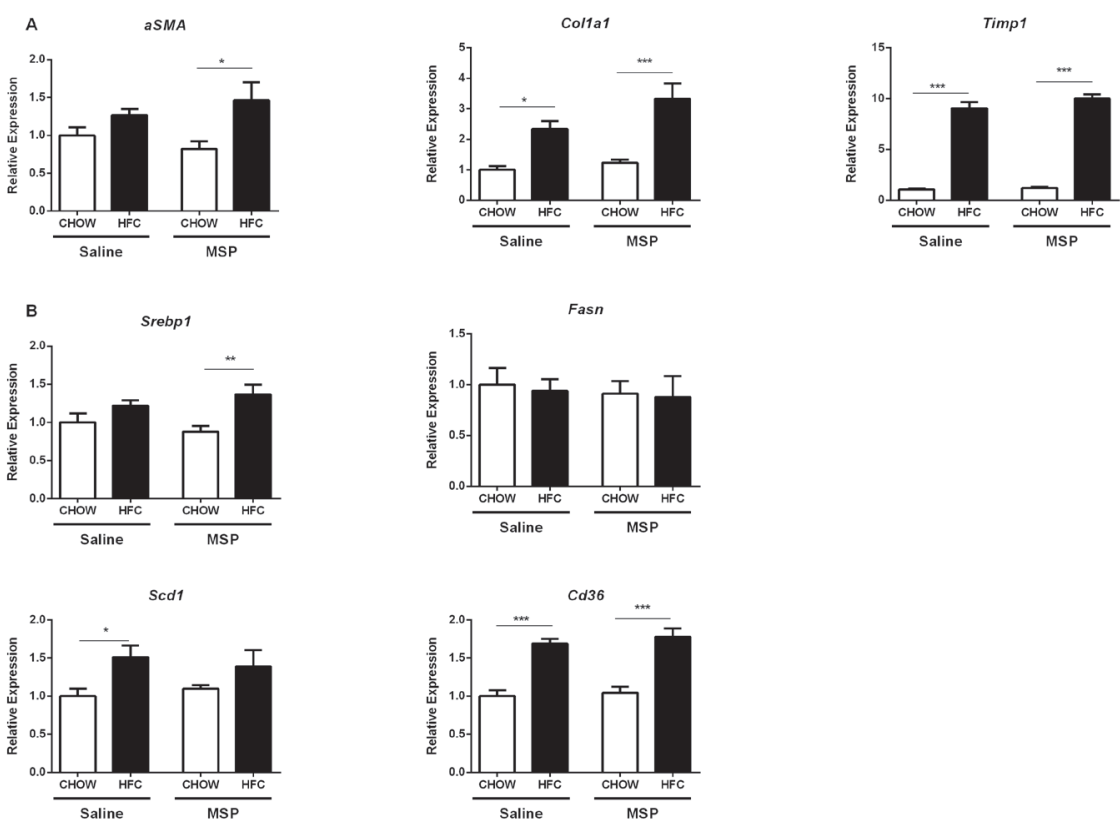

Figure 5. Hepatic expression levels of genes related to fibrosis and fatty acid metabolism.

(A) Gene expression levels of the fibrotic makers alpha-smooth muscle actin ( $\alpha S M A)$, collagen 1 type 1 (Col1a1) and TIMP metallopeptidase inhibitor 1 (Timp1) in the livers of Ldl/ ${ }^{\prime-}$ mice on chow or HFC diet, with or without MSP treatment. (B) Hepatic gene expression levels of Sterol regulatory elementbinding transcription factor 1 (Srebp1), Stearoyl-CoA desaturase-1 (Scd1), Fatty acid synthase (Fasn), and Cluster of differentiation $36(C d 36)$. Data are represented as mean $\pm \mathrm{SEM} .{ }^{*}, * *$ and $* * *$ indicate significant differences between groups, with $* p \leq 0.05, * * p<0.01, * * * p<0.001$. 


\section{Discussion}

In the present study, the role of MSP in lipid accumulation and hepatic inflammation was investigated for the first time in a mouse model for NASH. Our results showed that MSP could not ameliorate NASH in the early stage. Although data are inconclusive, the gene expression levels may suggest that MSP can promote the pro-inflammatory response in our model. These surprising results provide value to better comprehend the role of MSP in the metabolic syndrome.

MSP was first discovered in 1976 as a serum protein, which stimulates chemotactic responses, migration and spreading of peritoneal resident macrophages [16]. Subsequent evidences pointed out a correlation between MSP and liver injury; for example, MSP was transcriptionally up-regulated in the liver during hepatic inflammation and regeneration in rodent models [17]. Currently, the investigations of MSP in the context of hepatic inflammation are relatively limited, and are restricted to inflammation that is induced by exogenous substances [18]. Whereas MSP has emerged as a beneficial moderator in hepatic lipid and glucose metabolism $[7,8,18]$, the role of MSP in the context of the metabolic syndrome, especially in metabolic inflammation, has not been explored. $\mathrm{NASH}$, viewed as the hepatic manifestation of the metabolic syndrome, can be driven by the following risk factors: over-nutrition, lipid metabolites, production of proinflammatory cytokines and adipokines, gut bacteria and oxidation, among others. Cross-talk between metabolic organs, like adipose tissue and gut, may well participate in the pathogenesis of NASH $[1,19]$. However, MSP does not confine its effects to the liver only; it has multiple roles in other organs as well, as the MSP receptor RON is expressed universally inside the body $[3,20]$. Given the complexity of the pathogenesis and participation of organ cross-links, an in vivo NASH model will therefore offer more integrated insights in the systemic effects of MSP. In the current study, we observed increased expression of several pro-inflammatory genes in the livers of mice affected with NASH. TNF $\alpha$ has been shown to be a key factor in the development of NAFLD and NASH [21,22]. Since Kupffer cells, the liver's residential macrophages, are the first responding cells to hepatocyte injuries, the increased release of TNF $\alpha$ from these cells is one of the most common characters of early phase of NASH in mouse model. Similarly, hepatic expression of $\mathrm{C} / 2$ was also found elevated at an early stage in NASH mouse model, results that are consistent with data from NAFLD patients $[23,24]$. Increases in $\mathrm{Ccl} 2$ expression lead to infiltration of pro-inflammatory monocytes and $\mathrm{T}$ cells, which induces the secretion of inflammatory cytokines such as TNF $\alpha$ and IL1 $\beta$ in the liver. ICAM1, which is involved in inflammatory cell migration and invasion, was also upregulated in mice treated with MSP. In addition, IL1 $\beta$, an inflammatory cytokine produced upon inflammasome activation, also plays an important role in $\mathrm{NASH}$, as hepatocellular 
depletion of IL1 $\beta$ has been shown to protect mice from diet-induced steatohepatitis [25]. In the current study, our data showed increases in those pro-inflammatory gene expressions in response to MSP-treatment, when feeding mice a HFC diet, compared with saline-treated controls. This suggests a more severe inflammation after treatment of MSP, which is contrary to the mainstream point of view that MSP-RON acts as an antiinflammatory mediator during an inflammatory reaction. Nevertheless, studies deliberating the role of MSP, particularly in liver inflammation, are contradictive and limited. On one hand, when compared with control mice, RON-/- mice (i.e. these mice have an abolished MSP-RON signaling pathway) exhibited reduced expression of the anti-inflammatory cytokine, interleukin 10 (IL10), and the anti-oxidant superoxide dismutase (SOD) in the liver, in response to LPS-induced acute endotoxemia [26]. On the other hand, loss of RON signaling led to an attenuated inflammatory response in the liver, when challenged with acetaminophen-induced hepatotoxicity [27]. Furthermore, conflict has also been tracked by Leonis et al., showing that RON Tyrosine Kinase (TK)-/mouse (i.e. these mice are deficient for the TK domain of RON, in order to eliminate intracellular MSP-RON signaling) obtained increased serum pro-inflammatory cytokine levels, although their liver histology and liver damage was improved compared with control mice [28]. These results indicate that myeloid cells, compared to liver parenchyma cells, may react differently to MSP-RON signaling.

Although the reason for these contradictory findings is not clear, the hint that MSP-RON signaling exerts discriminating effects to different components within the liver fits the explanation. Kupffer cells and hepatocytes isolated from RON TK-/- were studied to further explore the specific effects of MSP on the liver. Compared with their wild type (RON TK+/+) controls, LPS-treated RON TK-/- Kupffer cells demonstrated more pronounced TNF $\alpha$ production, whereas RON TK-/- hepatocytes challenged with TNF $\alpha$ exhibited much better viability [4]. Moreover, mouse models with a specific deletion of RON in either the Kupffer cells or the hepatocytes were investigated and confirmed the diversity of MSP in those two different cell types. Compared with wild type control, hepatocyte-specific RON TK-/- mice exhibited lower alanine transaminase (ALT) levels and less apoptosis, accompanied with longer overall survival, while Kupffer cell-specific RON TK-/- mice showed the opposite pattern [4]. In short, disrupted MSP-RON signaling seems to evoke Kupffer cell activation and subsequent inflammatory cytokine production, but protects hepatocytes against a noxious stimulus. Therefore, in the current study, it is possible that the hepatocytes, in response to the MSP-RON activation, may have become more susceptible to the lipotoxic insult, which ultimately led to more severe cell damage and apoptosis, hence generating a pro-inflammatory hepatic phenotype. 
Another explanation for the contradictive findings can be ascribed to the overall effect of MSP within the whole body, including cross-talk between various organs. Some evidence indicates that MSP can act as a pro-inflammatory mediator in other cells/ tissues. Recombinant MSP is found to promote the release of inflammatory factors and activate the nuclear factor kappa B (NFKB) pathway, a common inflammatory pathway, in isolated alveolar macrophages from both rat and patient [29,30]. In addition, in a rodent model of mesangial proliferative nephritis, neutralization of MSP by means of anti-MSP antibodies attenuated inflammatory cell infiltration and eventually protected against further injury [31]. Moreover, adipose tissue from RON TK-/- mice fed an HFC diet showed less mass and significantly lower expression of TNF $\alpha$ in comparison to their wild type controls [32]. These data suggest that the effect of MSP on inflammation is complex; it participates in multiple pathological processes, which may bring variation in terms of ensemble effects.

It is noteworthy that, when investigating MSP-RON signaling, most previous studies were based on a disrupted RON signaling model. Yet, the current study utilized an enhanced MSP-RON signaling model, which certainly may bring some discrepancy. In the RON TK/- model, the TK region of RON is deleted to block its downstream intracellular signaling. However, it is still possible that the RON TK-/- receptor interacts with other signal transduction pathways through receptor complexes. In fact, the hepatocyte growth factor (HGF) and its receptor c-Met, a close family member of MSP and RON in both structure and function [33-36], have been found to cooperate with the insulin receptor (INSR) by forming a c-Met-INSR hybrid complex, which puts HGF-c-Met in participation of insulin responsiveness [37]. It is therefore possible that enhanced MSP-RON signaling activates other signaling pathways, which could potentially interfere with MSP-RONinduced inflammatory responses. Nevertheless, no evidence has shown that MSP shares the same effects with HGF in insulin signaling transduction. In the current study, Ld/r' mice fed a HFC diet for one week did not induce notable insulin resistance (IR) (Supplementary Fig. 3). This result is in line with previous work, indicating that increased fasted insulin levels and HOMA-IR were only observed after 15 weeks of HFC diet in these mice $[38,39]$. Given that, an advanced stage NASH model would be more suitable to investigate the effects of MSP on IR.

Overall, our data provide evidence for the first time that MSP could not ameliorate NASH in the hyperlipidemic Ldlr/- mouse model. Inversely, MSP could promote the expression of pro-inflammatory genes in the early stage of NASH. Therefore, future studies should evaluate the long-term effects of MSP in NASH. 


\section{References}

1. Farrell, G. C., van Rooyen, D., Gan, L., and Chitturi, S. (2012) NASH is an Inflammatory Disorder: Pathogenic, Prognostic and Therapeutic Implications. Gut and liver 6, 149-171

2. Bezerra, J. A., Witte, D. P., Aronow, B. J., and Degen, S. J. (1993) Hepatocyte-specific expression of the mouse hepatocyte growth factor-like protein. Hepatology (Baltimore, Md.) 18, 394-399

3. Gaudino, G., Avantaggiato, V., Follenzi, A., Acampora, D., Simeone, A., and Comoglio, P. M. (1995) The proto-oncogene RON is involved in development of epithelial, bone and neuro-endocrine tissues. Oncogene 11, 2627-2637

4. Stuart, W. D., Kulkarni, R. M., Gray, J. K., Vasiliauskas, J., Leonis, M. A., and Waltz, S. E. (2011) Ron receptor regulates Kupffer cell-dependent cytokine production and hepatocyte survival following endotoxin exposure in mice. Hepatology (Baltimore, Md.) 53, 1618-1628

5. Kulkarni, R. M., Stuart, W. D., Gurusamy, D., and Waltz, S. E. (2014) Ron receptor signaling is protective against DSS-induced colitis in mice. American journal of physiology. Gastrointestinal and liver physiology 306, G1065-1074

6. Nikolaidis, N. M., Kulkarni, R. M., Gray, J. K., Collins, M. H., and Waltz, S. E. (2011) Ron receptor deficient alveolar myeloid cells exacerbate LPSinduced acute lung injury in the murine lung. Innate immunity 17, 499-507

7. Bezerra, J. A., Carrick, T. L., Degen, J. L., Witte, D., and Degen, S. J. (1998) Biological effects of targeted inactivation of hepatocyte growth factor-like protein in mice. J Clin Invest 101, 11751183

8. Chanda, D., Li, T., Song, K. H., Kim, Y. H., Sim, J., Lee, C. H., Chiang, J. Y., and Choi, H. S. (2009) Hepatocyte growth factor family negatively regulates hepatic gluconeogenesis via induction of orphan nuclear receptor small heterodimer partner in primary hepatocytes. The Journal of biological chemistry 284, 28510-28521

9. Chanda, D., Li, J., Oligschlaeger, Y., Jeurissen, M. L., Houben, T., Walenbergh, S. M., Shiri-Sverdlov, R., and Neumann, D. (2016) MSP is a negative regulator of inflammation and lipogenesis in ex vivo models of non-alcoholic steatohepatitis. Experimental \& molecular medicine 48, e258

10. Walenbergh, S. M., Koek, G. H., Bieghs, V., and Shiri-Sverdlov, R. (2013) Non-alcoholic steatohepatitis: the role of oxidized low-density lipoproteins. Journal of hepatology $\mathbf{5 8 , 8 0 1 - 8 1 0}$
11. Bieghs, V., Hendrikx, T., van Gorp, P. J., Verheyen, F., Guichot, Y. D., Walenbergh, S. M., Jeurissen, M. L., Gijbels, M., Rensen, S. S., Bast, A., Plat, J., Kalhan, S. C., Koek, G. H., Leitersdorf, E., Hofker, M. H., Lutjohann, D., and Shiri-Sverdlov, R. (2013) The cholesterol derivative 27-hydroxycholesterol reduces steatohepatitis in mice. Gastroenterology 144, 167-178 e161

12. Shiri-Sverdlov, R., Wouters, K., van Gorp, P. J., Gijbels, M. J., Noel, B., Buffat, L., Staels, B., Maeda, N., van Bilsen, M., and Hofker, M. H. (2006) Early diet-induced non-alcoholic steatohepatitis in APOE2 knock-in mice and its prevention by fibrates. Journal of hepatology 44, 732-741

13. Ruijter, J. M., Lorenz, P., Tuomi, J. M., Hecker, M., and van den Hoff, M. J. (2014) Fluorescent-increase kinetics of different fluorescent reporters used for qPCR depend on monitoring chemistry, targeted sequence, type of DNA input and PCR efficiency. Mikrochim Acta 181, 1689-1696

14. Tuomi, J. M., Voorbraak, F., Jones, D. L., and Ruijter, J. M. (2010) Bias in the Cq value observed with hydrolysis probe based quantitative PCR can be corrected with the estimated PCR efficiency value. Methods 50, 313-322

15. Ruijter, J. M., Ramakers, C., Hoogaars, W. M., Karlen, Y., Bakker, O., van den Hoff, M. J., and Moorman, A. F. (2009) Amplification efficiency: linking baseline and bias in the analysis of quantitative PCR data. Nucleic Acids Res 37, e45

16. Leonard, E. J., and Skeel, A. (1976) A serum protein that stimulates macrophage movement, chemotaxis and spreading. Experimental cell research 102, 434-438

17. Bezerra, J. A., Laney, D. W., Jr., and Degen, S. J. (1994) Increased expression of mRNA for hepatocyte growth factor-like protein during liver regeneration and inflammation. Biochem Biophys Res Commun 203, 666-673

18. Li, J., Chanda, D., Shiri-Sverdlov, R., and Neumann, D. (2015) MSP: an emerging player in metabolic syndrome. Cytokine \& growth factor reviews 26, 75-82

19. Fujii, H., and Kawada, N. (2012) Inflammation and fibrogenesis in steatohepatitis. Journal of gastroenterology 47, 215-225

20. Quantin, B., Schuhbaur, B., Gesnel, M. C., Doll'e, P., and Breathnach, R. (1995) Restricted expression of the ron gene encoding the macrophage stimulating protein receptor during mouse development. Developmental dynamics: an official publication of the American Association of Anatomists 204, 383-390 
21. Pinto Lde, F., Compri, C. M., Fornari, J. V., Bartchewsky, W., Cintra, D. E., Trevisan, M., Carvalho Pde, O., Ribeiro, M. L., Velloso, L. A., Saad, M. J., Pedrazzoli, J., Jr., and Gambero, A. (2010) The immunosuppressant drug, thalidomide, improves hepatic alterations induced by a high-fat diet in mice. Liver international : official journal of the International Association for the Study of the Liver 30, 603-610

22. Koca, S. S., Bahcecioglu, I. H., Poyrazoglu, O. K., Ozercan, I. H., Sahin, K., and Ustundag, B. (2008) The treatment with antibody of TNF-alpha reduces the inflammation, necrosis and fibrosis in the non-alcoholic steatohepatitis induced by methionine- and choline-deficient diet. Inflammation 31, 91-98

23. Ito, M., Suzuki, J., Tsujioka, S., Sasaki, M., Gomori, A., Shirakura, T., Hirose, H., Ito, M., Ishihara, A., Iwaasa, H., and Kanatani, A. (2007) Longitudinal analysis of murine steatohepatitis model induced by chronic exposure to high-fat diet. Hepatol Res 37, 50-57

24. Haukeland, J. W., Damas, J. K., Konopski, Z., Loberg, E. M., Haaland, T., Goverud, I., Torjesen, P. A., Birkeland, K., Bjoro, K., and Aukrust, P. (2006) Systemic inflammation in nonalcoholic fatty liver disease is characterized by elevated levels of CCL2. Journal of hepatology 44, 1167-1174

25. Kamari, Y., Shaish, A., Vax, E., Shemesh, S., Kandel-Kfir, M., Arbel, Y., Olteanu, S., Barshack, I., Dotan, S., Voronov, E., Dinarello, C. A., Apte, R. N., and Harats, D. (2011) Lack of interleukin1alpha or interleukin-1beta inhibits transformation of steatosis to steatohepatitis and liver fibrosis in hypercholesterolemic mice. Journal of hepatology 55, 1086-1094

26. 26. Laskin, D. L., Chen, L., Hankey, P. A., and Laskin, J. D. (2010) Role of STK in mouse liver macrophage and endothelial cell responsiveness during acute endotoxemia. Journal of leukocyte biology 88, 373-382

27. 27. Gardner, C. R., Hankey, P., Mishin, V., Francis, M., Yu, S., Laskin, J. D., and Laskin, D. L. (2012) Regulation of alternative macrophage activation in the liver following acetaminophen intoxication by stem cell-derived tyrosine kinase. Toxicology and applied pharmacology 262, 139-148

28. 28. Leonis, M. A., Toney-Earley, K., Degen, S. J., and Waltz, S. E. (2002) Deletion of the Ron receptor tyrosine kinase domain in mice provides protection from endotoxin-induced acute liver failure. Hepatology (Baltimore, Md.) 36, 1053-1060
29. Gunella, G., Bardelli, C., Amoruso, A., Viano, I., Balbo, P., and Brunelleschi, S. (2006) Macrophage-stimulating protein differently affects human alveolar macrophages from smoker and non-smoker patients: evaluation of respiratory burst, cytokine release and NF-kappaB pathway. British journal of pharmacology 148, 478-489

30. Wang, T., Chen, X., Zhang, W., Xiang, X., Leng, C., and Jia, Q. (2015) Roles of macrophage stimulating protein and tyrosine kinase receptor RON in smoke-induced airway inflammation of rats. Int J Clin Exp Pathol 8, 8797-8808

31. Rampino, T., Soccio, G., Gregorini, M., Guidetti, C., Marasa, M., Maggio, M., Panichi, V., Migliori, M., Libetta, C., and Dal Canton, A. (2007) Neutralization of macrophage-stimulating protein ameliorates renal injury in anti-thy 1 glomerulonephritis. Journal of the American Society of Nephrology : JASN 18, 1486-1496

32. Stuart, W. D., Brown, N. E., Paluch, A. M., and Waltz, S. E. (2015) Loss of Ron receptor signaling leads to reduced obesity, diabetic phenotypes and hepatic steatosis in response to high-fat diet in mice. American journal of physiology. Endocrinology and metabolism 308, E562-572

33. Gentile, A., Trusolino, L., and Comoglio, P. M. (2008) The Met tyrosine kinase receptor in development and cancer. Cancer metastasis reviews 27, 85-94

34. Yao, H. P., Zhou, Y. Q., Zhang, R., and Wang, M. H. (2013) MSP-RON signalling in cancer: pathogenesis and therapeutic potential. Nature reviews. Cancer 13, 466-481

35. Nakamura, T., Sakai, K., Nakamura, T., and Matsumoto, K. (2011) Hepatocyte growth factor twenty years on: Much more than a growth factor. Journal of gastroenterology and hepatology 26 Suppl 1, 188-202

36. Wang, M. H., Zhou, Y. Q., and Chen, Y. Q. (2002) Macrophage-stimulating protein and RON receptor tyrosine kinase: potential regulators of macrophage inflammatory activities. Scand J Immunol 56, 545-553

37. Fafalios, A., Ma, J., Tan, X., Stoops, J., Luo, J., Defrances, M. C., and Zarnegar, R. (2011) A hepatocyte growth factor receptor (Met)-insulin receptor hybrid governs hepatic glucose metabolism. Nature medicine 17, 1577-1584

38. Gruben, N., Funke, A., Kloosterhuis, N. J., Schreurs, M., Sheedfar, F., Havinga, R., Houten, S. M., Shiri-Sverdlov, R., van de Sluis, B., Kuivenhoven, J. A., Koonen, D. P., and Hofker, M. H. (2015) Cholesterol-induced hepatic inflammation does not underlie the predisposition to insulin resistance in dyslipidemic female LDL receptor knockout mice. Journal of diabetes research 2015, 956854 
39. Funke, A., Schreurs, M., Aparicio-Vergara, M., Sheedfar, F., Gruben, N., Kloosterhuis, N. J., Shiri-Sverdlov, R., Groen, A. K., van de Sluis, B., Hofker, M. H., and Koonen, D. P. (2014) Cholesterol-induced hepatic inflammation does not contribute to the development of insulin resistance in male LDL receptor knockout mice. Atherosclerosis 232, 390-396 


\section{Supplementary Figures}

\section{Plasma ALT}

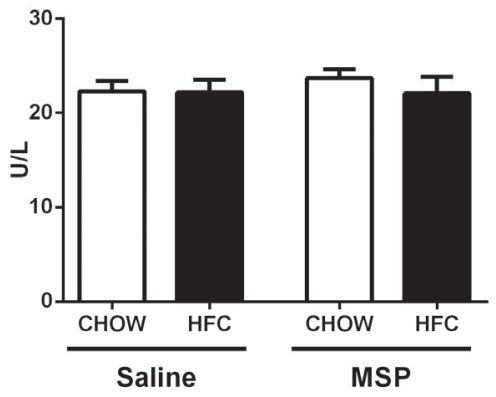

Supplementary figure 1. Plasma ALT level.

scoring steatosis

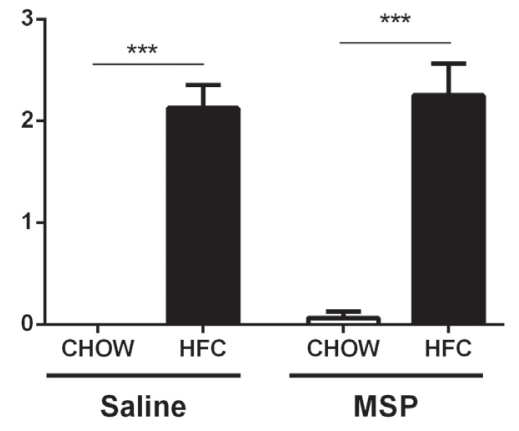

scoring inflammation

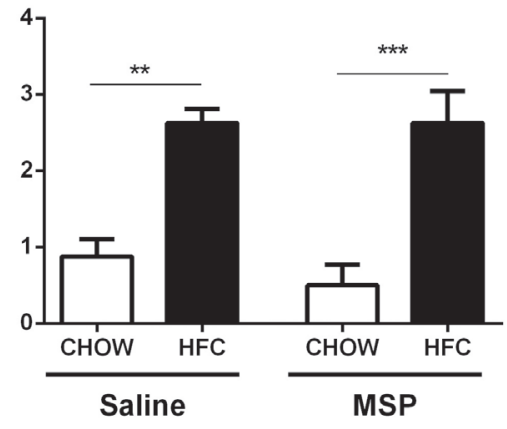

Supplementary figure 2. Scoring of steatosis and inflammation from histology. 


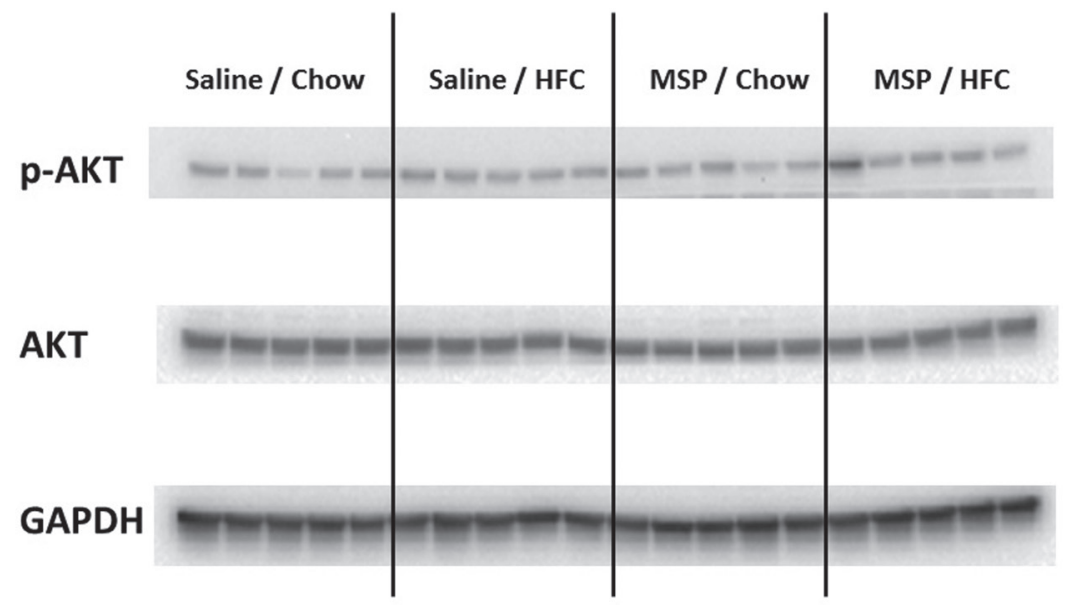

Supplementary figure 3. Protein level of pAKT in liver.

A

Chow

HFC

Saline

MSP

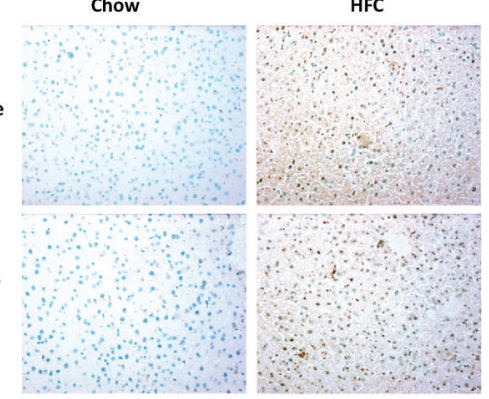

B Cyclind

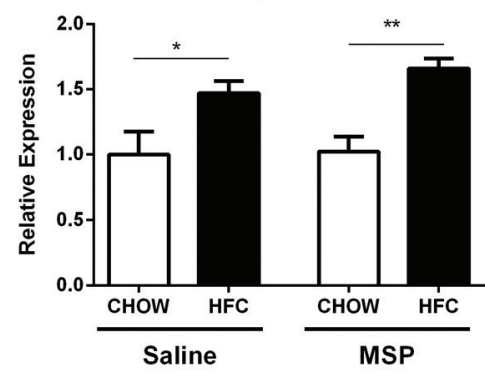

Supplementary figure 4. TUNEL staining (A) and cell regeneration marker (B). 



\section{Chapter 5}

\section{Macrophage stimulating protein (MSP) is inversely associated with fasting plasma glucose: The CODAM Study.}

Jieyi Li, Marleen M.J. van Greevenbroek, Will A. Coumans, Dipanjan Chanda, Johan W. E. Jocken, Carla van der Kallen, Coen D.

A. Stehouwer, Casper G. Schalkwijk, Jan F. C. Glatz, Ronit ShiriSverdlov, Dietbert Neumann 


\section{Abstract}

Objective: The current study was conducted to investigate the association of plasma macrophage stimulating protein (MSP) with plasma glucose and other metabolic parameters, and with risk of type 2 diabetes mellitus (T2DM).

Methods: Plasma MSP, fasting plasma glucose, and lipid profile were measured at baseline ( $n=553,61.3 \%$ men, age $59.5 \pm 7.0$ years) in a prospective cohort study. Multiple linear and logistic regression analyses were done with MSP (log2 transformed) as main independent variable and various metabolic variables and (pre)diabetes as outcomes. We also investigated whether baseline plasma MSP levels were associated with the 7-year cumulative incidence of T2DM or disturbed glucose metabolism (i.e. prediabetes or T2DM) using multiple logistic regression analysis.

Results: In cross-sectional evaluations of the baseline data, a 2-fold higher plasma MSP concentration was inversely associated with fasting glucose $(\beta=-1.24 \%$ [95\% Cl: $-2.40 ; 0.00])$, and positively associated with total cholesterol $(0.12$ $\mathrm{mmol} / \mathrm{l}$ [0.06; 0.17]), LDL-cholesterol (0.10 mmol/l [0.05; 0.15]) and apolipoprotein (apo)B (0.03 g/l [0.01; 0.04]), after adjustment for age and sex. Per 2-fold higher MSP, T2DM prevalence was lower (odds ratio (OR)= $0.87[95 \% \mathrm{Cl} 0.76 ; 1.00])$, but this association lost significance after adjustments for potential confounders. On the other hand, 2-fold higher baseline MSPs level were not associated with less incidence of T2DM (OR= $1.14[95 \% \mathrm{Cl} 0.91,1.41])$.

Conclusions: In this observational human cohort, MSP was inversely associated with fasting glucose, although. Yet, higher baseline MSP concentrations did not appear to protect against the development T2DM over time. Furthermore, MSP was prominently and positively associated with apoB-containing lipoproteins. 


\section{Introduction}

Recent evidence points towards a potential role for macrophage stimulating protein (MSP) in several aspects of the metabolic syndrome [1-3]. MSP is an endogenous protein that is mainly secreted by the liver, while some other organs, such as the kidney and the pancreas, may also contribute to systemic MSP levels [4,5]. After release into the circulation, MSP exerts its biological effects via its receptor, the transmembrane tyrosine kinase Recepteur d'Origine Nantais (receptor tyrosine kinase RON) which is ubiquitously expressed in different types of cells, and is currently the only known receptor for MSP. First discovered in 1976, MSP was documented as a serum protein that stimulated macrophage movement, chemotaxis, and spreading [6]. The importance of MSP-RON signaling for the invasive growth of cancers has led the development of inhibitors blocking RON signaling that are under investigation [7]. MSP-RON signaling has also been shown to be involved in anti-inflammatory responses in multiple tissues, including liver, kidney, lung, and gut [8-11]. More recent evidence suggests that MSP may additionally have a role in metabolism. It has been shown that MSP can inhibit gluconeogenesis and suppress glucose production in rat and human hepatocytes [2]. In line with this, mice that lacked MSP-RON signaling displayed an elevated plasma glucose level [12]. In addition, MSP may also function in the regulation of hepatic lipid metabolism $[1,12,13]$.

Although a potential role of MSP in glucose regulation has been investigated in in vitro studies and in several animal models [2,12], no relevant human data are available, yet. Remarkably, MSP has been shown as an endogenous activator of AMP-activated protein kinase (AMPK) [2,14], a well-known master regulator in maintaining energy homeostasis [15]. This makes MSP a promising research target in the field of glucose metabolism. In addition, belonging to the same growth factor family, MSP is highly homologous to hepatocyte growth factor (HGF) both in structure and in function [16]. Similar effects have been suggested for MSP and HGF in suppression of inflammation $[17,18]$ and hepatic gluconeogenesis [2]. As a more thoroughly studied protein compared to MSP, HGF has been found to associate with the development of insulin resistance and type 2 diabetes mellitus (T2DM) in human populations [19-22].

In our current analyses, we therefore investigated the cross-sectional association of plasma MSP with glucose and other metabolic parameters in a prospective cohort of Caucasian individuals. In addition, we evaluated the association of plasma MSP with development of glucose intolerance and T2DM during a 7-year follow-up period. 


\section{Subjects and Methods}

\section{Study Design}

Data were obtained from the Cohort on Diabetes and Atherosclerosis Maastricht (CODAM) study, a prospective, observational study on, among others, the natural progression of glucose tolerance. This cohort was initiated in 1999 [23] and staging of glucose tolerance was done according to the WHO1999 criteria [24]. A total of 574 individuals were selected from a large population-based cohort as described in detail elsewhere [25] and were extensively characterized at baseline with regard to lifestyle and cardiovascular and metabolic profile. After a median of 7.0 years (interquartile range 6.9-7.1), 495 individuals participated in the follow-up measurements. The CODAM study was approved by the medical ethics committee of the Maastricht University Medical Centre, and all participants gave written informed consent.

In the present study, we excluded participants with missing data on MSP ( N=16 at baseline) (of whom 13 were due to the missing samples and 3 were due to undetectable value. In one additional participant, an extreme value of plasma MSP was obtained (0.07 $\mathrm{ng} / \mathrm{ml}$ ). This participant was excluded as an outlier. Four participants were excluded because of missing data on physical activity. The main cross-sectional analyses in this study were therefore conducted in 553 participants. At baseline, 285 participants were classified as having normal glucose metabolism (NGM), 124 as having impaired glucose metabolism (prediabetes, i.e. impaired fasting glucose (IFG) and/or impaired glucose tolerance (IGT)), and 144 as T2DM patients on the basis of a standard 75 grams oral glucose tolerance test (OGTT) [24]. Individuals with known T2DM or those with fasting glucose levels $>68.5 \mathrm{~mol} / \mathrm{L}$ were excluded from undergoing OGTT.

\section{Measurement of MSP}

Participants were asked to stop their lipid-lowering medication 14 days before the visit to our research facility and to stop all other medication the day before the visit. After an overnight fast, venous blood samples were collected for assessment of biomarkers. EDTA samples were collected on ice, and after centrifugation at 3,000 $\times$ g for $15 \mathrm{~min}$ at $4^{\circ} \mathrm{C}$, plasma aliquots were stored at $-80^{\circ} \mathrm{C}$ until use. Samples were thawed only once prior to the MSP measurements. MSP levels were determined in duplicate by ELISA (RD duoset ELISA development kit, Catalog number DY352, LOT1364014)-interassay coefficient of variation was $8.6 \%$. 


\section{Glucose and lipid measurements}

Glucose was measured in sodium fluoride-potassium oxalate (NaF-KO) plasma (fasting and $2 \mathrm{hrs}$ post-OGTT) by the hexokinase method $[23,26]$. Total cholesterol, high-density lipoprotein (HDL) cholesterol, apolipoprotein B (apoB) and triglycerides were measured in EDTA plasma by enzymatic methods (Roche, Mannheim, Germany) as reported previously [27]. Low-density lipoprotein (LDL) cholesterol was calculated with the Friedewald formula $[27,28]$.

\section{Other Covariates}

Body mass index (BMI), waist circumference, blood pressure, smoking behavior, dietary calorie intake, daily alcohol consumption, physical activity, and use of antihypertensive, glucose-lowering, and lipid-lowering medication were determined as described previously $[25,27,29]$. Measurements of glycosylated haemoglobin (HbA1c) and insulin were done as described previously [25]. Insulin resistance was estimated using the Homeostasis model 2 assessment (HOMA2) calculator (http://www.dtu.ox.ac.uk) $[30,31]$. High-sensitivity C-reactive protein (hs-CRP), serum amyloid A (SAA), interleukin 6 (IL-6), interleukin 8 (IL-8), tumour necrosis factor- $\alpha$ (TNF- $\alpha$ ) and soluble intercellular adhesion molecule-1 (sICAM-1) were determined as described previously [32]. Estimated liver fat (\%) (eLF\%) was calculated according to a predictive equation that has been developed and validated against proton magnetic resonance spectroscopy (1H-MRS) and which provides an inexpensive tool for epidemiological research [33]. Presence of the metabolic syndrome was defined according to the harmonized definition [34]. Prior cardiovascular disease was defined as described previously $[25,35]$.

\section{Statistical Analyses}

Variables with a skewed distribution, i.e., MSP, triglycerides, inflammatory markers, eLF\% and IR were $\log _{2}$ transformed prior to further analyses. Differences in general characteristics according to tertiles of MSP concentrations were compared with one-way ANOVA (for continuous variables) and $\mathrm{chi}^{2}$ (for dichotomous variables).

Multiple linear regression analyses were used to investigate the associations between fasting plasma levels of MSP and markers of glucose metabolism, i.e. fasting glucose, $\mathrm{HbA} 1 \mathrm{c}$, area under the curve (AUC) for glucose, and $2 \mathrm{~h}$ post-challenge glucose in the OGTT. Associations of plasma MSP concentration with prevalent prediabetes and T2DM were evaluated in multiple logistic regression analyses. Also, we investigated whether baseline plasma MSP levels were associated with 7-year cumulative incidence of T2DM or a disturbed glucose metabolism (i.e. prediabetes or T2DM) via multiple logistic regression analysis. Multiple linear regression was also used to investigate the 
associations between MSP and markers of lipid metabolism, i.e. plasma levels of fasting cholesterol, LDL-cholesterol and apolipoprotein (apo) B. The results of the analyses are presented as crude effect size [model 1], adjusted for age (in years) and sex [model 2], additionally adjusted for smoking status (current smoker yes/no), alcohol consumption (units/day), total energy intake (kJ/day), and physical activity (meets the Dutch guideline for daily activity level) [model3], and additionally adjusted for use of medication (glucoselowering medication yes/no, lipid-lowering medication yes/no, anti-hypertensive medication yes/no as individual variables) [model 4]. When plasma lipids were the outcome, also glucose metabolism status (as dummy variables with NGM as reference category) was added to model 4 of the multiple linear regression analyses.

Furthermore, since MSP tends to be lower in post-menopausal compared with premenopausal women (independent $T$ test: $P=0.06$ ), sensitivity analyses was performed in addition to the main analyses described above. Menopausal status of women was included as a potential confounder to these additional analyses.

All statistical analyses were carried out with the use of the Statistical Package of Social Sciences (SPSS) version 20.0 for Windows (SPSS, Inc., Chicago, IL, USA). A p-value $<0.05$ was considered statistically significant.

\section{Results}

\section{Study population}

Baseline characteristics of the CODAM study population according to tertiles of MSP concentrations are shown in Table 1. Individuals in the lowest MSP tertile generally had the highest plasma glucose concentration. In contrast, total and LDL cholesterol, as well as apoB concentrations were lowest in the lowest MSP tertile. HDL cholesterol and triglyceride did not differ across MSP tertiles. Other metabolic and lifestyle parameters also did not differ between the MSP tertiles.

\section{MSP is inversely associated with fasting plasma glucose}

Table 2 shows the associations of plasma glucose with MSP concentrations in different regression models. After adjustment for age, sex, smoking status, alcohol consumption, total energy intake, physical activity, and use of medication (lipid-, glucose-, and blood pressure-lowering medication), MSP remained inversely associated with fasting glucose ( $\beta=-0.013$ [95\% Cl-0.027; 0.000] (Table 2, Model 4). Similar associations were observed the $2 \mathrm{~h}$ post-challenge glucose, the AUC for glucose during the OGTT, and for HbA1c, which represents the glucose load over the past 6-12 weeks, although these were weaker and did not reach statistical significance. 
Table 1: Baseline characteristics of the CODAM study population according to tertiles of plasma concentrations of MSP.

\begin{tabular}{|c|c|c|c|c|}
\hline & $\begin{array}{l}\text { Lowest MSP tertile } \\
\qquad(\mathrm{N}=185)\end{array}$ & $\begin{array}{l}\text { Medium MSP tertile } \\
\qquad(\mathrm{N}=186)\end{array}$ & $\begin{array}{l}\text { Highest MSP tertile } \\
\qquad(\mathrm{N}=186)\end{array}$ & $P$ value \\
\hline age (years) & $59.95 \pm 6.92$ & $60.22 \pm 6.57$ & $58.59 \pm 7.37$ & 0.054 \\
\hline sex (\%men) & 64.9 & 63.4 & 55.9 & 0.163 \\
\hline Waist circumference $(\mathrm{cm})$ & $98.92 \pm 12.12$ & $99.24 \pm 11.54$ & $99.78 \pm 12.27$ & 0.786 \\
\hline BMI $\left(\mathrm{kg} / \mathrm{m}^{2}\right)$ & $28.43 \pm 4.64$ & $28.31 \pm 3.88$ & $28.94 \pm 4.47$ & 0.340 \\
\hline Systolic BP (mmHg) & $142.48 \pm 19.95$ & $138.04 \pm 16.74$ & $140.03 \pm 19.87$ & 0.078 \\
\hline Diastolic BP (mmHg) & $82.52 \pm 9.16$ & $81.01 \pm 8.35$ & $81.85 \pm 9.85$ & 0.282 \\
\hline FPG (mmol/l) & $5.80(5.31-7.00)$ & $5.47(5.14-6.00)$ & $5.60(5.20-6.38)$ & 0.001 \\
\hline $\mathrm{HbA} 1 \mathrm{C}(\%)$ & $6.02 \pm 0.97$ & $5.90 \pm 0.62$ & $6.00 \pm 0.85$ & 0.377 \\
\hline HOMA2IR & $1.61(1.11-2.85)$ & $1.62(1.13-2.38)$ & $1.62(1.09-2.58)$ & 0.715 \\
\hline T2DM (\%) & 32.4 & 17.7 & 27.4 & 0.005 \\
\hline Total cholesterol $(\mathrm{mmol} / \mathrm{l})$ & $5.01 \pm 1.00$ & $5.28 \pm 0.88$ & $5.38 \pm 1.05$ & 0.001 \\
\hline LDL cholesterol ( $\mathrm{mmol} / \mathrm{l})$ & $3.12 \pm 0.86$ & $3.39 \pm 0.82$ & $3.40 \pm 0.90$ & 0.003 \\
\hline Apolipoprotein B (g/l) & $1.08 \pm 0.24$ & $1.14 \pm 0.23$ & $1.16 \pm 0.26$ & 0.008 \\
\hline HDL cholesterol ( $\mathrm{mmol} / \mathrm{l})$ & $1.16 \pm 0.36$ & $1.22 \pm 0.35$ & $1.21 \pm 0.33$ & 0.160 \\
\hline Triglyceride $(\mathrm{mmol} / \mathrm{l})$ & $1.40(0.90-1.95)$ & $1.40(0.90-1.90)$ & $1.40(1.10-2.03)$ & 0.086 \\
\hline eLF (\%) & $5.48(2.93-9.87)$ & $4.17(2.35-7.93)$ & $5.36(2.63-9.26)$ & 0.259 \\
\hline Metabolic syndrome (\%) & 64.3 & 54.3 & 62.9 & 0.102 \\
\hline Cardiovascular disease (\%) & 31.4 & 24.7 & 26.9 & 0.347 \\
\hline hs-CRP (mg/l) & $1.85(0.90-3.72)$ & $1.88(0.82-3.94)$ & $2.21(1.14-4.28)$ & 0.227 \\
\hline $\mathrm{SAA}(\mathrm{mg} / \mathrm{l})$ & $1.35(1.00-2.23)$ & $1.37(0.97-2.27)$ & $1.58(0.99-2.32)$ & 0.721 \\
\hline IL-6 (ng/l) & $1.67(1.21-2.33)$ & $1.54(1.08-2.40)$ & $1.45(1.10-2.19)$ & 0.071 \\
\hline IL-8 (ng/l) & $4.34(3.59-5.47)$ & $4.23(3.51-5.51)$ & $4.60(3.72-5.67)$ & 0.514 \\
\hline TNF- $\alpha$ (ng/l) & $6.08(5.13-7.39)$ & $6.36(5.41-7.54)$ & $6.23(5.25-7.66)$ & 0.632 \\
\hline sICAM-1 (ug/l) & $214(191-243)$ & $211(187-247)$ & $213(184-241)$ & 0.641 \\
\hline Anti-hypertensive medication (\% yes) & 41.6 & 35.5 & 38.2 & 0.476 \\
\hline Glucose-lowering medication (\% yes) & 16.2 & 9.1 & 14.5 & 0.111 \\
\hline Lipid-modifying medication (\% yes) & 18.9 & 21 & 18.3 & 0.791 \\
\hline
\end{tabular}

Notes: The range of MSP concentrations was $1.0-24.6 \mathrm{ng} / \mathrm{ml}$ in lowest tertile, $24.6-43.9$ $\mathrm{ng} / \mathrm{ml}$ in medium tertile and $44.1-454.9 \mathrm{ng} / \mathrm{ml}$ in highest tertile. Data were available in $\mathrm{N}=532$ (HbA1c) to 557 participants, and are expressed as mean $\pm \mathrm{SD}$, median [interquartile range] or percentages;

Abbreviations: BMI: body mass index; BP: blood pressure; FPG: fasting plasma glucose; HbA1c: glycosylated hemoglobin; HOMA2IR: homoeostasis model 2 assessment insulin resistance; T2DM: type 2 diabetes mellitus; LDL: low density lipoprotein; HDL: high density lipoprotein; eLF (\%): estimated liver fat percentage; hs-CRP: high-sensitivity C-reactive protein; SAA: serum amyloid A; IL-6: Interleukin 6; IL-8: Interleukin 8, TNF- $\alpha$ : tumour necrosis factor- $\alpha$; sICAM-1: soluble intercellular adhesion molecule-1. 


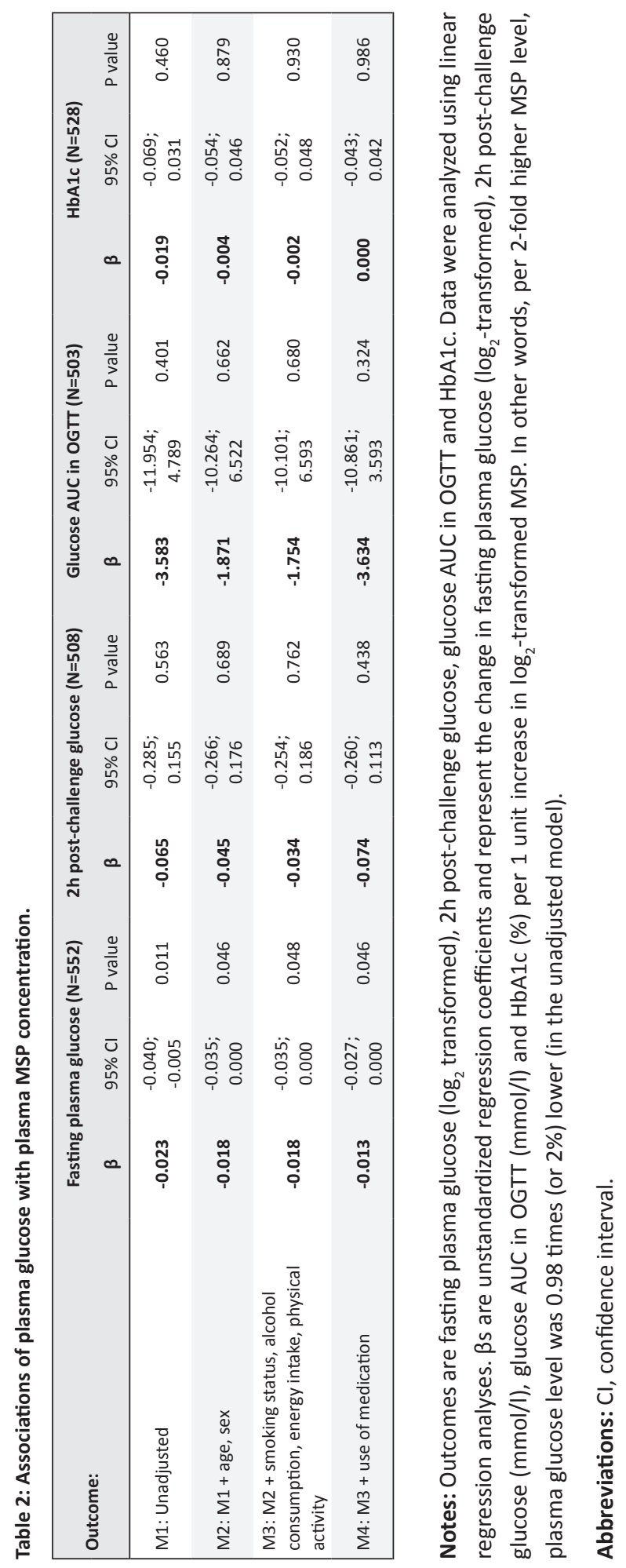


Table 3: Associations of plasma MSP concentration with prevalent prediabetes and T2DM.

\begin{tabular}{|c|c|c|c|c|c|c|}
\hline \multirow[b]{2}{*}{ Models } & \multicolumn{3}{|c|}{$\begin{array}{l}\text { Prevalent prediabetes } \\
\qquad(n=124)\end{array}$} & \multicolumn{3}{|c|}{$\begin{array}{l}\text { Prevalent T2DM } \\
\qquad(n=144)\end{array}$} \\
\hline & OR & $95 \% \mathrm{Cl}$ & $P$ value & OR & $95 \% \mathrm{Cl}$ & $P$ value \\
\hline M1: Unadjusted & 1.02 & $0.89 ; 1.18$ & 0.753 & 0.87 & $0.76 ; 1.00$ & 0.041 \\
\hline M2: M1 + age, sex & 1.02 & $0.89 ; 1.18$ & 0.753 & 0.89 & $0.78 ; 1.02$ & 0.106 \\
\hline M4: M3 + use of medication & 1.01 & $0.87 ; 1.17$ & 0.914 & 0.88 & $0.73 ; 1.05$ & 0.145 \\
\hline
\end{tabular}

Notes: Data were analyzed using multiple logistic regression analysis (normal glucose metabolism ( $n=285$ ) is reference). OR represent the associations between plasma MSP levels and prevalent impaired glucose metabolism (prediabetes) / T2DM. In other words, per 2-fold higher MSP level at baseline, the odds to have prevalent T2DM were 0.87 times lower (unadjusted model).

Abbreviations: $\mathrm{Cl}$, confidence interval; OR, odds ratio; T2DM, type 2 diabetes mellitus.

Median [interquartile] levels of plasma MSP were $35.0 \mathrm{ng} / \mathrm{ml}$ [21.4; 52.3], $32.9 \mathrm{ng} / \mathrm{ml}$ [20.6; 51.6] and $30.8 \mathrm{ng} / \mathrm{ml}$ [13.4; 53.4] in participants with NGM, prediabetes and T2DM, respectively. To investigate the associations of plasma MSP concentration with the glucose metabolism groups, multiple logistic regression analyses was performed. Table 3 shows the associations of plasma MSP concentration with the prevalent prediabetes and/or T2DM. The presence of prediabetes was not associated with lower plasma levels of MSP, neither in the crude analyses nor adjusted for age, sex, smoking status, alcohol consumption, total energy intake, physical activity and use of medication. Per 2-fold higher MSP concentration, the odds of prevalent T2DM are 0.87 times lower [95\% Cl 0.76; 1.00] (Table 3, model 1). However this association did not remain significant after additional adjustments for potential confounders (Table 3, models 2-4), indicating only a modest association of MSP concentration with glucose metabolism status.

\section{Baseline plasma MSP is not associated with incident T2DM during the 7-year follow-up}

After exclusion of participants with T2DM at baseline, 364 individuals were available for logistic regression analysis on incident T2DM. During the 7-year follow-up period, 59 out of 364 participants developed T2DM (16.2\%). Baseline MSP level was not associated with risk of developing T2DM after adjustment for baseline age and sex (Table 4, model 2). Also, after additional adjustment for smoking status, alcohol consumption, physical activity and dietary energy intake (Table 4, model 3), baseline MSP remained not associated with incident T2DM (odds ratio 1.14 [95\% Cl 0.91; 1.41]).

We additionally analyzed the association of baseline MSP with incident disturbed glucose metabolism (DGM, i.e., T2DM combined with prediabetes). After exclusion of indi- 
Table 4: Association of baseline plasma MSP level with incident T2DM or incident disturbed glucose metabolism (prediabetes/T2DM) during the 7-year follow-up.

\begin{tabular}{|c|c|c|c|c|c|c|}
\hline \multirow[b]{2}{*}{ Models } & \multicolumn{3}{|c|}{$\begin{array}{c}\text { Incident T2DM } \\
\text { ( } n=364,59 \text { cases) }\end{array}$} & \multicolumn{3}{|c|}{$\begin{array}{c}\text { Incident DGM } \\
\text { ( } n=253,84 \text { cases) }\end{array}$} \\
\hline & OR & $95 \% \mathrm{Cl}$ & $P$ value & OR & $95 \% \mathrm{Cl}$ & $P$ value \\
\hline M1: unadjusted & 1.11 & $0.90 ; 1.37$ & 0.324 & 1.16 & $0.95 ; 1.41$ & 0.146 \\
\hline M2: M1+ age, sex & 1.13 & $0.91 ; 1.40$ & 0.265 & 1.22 & $0.99 ; 1.50$ & 0.064 \\
\hline $\begin{array}{l}\text { M3: M2+ smoking status, } \\
\text { alcohol consumption, energy intake, physical } \\
\text { activity }\end{array}$ & 1.14 & $0.91 ; 1.41$ & 0.250 & 1.24 & $1.00 ; 1.53$ & 0.055 \\
\hline
\end{tabular}

Notes: Data were analyzed using logistic regression analysis. OR represent the associations between baseline plasma MSP levels and incident T2DM, or incident DGM (i.e., T2DM combined with impaired glucose metabolism (prediabetes)) at 7-year follow-up. In other words, per 2-fold higher MSP level at baseline, the odds to develop incident T2DM during 7 years follow-up were 1.11 times higher (unadjusted model).

Abbreviations: $\mathrm{Cl}$, confidence interval; DGM, disturbed glucose metabolism; OR, odds ratio; T2DM, type 2 diabetes mellitus.

viduals with T2DM or prediabetes at baseline, 253 participants were available for logistic regression analysis on incident DGM. During the 7-year follow-up, 84 out of 253 participants developed DGM (33.2\%). Baseline MSP level was not associated with risk of developing DGM, neither in crude analysis nor after adjustment for baseline age, sex, smoking status, alcohol consumption and dietary energy intake, (odds ratio 1.24 [95\% $\mathrm{Cl} 1.00$; 1.53], Table 4, model 3). Altogether these data suggest that higher levels of MSP do not appear to protect against the development of T2DM or prediabetes in the 7-year followup. Likewise, baseline MSP concentrations were not associated with changes in plasma concentrations of glucose or $\mathrm{HbA} 1 \mathrm{c}$ during the 7-year follow-up period (data not shown).

\section{MSP is positively associated with apoB-containing lipoproteins}

Table 5 shows the associations of apoB-containing lipoproteins with MSP concentrations. Interestingly, we found that MSP was positively associated with total cholesterol, LDL cholesterol, and apoB levels, after adjustment for age, sex, smoking status, alcohol consumption, total energy intake, physical activity, use of medication and glucose metabolism status (Table 5, Model 4) (all P $\leq 0.001$ ), indicating a prominent association with MSP and apoB-containing lipoprotein particles.

\section{Additional analyses}

To investigate whether the associations differed between menopausal statuses in women, we repeated all analyses with adding menopausal status to the (fully adjusted) models, and inclusion of this potential confounder did not influence our findings (data 
Table 5. Associations of lipoprotein particles with plasma MSP concentration.

\begin{tabular}{|c|c|c|c|c|c|c|c|c|c|}
\hline & \multicolumn{3}{|c|}{$\begin{array}{l}\text { Outcome }=\text { Total cholesterol } \\
\qquad(\mathrm{N}=553)\end{array}$} & \multicolumn{3}{|c|}{$\begin{array}{l}\text { Outcome }=\text { LDL cholesterol } \\
\qquad(N=544)\end{array}$} & \multicolumn{3}{|c|}{$\begin{array}{l}\text { Outcome }=\text { apoB } \\
\qquad(N=550)\end{array}$} \\
\hline & $\beta$ & $95 \% \mathrm{Cl}$ & $P$ value & $\beta$ & $95 \% \mathrm{Cl}$ & $P$ value & $\beta$ & $95 \% \mathrm{Cl}$ & $P$ value \\
\hline M1: unadjusted & 0.111 & $\begin{array}{l}0.054 \\
0.169\end{array}$ & $<0.001$ & 0.095 & $\begin{array}{c}0.044 \\
0.146\end{array}$ & $<0.001$ & 0.025 & $\begin{array}{l}0.011 \\
0.039\end{array}$ & 0.001 \\
\hline M2: M1+ age, sex & 0.115 & $\begin{array}{l}0.057 \\
0.173\end{array}$ & $<0.001$ & 0.102 & $\begin{array}{l}0.050 \\
0.153\end{array}$ & $<0.001$ & 0.027 & $\begin{array}{l}0.013 \\
0.041\end{array}$ & $<0.001$ \\
\hline $\begin{array}{l}\text { M3: M2+ smoking status, alcohol } \\
\text { consumption, energy intake, } \\
\text { physical activity }\end{array}$ & 0.112 & $\begin{array}{l}0.054 \\
0.170\end{array}$ & $<0.001$ & 0.100 & $\begin{array}{l}0.049 \\
0.152\end{array}$ & $<0.001$ & 0.027 & $\begin{array}{l}0.012 \\
0.041\end{array}$ & $<0.001$ \\
\hline $\begin{array}{l}\text { M4: M3+ use of medication + } \\
\text { glucose metabolism status }\end{array}$ & 0.112 & $\begin{array}{l}0.055 \\
0.169\end{array}$ & $<0.001$ & 0.094 & $\begin{array}{c}0.043 \\
0.145\end{array}$ & $<0.001$ & 0.027 & $\begin{array}{l}0.013 \\
0.042\end{array}$ & $<0.001$ \\
\hline
\end{tabular}

Notes: Data were analyzed using linear regression analysis. $\beta$ s are unstandardized regression coefficients and represent the change in cholesterol $(\mathrm{mmol} / \mathrm{l}), \mathrm{LDL}$ cholesterol ( $\mathrm{mmol} / \mathrm{l})$, and apolipoprotein $\mathrm{B}(\mathrm{apoB})(\mathrm{g} / \mathrm{l})$ per 1 unit higher in $\log _{2}$-transformed MSP. In other words, per 2-fold higher MSP level, plasma cholesterol level was $0.11 \mathrm{mmol} / \mathrm{l}$ higher (in the unadjusted model).

Abbreviations: $\mathrm{Cl}$, confidence interval.

not shown). A substantial number of CODAM participants were treated with glucoselowering and / or lipid-lowering medication during the course of the study. To evaluate if the current observation were influenced by pharmacological treatment, the evaluations of a possible relation between MSP and glucose metabolism or diabetes were repeated while excluding participants who were taking glucose lowering medication. Additionally, analyses on the relations between MSP and cholesterol or apoB containing lipoproteins were redone while excluding participants on lipid-lowering medication. The results of these analyses did not materially differ from the main analyses.

\section{Discussion}

The current study was conducted to investigate the relation of circulating MSP with plasma glucose and other metabolic parameters in humans. The present work has generated three main findings. First, plasma MSP levels showed a modest inverse association with glucose levels in a well-defined human cohort that included both healthy participants and individuals with different degrees of abnormal glucose metabolism. Second, despite the inverse association between MSP and glucose levels, a higher baseline MSP concentration did not protect against the development of T2DM over a 7-year follow-up period. Third, we showed that plasma MSP was prominently associated with apoB-containing lipoproteins, as represented by total cholesterol, LDL cholesterol and $а р о B$ levels. These observations provide further evidence to the relevance of MSP in the regulation of glucose and lipid metabolism. 
The current human study presents an inverse association between plasma MSP and glucose levels. This novel observation is in line with previous in vitro findings [2]. In hepatocytes of both human and rat, MSP treatment dramatically suppressed the CAMP/ dexamethasone (Dex)-mediated glucose production, negatively regulated the gene promoter activities and expression levels of key hepatic gluconeogenic enzyme genes, i.e., phosphoenolpyruvate carboxykinase (PEPCK) and glucose-6-phosphatase (Glc-6Pase), in a dose-dependent manner. This effect has been shown to be mediated through the MSP-AMPK-small heterodimer partner (SHP) signaling pathway [2,14]. Moreover, mice with disrupted MSP signaling had disturbed glucose metabolism and higher blood glucose levels than control mice [12]. This also supports that MSP participates in glucose control and may suppress the plasma glucose level to maintain a proper blood sugar balance.

Our current data showed that higher plasma MSP levels were not associated with a lower-prevalence of prediabetes, while they were associated with a slightly lower prevalence of T2DM (crude analyses), although this effect was attenuated after adjustment for several potential confounders. A possible explanation for this very modest association lies in the fact that regulation of blood glucose homeostasis by the liver is particularly relevant under fasting conditions [36] and glucose-lowering effects of MSP may be mostly on hepatic glucose metabolism. The classification into NGM, prediabetes and T2DM status is not only based on fasting, but also on post-challenge glucose concentrations. Multiple organs, including fat, liver and muscle are involved in the control of post-challenge glucose concentrations and insulin resistance is a strong determinant of post-challenge glucose concentrations. Notably, in our current evaluation MSP levels were not significantly associated with post challenge glucose concentrations, and also not with insulin resistance as estimated by HOMA2IR. This is in line with our observation that during the 7-year follow-up, higher baseline MSP levels did not appear to protect against the development of T2DM. We propose that this is at least partly due to the regulatory mechanism of MSP on blood glucose levels: MSP may regulate blood glucose level possibly via the hepatic glucose production, whereas, during the development of T2DM, dysfunctional pancreatic $\beta$ cells and insulin resistance (of peripheral tissues) play vital roles $[37,38]$. Hence, the prospective relation of MSP on risk of T2DM may have diminished, due to the peripheral events overriding the putatively hepatic MSP effects.

Relevantly, in addition to the modest and inverse association of MSP with fasting glucose, we observed a strong and positive association of MSP with apoB-containing lipoproteins. To the best of our knowledge, the link between MSP and cholesterol metabolism, particularly in humans, is still a vacant area in literature and the current findings should 
therefore be interpreted with caution until confirmed in an independent population. Our previous work showed that a very short-term supplement of MSP in a NASH mouse model did not change systemic or hepatic accumulation of triglyceride and cholesterol [3]. MSP knock-out mice, fed on normal chow diet, displayed lipid accumulation in their livers [13], pointing towards the potential role of MSP in lipid regulation. Another study revealed that MSP, via activation of AMPK, inhibited the lipogenic enzymes sterol regulatory element-binding protein $1 c$ (SREBP-1c) and fatty acid synthase (FAS), thereby reducing palmitic acid-induced hepatic lipogenesis and lipid accumulation in a hepatocyte cell line [1]. In our current study, we observed that plasma MSP was positively associated with plasma cholesterol, but not triglycerides. This suggests that MSP may be involved specifically in cholesterol homeostasis. It has been demonstrated that cholesterol synthesis regulation mainly depends on the activation of SREBPS, preferentially SREBP-2 [39]. MSP has been found to be a regulator of SREBP-1c, which preferentially activates genes of fatty acid and triglyceride metabolism, but no information is currently available with respect to SREBP-2. Thus, it may worthwhile to further explore the effects of MSP on individual members of the SREBP family. Moreover, since MSP is positively associated with LDL cholesterol and apoB, but not HDL cholesterol, it can be anticipated that MSP, via unknown mechanisms, could reduce the absorption of LDL particles from the circulation, for example by regulating cell surface availability of LDL receptors. Interestingly, a recent evidence showed that loss of MSP signaling in mice did not influence their serum triglyceride and cholesterol levels after feeding a high-fat diet, while it turned out those mice obtained a higher ratio of LDL/HDL than wild-type mice [12]. The latter finding indicates that MSP signaling may also participate in the cholesterol metabolism in mice. Note that in the interpretation of the data on the role of MSP in cholesterol regulation, species discrepancy should be carefully considered. Unlike humans, wild-type mice carry most of their lipids in HDL thus have crucially different lipoprotein profiles. Thus, the causal relationship between MSP and cholesterol is still unclear, and further studies exploring the underlying mechanism are needed.

Novel drugs that target specific signaling pathways may have unanticipated side effects in specific sub-populations, for instance in those with suboptimal glucose control [40]. Our current findings are therefore relevant in the light of ongoing explorations of MSPRON signaling as a potential target in cancer therapy [7]. Potential adverse metabolic effects of reduced MSP-RON signaling may be more pronounced in those who are metabolically challenged, such as individuals with impaired fasting glucose metabolism or T2DM. 
The strength of our study is that we have measured, for the first time, MSP in a relatively large cohort of well-phenotyped human individuals with a broad range of fasting glucose concentrations. The samples that were used had been stored in a well-controlled manner and the MSP measurements were robust with acceptable variation coefficients. Our study also has limitations. Most of the reported findings derive from cross-sectional evaluations, which do not allow conclusions on causality. However, most available experimental data point towards an effect of MSP on glucose and/or lipid homeostasis, rather than the reverse. In addition, the fact that we did not have detailed information on, for instance, glucose production and fluxes may have limited the biological interpretation of our findings. Lastly, our study was done in middle-aged and elderly Caucasian individuals with a moderately increased risk for cardiometabolic diseases. This does not impair the value of our cohort for etiological research, but it does imply that extrapolation of our findings to the general population and to other ethnicities should be done with caution.

\section{Conclusion}

The present study showed that MSP was inversely associated with fasting glucose concentrations, but higher baseline MSP concentrations did not protect against development T2DM over a 7-year follow-up period. The positive association between MSP and cholesterol provoke further mechanistic studies on the role of MSP in cholesterol homeostasis. These epidemiological observations should be regarded as hypothesis generating for further studies aimed at elucidating the role of MSP in the pathogenesis of glucose and lipid dysregulation. 


\section{References}

1. Chanda, D., Li, J., Oligschlaeger, Y., Jeurissen, M. L., Houben, T., Walenbergh, S. M., Shiri-Sverdlov, R., and Neumann, D. (2016) MSP is a negative regulator of inflammation and lipogenesis in ex vivo models of non-alcoholic steatohepatitis. Exp Mol Med 48, e258

2. Chanda, D., Li, T., Song, K. H., Kim, Y. H., Sim, J., Lee, C. H., Chiang, J. Y., and Choi, H. S. (2009) Hepatocyte growth factor family negatively regulates hepatic gluconeogenesis via induction of orphan nuclear receptor small heterodimer partner in primary hepatocytes. I Biol Chem 284, 28510-28521

3. Li, J., Chanda, D., van Gorp, P. J., Jeurissen, M. L., Houben, T., Walenbergh, S. M., Debets, J., Oligschlaeger, Y., Gijbels, M. J., Neumann, D., and Shiri-Sverdlov, R. (2016) Macrophage Stimulating Protein Enhances Hepatic Inflammation in a NASH Model. PLoS One 11, e0163843

4. Rampino, T., Collesi, C., Gregorini, M., Maggio, M., Soccio, G., Guallini, P., and Dal Canton, A. (2002) Macrophage-stimulating protein is produced by tubular cells and activates mesangial cells. Journal of the American Society of $\mathrm{Ne}$ phrology : JASN 13, 649-657

5. Yoshimura, T., Yuhki, N., Wang, M. H., Skeel, A., and Leonard, E. J. (1993) Cloning, sequencing, and expression of human macrophage stimulating protein (MSP, MST1) confirms MSP as a member of the family of kringle proteins and locates the MSP gene on chromosome 3. J Biol Chem 268, 15461-15468

6. Leonard, E. J., and Skeel, A. (1976) A serum protein that stimulates macrophage movement, chemotaxis and spreading. Exp Cell Res 102, 434-438

7. Yao, H. P., Zhou, Y. Q., Zhang, R., and Wang, M. H. (2013) MSP-RON signalling in cancer: pathogenesis and therapeutic potential. Nature reviews. Cancer 13, 466-481

8. Stuart, W. D., Kulkarni, R. M., Gray, J. K., Vasiliauskas, J., Leonis, M. A., and Waltz, S. E. (2011) Ron receptor regulates Kupffer cell-dependent cytokine production and hepatocyte survival following endotoxin exposure in mice. Hepatology 53, 1618-1628

9. Nikolaidis, N. M., Kulkarni, R. M., Gray, J. K., Collins, M. H., and Waltz, S. E. (2011) Ron receptor deficient alveolar myeloid cells exacerbate LPSinduced acute lung injury in the murine lung. Innate Immun 17, 499-507
10. Kulkarni, R. M., Stuart, W. D., Gurusamy, D., and Waltz, S. E. (2014) Ron receptor signaling is protective against DSS-induced colitis in mice. Am J Physiol Gastrointest Liver Physiol 306, G10651074

11. Lee, K. E., Kim, E. Y., Kim, C. S., Choi, J. S., Bae, E. H., Ma, S. K., Kim, K. K., Lee, J. U., and Kim, S. W. (2013) Macrophage-stimulating protein attenuates gentamicin-induced inflammation and apoptosis in human renal proximal tubular epithelial cells. Biochem Biophys Res Commun 434, 527-533

12. Yu, S., Allen, J. N., Dey, A., Zhang, L., Balandaram, G., Kennett, M. J., Xia, M., Xiong, N., Peters, J. M., Patterson, A., and Hankey-Giblin, P. A. (2016) The Ron Receptor Tyrosine Kinase Regulates Macrophage Heterogeneity and Plays a Protective Role in Diet-Induced Obesity, Atherosclerosis, and Hepatosteatosis. Journal of immunology (Baltimore, Md. : 1950) 197, 256-265

13. Bezerra, J. A., Carrick, T. L., Degen, J. L., Witte, D., and Degen, S. J. (1998) Biological effects of targeted inactivation of hepatocyte growth factor-like protein in mice. J Clin Invest 101, 11751183

14. Yuk, J. M., Shin, D. M., Lee, H. M., Kim, J. J., Kim, S. W., Jin, H. S., Yang, C. S., Park, K. A., Chanda, D., Kim, D. K., Huang, S. M., Lee, S. K., Lee, C. H., Kim, J. M., Song, C. H., Lee, S. Y., Hur, G. M., Moore, D. D., Choi, H. S., and Jo, E. K. (2011) The orphan nuclear receptor SHP acts as a negative regulator in inflammatory signaling triggered by Toll-like receptors. Nat Immunol 12, 742-751

15. Hardie, D. G. (2014) AMP-activated protein kinase: maintaining energy homeostasis at the cellular and whole-body levels. Annu Rev Nutr 34, 31-55

16. Donate, L. E., Gherardi, E., Srinivasan, N., Sowdhamini, R., Aparicio, S., and Blundell, T. L. (1994) Molecular evolution and domain structure of plasminogen-related growth factors (HGF/SF and HGF1/MSP). Protein Sci 3, 2378-2394

17. Nakamura, T., Sakai, K., Nakamura, T., and Matsumoto, K. (2011) Hepatocyte growth factor twenty years on: Much more than a growth factor. Journal of gastroenterology and hepatology 26 Suppl 1, 188-202

18. Wang, M. H., Zhou, Y. Q., and Chen, Y. Q. (2002) Macrophage-stimulating protein and RON receptor tyrosine kinase: potential regulators of macrophage inflammatory activities. Scand J Immunol 56, 545-553 
19. Bancks, M. P., Bielinski, S. J., Decker, P. A., Hanson, N. Q., Larson, N. B., Sicotte, H., Wassel, C. L., and Pankow, J. S. (2016) Circulating level of hepatocyte growth factor predicts incidence of type 2 diabetes mellitus: The Multi-Ethnic Study of Atherosclerosis (MESA). Metabolism: clinical and experimental 65, 64-72

20. Akour, A., Kasabri, V., Boulatova, N., Bustanji, Y., Naffa, R., Hyasat, D., Khawaja, N., Bustanji, H., Zayed, A., and Momani, M. (2016) Levels of metabolic markers in drug-naive prediabetic and type 2 diabetic patients. Acta Diabetol

21. Tsukagawa, E., Adachi, H., Hirai, Y., Enomoto, M., Fukami, A., Ogata, K., Kasahara, A., Yokoi, K., and Imaizumi, T. (2013) Independent association of elevated serum hepatocyte growth factor levels with development of insulin resistance in a 10-year prospective study. Clinical endocrinology 79, 43-48

22. de Courten, B., de Courten, M. P., Dougherty, S., Forbes, J. M., Potts, J. R., and Considine, R. V. (2013) Insulin infusion reduces hepatocyte growth factor in lean humans. Metabolism 62, 647-650

23. Kruijshoop, M., Feskens, E. J., Blaak, E. E., and de Bruin, T. W. (2004) Validation of capillary glucose measurements to detect glucose intolerance or type 2 diabetes mellitus in the general population. Clin Chim Acta 341, 33-40

24. Kato, Y., Yu, D., and Schwartz, M. Z. (1998) Hepatocyte growth factor up-regulates SGLT1 and GLUT5 gene expression after massive small bowel resection. Journal of pediatric surgery 33, 13-15

25. Jacobs, M., van Greevenbroek, M. M., van der Kallen, C. J., Ferreira, I., Blaak, E. E., Feskens, E. J., Jansen, E. H., Schalkwijk, C. G., and Stehouwer, C. D. (2009) Low-grade inflammation can partly explain the association between the metabolic syndrome and either coronary artery disease or severity of peripheral arterial disease: the CODAM study. European journal of clinical investigation 39, 437-444

26. Mensink, M., Corpeleijn, E., Feskens, E. J., Kruijshoop, M., Saris, W. H., de Bruin, T. W., and Blaak, E. E. (2003) Study on lifestyle-intervention and impaired glucose tolerance Maastricht (SLIM): design and screening results. Diabetes research and clinical practice 61, 49-58

27. Brouwers, M. C., Troutt, J. S., van Greevenbroek, M. M., Ferreira, I., Feskens, E. J., van der Kallen, C. J., Schaper, N. C., Schalkwijk, C. G., Konrad, R. J., and Stehouwer, C. D. (2011) Plasma proprotein convertase subtilisin kexin type 9 is not altered in subjects with impaired glucose metabolism and type 2 diabetes mellitus, but its relationship with non-HDL cholesterol and apolipo- protein B may be modified by type 2 diabetes mellitus: The CODAM study. Atherosclerosis 217, 263-267

28. Friedewald, W. T., Levy, R. I., and Fredrickson, D. S. (1972) Estimation of the concentration of low-density lipoprotein cholesterol in plasma, without use of the preparative ultracentrifuge. Clin Chem 18, 499-502

29. Wlazlo, N., van Greevenbroek, M. M., Ferreira, I., Jansen, E. H., Feskens, E. J., van der Kallen, C. J., Schalkwijk, C. G., Bravenboer, B., and Stehouwer, C. D. (2013) Iron metabolism is associated with adipocyte insulin resistance and plasma adiponectin: the Cohort on Diabetes and Atherosclerosis Maastricht (CODAM) study. Diabetes care 36, 309-315

30. van Greevenbroek, M. M., Jacobs, M., van der Kallen, C. J., Vermeulen, V. M., Jansen, E. H., Schalkwijk, C. G., Ferreira, I., Feskens, E. J., and Stehouwer, C. D. (2011) The cross-sectional association between insulin resistance and circulating complement C3 is partly explained by plasma alanine aminotransferase, independent of central obesity and general inflammation (the CODAM study). European journal of clinical investigation 41, 372-379

31. Levy, J. C., Matthews, D. R., and Hermans, M. P. (1998) Correct homeostasis model assessment (HOMA) evaluation uses the computer program. Diabetes care 21, 2191-2192

32. Wlazlo, N., van Greevenbroek, M. M., Ferreira, I., Feskens, E. J., van der Kallen, C. J., Schalkwijk, C. G., Bravenboer, B., and Stehouwer, C. D. (2014) Complement factor 3 is associated with insulin resistance and with incident type 2 diabetes over a 7-year follow-up period: the CODAM Study. Diabetes care 37, 1900-1909

33. Kotronen, A., Peltonen, M., Hakkarainen, A., Sevastianova, K., Bergholm, R., Johansson, L. M., Lundbom, N., Rissanen, A., Ridderstrale, M., Groop, L., Orho-Melander, M., and Yki-Jarvinen, H. (2009) Prediction of non-alcoholic fatty liver disease and liver fat using metabolic and genetic factors. Gastroenterology 137, 865-872

34. Alberti, K. G., Eckel, R. H., Grundy, S. M., Zimmet, P. Z., Cleeman, J. I., Donato, K. A., Fruchart, J. C., James, W. P., Loria, C. M., and Smith, S. C., Jr. (2009) Harmonizing the metabolic syndrome: a joint interim statement of the International Diabetes Federation Task Force on Epidemiology and Prevention; National Heart, Lung, and Blood Institute; American Heart Association; World Heart Federation; International Atherosclerosis Society; and International Association for the Study of Obesity. Circulation 120, 1640 1645 
35. van Greevenbroek, M. M., Jacobs, M., van der Kallen, C. J., Blaak, E. E., Jansen, E. H., Schalkwijk, C. G., Feskens, E. J., and Stehouwer, C. D. (2012) Human plasma complement C3 is independently associated with coronary heart disease, but only in heavy smokers (the CODAM study). Int J Cardiol 154, 158-162

36. Han, H. S., Kang, G., Kim, J. S., Choi, B. H., and Koo, S. H. (2016) Regulation of glucose metabolism from a liver-centric perspective. Exp Mol Med 48, e218

37. Florez, J. C. (2008) Newly identified loci highlight beta cell dysfunction as a key cause of type 2 diabetes: where are the insulin resistance genes? Diabetologia 51, 1100-1110

38. Kahn, S. E. (2003) The relative contributions of insulin resistance and beta-cell dysfunction to the pathophysiology of Type 2 diabetes. Diabetologia 46, 3-19
39. Horton, J. D., Goldstein, J. L., and Brown, M. S. (2002) SREBPs: activators of the complete program of cholesterol and fatty acid synthesis in the liver. J Clin Invest 109, 1125-1131

40. Simons, N., Dekker, J. M., van Greevenbroek, M. M., Nijpels, G., t Hart, L. M., van der Kallen, C. J., Schalkwijk, C. G., Schaper, N. C., Stehouwer, C. D., and Brouwers, M. C. (2016) A Common Gene Variant in Glucokinase Regulatory Protein Interacts With Glucose Metabolism on Diabetic Dyslipidemia: the Combined CODAM and Hoorn Studies. Diabetes care 39, 1811-1817 



\section{Chapter 6}

General Discussion 


\section{Novel findings of this thesis}

The metabolic syndrome (MetS) refers to a constellation of risk factors for the development of cardiovascular disease, type 2 diabetes mellitus (T2DM) and fatty liver disease. Common features of MetS include various metabolic disturbances and mostly are associated with a low-grade inflammatory state [1,2]. While macrophage stimulating protein (MSP) has been shown to participate in both inflammation [3] and metabolic dysregulation [4,5], the knowledge on its general effects in the MetS models remains very limited. In this thesis, we investigated the role of MSP in different models of MetS, specifically in the context of non-alcoholic steatohepatitis (NASH) and T2DM. The main findings of this thesis are listed below.

1. MSP activates the AMPK signaling pathway in hepatocytes and consequently inhibits expression of mediators involved in inflammation and lipogenesis under metabolic challenge conditions in vitro. (Chapter 3)

2. MSP was unable to ameliorate NASH in the female hyperlipidemic Ldlr/- (low-density lipoprotein knock out) mouse model. (Chapter 4)

3. Plasma MSP concentration is inversely associated with fasting plasma glucose in humans. (Chapter 5)

4. Plasma MSP levels could not predict the prevalence and incidence of T2DM in a human population. (Chapter 5)

5. Plasma MSP concentration is positively associated with plasma low-density lipoprotein cholesterol in humans. (Chapter 5)

In summary, a strong link of MSP with the MetS has been disclosed from both cellular studies and various clinical analyses in the present thesis, while several controversial issues and open questions have remained that need further exploration. In the current chapter, results from individual experimental chapters are brought together and the clinical potential of MSP in NASH and T2DM are discussed. In addition, after integrating the data from the present studies, an emerging link regarding MSP and sex hormones is formulated. Furthermore, as an interesting association between MSP and low-density lipoprotein (LDL) cholesterol was hit upon in the presented studies, possible mechanism about how MSP interacts with LDL cholesterol are discussed, and future perspectives are given as to how the presented work could be followed up.

\section{MSP: clinical potential and perspectives}

MSP in NASH: A possible treatment option?

The incidence and prevalence of NASH are rapidly rising to epidemic proportions around the globe. Despite a number of attempts in drug development, the treatment options of 
NASH are still poor and lack efficacy. Currently, there are no FDA (U.S. Food and Drug Administration)-approved therapies available for this disease yet.

As reviewed in detail in the current thesis (Chapter 2), emerging evidence showed that MSP plays beneficial effects in both inflammation and metabolic dysregulation, pointing towards the treatment potential of MSP in MetS. In particular, given that MSP serves as an endogenous activator of AMP-activated protein kinase (AMPK) in the liver, plus the fact that liver is the main source of MSP, exploring the therapeutic effects of MSP in $\mathrm{NASH}$, i.e., the liver equivalent of MetS, presented itself as a worthwhile research option. In line with this view, in Chapter 3, we observed that MSP inhibited the oxidized lowdensity lipoprotein (OxLDL)/ lipopolysaccharides (LPS)-induced inflammation and attenuated lipid accumulation under metabolic challenging conditions. OxLDL has been recently suggested as a crucial contributor to hepatic inflammation in NASH [6], and LPS was shown to augment the uptake of oxLDL in macrophages [7]. Therefore, MSP could reduce inflammation in the ex vivo model of NASH. Hence, we directly applied the recombinant MSP to the $L d l r^{\prime}$ - (low-density lipoprotein knock out) mice - an established NASH mouse model - as a short-term treatment (Chapter 4). Results showed that MSP could not ameliorate NASH in this mouse model. Unexpectedly, despite inconclusive data, the gene expression levels indicate that MSP even promotes the pro-inflammatory response in our model, which brings a contradictory view to the treatment prospects of MSP in NASH. In line with our data, literature studies to deliberate the effects of MSP, in particular liver inflammation, are inconsistent. Several studies showed contradictive findings towards the effects of MSP- Recepteur d'Origine Nantais (RON) signaling in response to acute hepatotoxicity: one study reported inhibition of anti-inflammatory cytokines in mice with an abolished MSP-RON signaling (RON ${ }^{-1}$ mice) [8], whereas in another study these $\mathrm{RON}^{-/}$mice exhibited attenuated hepatic inflammatory responses [9]. Additionally, disrupted MSP-RON signaling evokes Kupffer cell activation and subsequent inflammatory cytokine production, but protects hepatocytes against the noxious stimulus $[10,11]$, pointing to a possible diverse role of MSP in different cell types within the liver. Therefore, it is possible that MSP treatment primes hepatocytes to be more susceptible to the lipotoxic insult, which ultimately leads to more severe cell damage and a pro-inflammatory hepatic phenotype. Moreover, as MSP has been indicated to act as a pro-inflammatory mediator in other organs, such as adipose tissue and lung [12-14], cross-talks between organs may also contribute to the ensemble effects of MSP and may partly explain the contradictive results between in vitro and in vivo experiments described in this thesis.

Furthermore, the limitations of our mouse study (Chapter 4 ) also need to be considered: Firstly, long-term effects of MSP were not investigated. After 4-day treatment of MSP to 
NASH mouse model, we only observed upregulation in gene expression, without obvious histological changes in the liver, indicating that the responses were still in a very early stage. Particularly, the pro-inflammatory cytokine such as tumor necrosis factor-alpha (TNF- $\alpha$ ) plays a crucial role in promoting hepatocyte proliferation and survival $[15,16]$, thereby its early increase could possibly be a protective, rather than a detrimental, action in the stressed liver [17]. Thus, a longer-term application of MSP would preferably provide a clearer and more comprehensive view in terms of its treatment potential. Secondly, a dose-dependency of MSP treatment has not been investigated, and an optimal concentration of MSP for treatment therefore remains unclear, which causes further difficulty in evaluating the treatment potential of MSP. Notably, the turnover of MSP as a plasma factor has not been thoroughly studied. Thus, the relevant pharmacokinetic properties of MSP, like dosing, half-life and clearance, are still missing. At the same time, we lack knowledge about the physiological or pathological levels of MSP in animal or human populations. Thus, the current dose application of MSP largely refers to its homolog - the hepatocyte growth factor (HGF), however the possible imparity is inevitable. Furthermore, with the progress achieved in our current MSP studies, we observed few possible factors that may influence the actions of MSP (which will be further discussed in following paragraphs), i.e., the gender difference and the correlation with LDL cholesterol (Chapters 4 \& 5). Since we used female $L d / r^{\prime-}$ mice as our NASH model, those factors should be taken into consideration when assessing the treatment effects of MSP.

Taken together, it is inadequate to identify the treatment potential of MSP in NASH based on the existing evidence. However, the presented studies provide with several perspectives for future research: Firstly, studies evaluating the long-term treatment effects of MSP in NASH will be worthwhile. Such MSP treatment should be backed up by a dose-dependency study. Secondly, tissue- or cell type-specific targeting of MSP signaling would also be an interesting angle to study its treatment potential. Thirdly, testing the therapeutic effects of MSP with male mice, or using another NASH model without deliberately disturbed LDL regulation will offer new insight. Furthermore, multiple factors should be considered when considering MSP as a treatment option to NASH. We found that the circulating MSP levels vary in a very broad physiological range (Chapter 5), indicating the levels of MSP to be affected by many other factors. For example, some assumed factors such as dietary formula, the smoking habit, the menopausal status, certain systemic chronic diseases, or long-term medication history may impact on the levels of MSP. Hence, before using MSP as a therapy option, probable factors should be evaluated and some selecting criteria may be made for clinical indications and contraindications. 


\section{Clinical potential of MSP in T2DM}

T2DM affects a large part of the world population and poses a long-term burden to the societies. Currently, the knowledge about the etiology and pathogenesis of T2DM is still not fully understood, and treatment needs to be improved. There is clearly a need for gaining novel insights into the pathogenesis of T2DM, and investigating new targets that could be used to replace or support the current anti-diabetic therapies.

In this thesis, the association between MSP and T2DM was explored in Chapter 5. We showed, for the first time, that MSP is inversely associated with plasma glucose levels in human population. In view of previous in vitro findings, that MSP treatment dramatically inhibited the CAMP/ dexamethasone (Dex)-mediated glucose production and gluconeogenesis in hepatocytes via the MSP-AMPK-small heterodimer partner (SHP) signaling $[4,18]$, it can be anticipated that MSP suppresses hepatic gluconeogenesis, thus negatively regulates the systemic glucose levels. Another recent work also showed that mice with disrupted MSP signaling exhibited disturbed glucose metabolism along with higher blood glucose levels compared with control mice [19]. Such evidence supports the possibility that MSP participates in the negative regulation of the blood glucose, thus providing a basis to the therapeutic strategy of using MSP for improved glucose control in T2DM patients. Nevertheless, though MSP shows a clear inverse association with blood glucose level, the association between plasma MSP levels and T2DM prevalence was not significant after confounder adjustments, and a predictive value of MSP to the incidence of T2DM during the 7-year follow-up has not been found (Chapter 5). It is possible that MSP regulates blood glucose level mainly via glucose production in liver, whereas, during the development of insulin resistance and impaired glucose tolerance, dysfunctional pancreatic $\beta$ cells play the vital role in T2DM $[20,21]$. Hence, the prospective effects of MSP in the glucose tolerance status and incident T2DM got diminished. In conclusion, even though MSP did not show predictive value in the prevalent and incident T2DM, relevant data suggest that treatment with MSP could be explored as a new therapeutic glucose-lowering medication. Particularly, the effect of MSP in hepatic glucose metabolism should be closely investigated. In addition, dyslipidemia has been shown to tightly link with T2DM [22,23]. The newly discovered correlation of LDL cholesterol with MSP levels therefore could add to the motivation of exploring MSP for therapeutic use in T2DM and is further discussed below.

\section{MSP and the sexual hormone influence}

Numerous studies have shown that sexual hormones play an important role in the control of insulin, glucose and lipid metabolism [24-27], and their associations with obesity, cardiovascular diseases and the metabolic syndrome [28-30]. In addition, there 
is an increasing recognition on the potential influence of sexual hormones in drug effects, probably through its impact on the pharmacokinetics and pharmacodynamics of the pharmaceutical agents [31,32]. Hence, particular attention needs to be given to sex hormones when investigating any newly developed agent.

In the present thesis, we spotted several clues that the sexual hormones may interfere with the actions of MSP. In Chapter 5, we found that in the women population, the plasma levels of MSP tend to differ from pre-menopausal to post-menopausal women (median [interquartile range] $40.88 \mathrm{ng} / \mathrm{mL}$ [21.70; 72.30] in pre-menopausal women and $34.38 \mathrm{ng} / \mathrm{mL}$ [19.60; 58.03] in post-menopausal women, $p=0.061$ ). This observation may suggest that the menopausal status, specifically the sexual hormone fluctuation, influences the regulation of MSP and subsequently induces a difference in its circulating levels. It has been reported that the time since menopause makes a crucial difference in the regulation of plasma glucose in women. Early post-menopausal women tend to improve the insulin-stimulated glucose disposal rate in response to estradiol (E2), whereas late post-menopausal women react in a completely opposite manner. In parallel, AMPK in skeletal muscle was found to be upregulated by E2 in early postmenopausal women, but was suppressed in late post-menopausal women [33]. These data suggest that during menopause and the changes of sexual hormones, there is a switch in the reaction of the body to the regulation of cellular energy homeostasis. Notably, the alteration of AMPK also indicates that MSP signaling might be affected. Considering the potential influence of menopause status to MSP, in Chapter $\mathbf{5}$, all analyses were repeated with additional adjustment of menopausal status as one confounder, but the adjustment did not materially change our results. However, the possibility that MSP interacts with menopausal status and hormones cannot be excluded, because of the inability to adjust for the concrete time after menopause, which is an important parameter since the switch of reaction seems to happen after certain time of menopause $[33,34]$. Moreover, in the CODAM population women are in the minority (38.7\%) and most of them are belonging to the post-menopausal group (78.1\%). Thus, lack of sufficient numbers in each group may also contribute to the errors of menopausal status adjustment. Therefore, adjustment of signal menopausal status in this study actually cannot totally eliminate the effects of hormones. Nevertheless, we found that MSP in the male population of the CODAM study shows a clearer difference between the normal glucose metabolism (NGM) group and the T2DM group than that in women (independent t-test: Men: NGM vs. T2DM P=0.042; Women: NGM vs. T2DM P=0.503). These data indicate that after exclusion of the volatility of sex hormone levels, MSP more closely correlates to glucose tolerance regulation. In the mouse study (Chapter 4), female mice aging from 10-12 weeks were used. As mice are sexually mature by 6-8 
weeks of age [35], the hormone factors could not be fully exempted when evaluating the effects of MSP. It may also provide a possible explanation in view of the contradictive results from the in vitro (Chapter 3 ) to the in vivo (Chapter 4 ) study, since the cell experiments would not be affected by fluctuating sexual hormones. Hence, there is now evidence suggesting that sexual hormones might interfere with MSP action. Therefore, the gender issue and a more detailed analysis of sex hormonal status of subjects should be a point of attention in future investigations.

\section{MSP and LDL cholesterol}

Cholesterol metabolism plays an important role in the development of MetS. Studies have shown that cholesterol contributes to the pathogenesis of T2DM [36-38], and acts a key player in the development of NASH as well $[39,40]$. Specifically, LDL cholesterol (the low-density lipoprotein particle which carries the blood cholesterol) is referred to as "bad cholesterol" because of transporting their content of lipid molecules into artery walls, attracting macrophages, thus driving atherosclerosis, heart attacks, strokes, and other associated medical problems. Many epidemiologic studies also have highlighted the importance of reducing LDL cholesterol in preventing cardiovascular disease and MetS $[41,42]$. Hence, LDL cholesterol has been suggested as one of the primary targets of the treatment of dyslipidemia in MetS [43].

Although we showed that MSP could inhibit lipid-induced lipogenesis and attenuate lipid accumulation in hepatocytes (Chapter 3 ), to our knowledge the role of MSP in cholesterol metabolism has never been investigated. In Chapter 4, the plasma total cholesterol level in high fat, high cholesterol diet-fed mice was not altered after MSP treatment, however, the cholesterol profile has not been analyzed. In Chapter 5, we observed that MSP is strongly positively correlated with LDL cholesterol and apolipoprotein B, rather than high-density lipoprotein (HDL) cholesterol. So far, knowledge regarding MSP signaling and cholesterol is very limited in the literature: one mouse study reported that abolished MSP-RON signaling led to an increased plasma LDL/HDL ratio, and worsen the hepatic steatosis in high fat diet-fed mice [19], though the causal link was not explored. Overall, despite the unclear causative associations between MSP and LDL cholesterol, the evidence obtained from mouse and human studies points to a possible role of MSP in cholesterol metabolism, or a potential impact of cholesterol on MSP signaling. The molecular mechanism(s) how MSP interacts with LDL cholesterol remains elusive so far, but require further investigation: Firstly, future studies targeting a (putatively direct) role of MSP in cholesterol metabolism should be done (in vitro and in vivo) to provide more evidence to this link. Secondly, attention should be focused on the regulatory role of MSP in very low-density lipoprotein (VLDL) secretion, as VLDL is produced by the liver (where also MSP originates from), and LDL particles are formed from VLDL lipoproteins. 
In addition, the LDL catabolism could be an interesting starting point, for example, MSP may regulate LDL receptor expression therefore reducing the absorption of LDL particles in the circulating system. Furthermore, controlling hepatic cholesterol biosynthesis could also be one possible pathway by which MSP regulates cholesterol metabolism. Notably, AMPK regulates lipid metabolism and, in particular, controls HMG-CoA reductase, an enzyme that performs the rate-limiting step of cholesterol synthesis. Moreover, AMPK is acting at both the cellular and whole body levels [44].

In summary, the present thesis offers new insights into understanding the regulation and roles of MSP, as a novel factor, in the field of MetS. MSP showed contradictive effects in terms of inflammation in in vitro and in vivo studies of NASH, which needs further mechanistic investigation. Moreover, MSP displays strong links with metabolic dysregulation as appeared from both cellular studies and clinical analyses. The findings provide valuable evidence to the importance of MSP in the regulation of inflammation and metabolism, and new perspectives for future research.

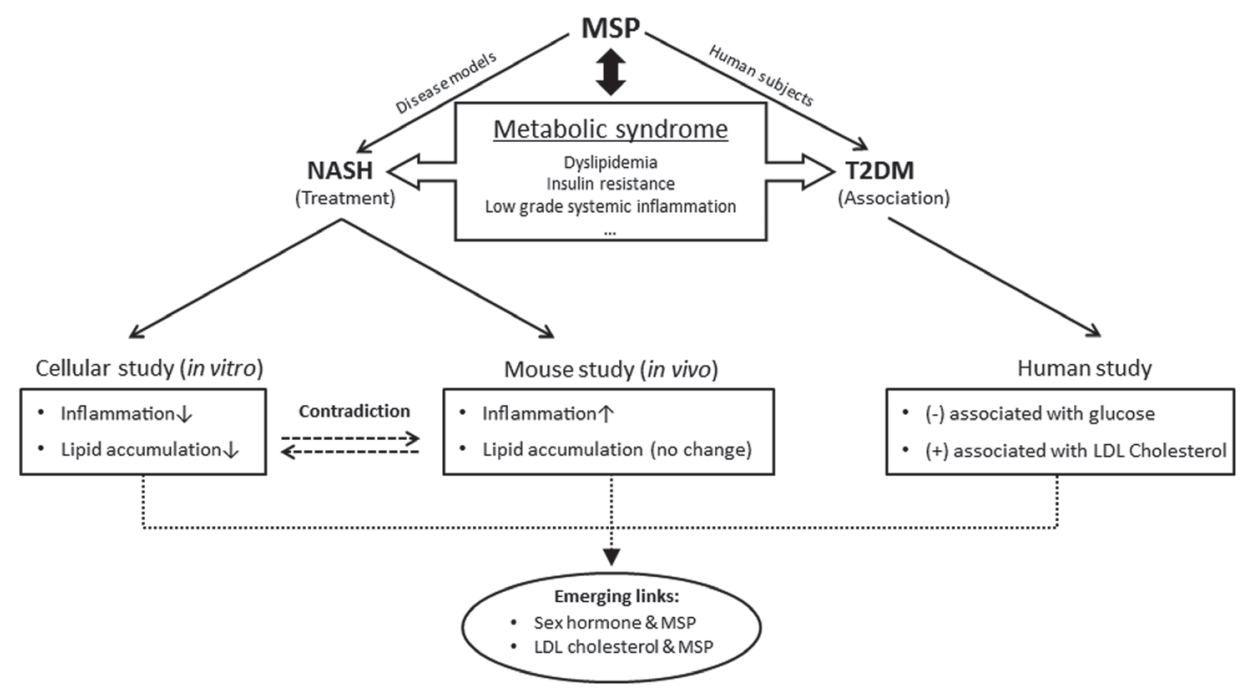

Graphical summary of this thesis. In the current thesis, we investigated the role of MSP in the field of MetS, specifically in the context of NASH and T2DM. To investigate the treatment effects of MSP in $\mathrm{NASH}$, disease models of both in vitro and in vivo were used. However, a contradiction between them was found, for which possible explanations are discussed. To explore the predictive value of MSP in T2DM, clinical investigations were conducted by studying a human cohort - the CODAM study. Significant associations of MSP with plasma glucose and cholesterol are disclosed. The emerging links between either MSP and sexual hormones, or MSP and LDL cholesterol, impact on interpretation of results and further direct future research into underlying mechanisms. 


\section{References}

1. Esser, N., Legrand-Poels, S., Piette, J., Scheen, A. J., and Paquot, N. (2014) Inflammation as a link between obesity, metabolic syndrome and type 2 diabetes. Diabetes research and clinical practice 105, 141-150

2. Haffner, S. M. (2006) The metabolic syndrome: inflammation, diabetes mellitus, and cardiovascular disease. The American journal of cardiology 97, 3a-11a

3. Wang, M. H., Zhou, Y. Q., and Chen, Y. Q. (2002) Macrophage-stimulating protein and RON receptor tyrosine kinase: potential regulators of macrophage inflammatory activities. Scand J Immunol 56, 545-553

4. Chanda, D., Li, T., Song, K. H., Kim, Y. H., Sim, J., Lee, C. H., Chiang, J. Y., and Choi, H. S. (2009) Hepatocyte growth factor family negatively regulates hepatic gluconeogenesis via induction of orphan nuclear receptor small heterodimer partner in primary hepatocytes. The Journal of biological chemistry 284, 28510-28521

5. Bezerra, J. A., Carrick, T. L., Degen, J. L., Witte, D., and Degen, S. J. (1998) Biological effects of targeted inactivation of hepatocyte growth factor-like protein in mice. J Clin Invest 101, 1175-1183

6. Walenbergh, S. M., Koek, G. H., Bieghs, V., and Shiri-Sverdlov, R. (2013) Non-alcoholic steatohepatitis: the role of oxidized low-density lipoproteins. Journal of hepatology 58, 801-810

7. Hossain, E., Ota, A., Karnan, S., Takahashi, M., Mannan, S. B., Konishi, H., and Hosokawa, Y. (2015) Lipopolysaccharide augments the uptake of oxidized LDL by up-regulating lectin-like oxidized LDL receptor-1 in macrophages. Molecular and cellular biochemistry 400, 29-40

8. Laskin, D. L., Chen, L., Hankey, P. A., and Laskin, J. D. (2010) Role of STK in mouse liver macrophage and endothelial cell responsiveness during acute endotoxemia. Journal of leukocyte biology 88, 373-382

9. Gardner, C. R., Hankey, P., Mishin, V., Francis, M., Yu, S., Laskin, J. D., and Laskin, D. L. (2012) Regulation of alternative macrophage activation in the liver following acetaminophen intoxication by stem cell-derived tyrosine kinase. Toxicology and applied pharmacology 262, 139-148

10. Stuart, W. D., Kulkarni, R. M., Gray, J. K., Vasiliauskas, J., Leonis, M. A., and Waltz, S. E. (2011) Ron receptor regulates Kupffer celldependent cytokine production and hepatocyte survival following endotoxin exposure in mice. Hepatology (Baltimore, Md.) 53, 1618-1628
11. Leonis, M. A., Toney-Earley, K., Degen, S. J., and Waltz, S. E. (2002) Deletion of the Ron receptor tyrosine kinase domain in mice provides protection from endotoxin-induced acute liver failure. Hepatology (Baltimore, Md.) 36, 10531060

12. Gunella, G., Bardelli, C., Amoruso, A., Viano, I., Balbo, P., and Brunelleschi, S. (2006) Macrophage-stimulating protein differently affects human alveolar macrophages from smoker and non-smoker patients: evaluation of respiratory burst, cytokine release and NFkappaB pathway. British journal of pharmacology 148, 478-489

13. Wang, T., Chen, X., Zhang, W., Xiang, X., Leng, C., and Jia, Q. (2015) Roles of macrophage stimulating protein and tyrosine kinase receptor RON in smoke-induced airway inflammation of rats. Int J Clin Exp Pathol 8, 8797-8808

14. Stuart, W. D., Brown, N. E., Paluch, A. M., and Waltz, S. E. (2015) Loss of Ron receptor signaling leads to reduced obesity, diabetic phenotypes and hepatic steatosis in response to high-fat diet in mice. American journal of physiology. Endocrinology and metabolism 308, E562-572

15. Yamada, Y., Kirillova, I., Peschon, J. J., and Fausto, N. (1997) Initiation of liver growth by tumor necrosis factor: deficient liver regeneration in mice lacking type I tumor necrosis factor receptor. Proceedings of the National Academy of Sciences of the United States of America 94, 1441-1446

16. Wullaert, A., Heyninck, K., and Beyaert, R. (2006) Mechanisms of crosstalk between TNFinduced NF-kappaB and JNK activation in hepatocytes. Biochemical pharmacology 72, 1090-1101

17. Hishinuma, I., Nagakawa, J., Hirota, K., Miyamoto, K., Tsukidate, K., Yamanaka, T., Katayama, K., and Yamatsu, I. (1990) Involvement of tumor necrosis factor-alpha in development of hepatic injury in galactosaminesensitized mice. Hepatology (Baltimore, Md.) 12, 1187-1191

18. Yuk, J. M., Shin, D. M., Lee, H. M., Kim, J. J., Kim, S. W., Jin, H. S., Yang, C. S., Park, K. A., Chanda, D., Kim, D. K., Huang, S. M., Lee, S. K., Lee, C. H., Kim, J. M., Song, C. H., Lee, S. Y., Hur, G. M., Moore, D. D., Choi, H. S., and Jo, E. K. (2011) The orphan nuclear receptor SHP acts as a negative regulator in inflammatory signaling triggered by Toll-like receptors. Nature immunology 12, 742751 
19. Yu, S., Allen, J. N., Dey, A., Zhang, L., Balandaram, G., Kennett, M. J., Xia, M., Xiong, N., Peters, J. M., Patterson, A., and Hankey-Giblin, P. A. (2016) The Ron Receptor Tyrosine Kinase Regulates Macrophage Heterogeneity and Plays a Protective Role in Diet-Induced Obesity, Atherosclerosis, and Hepatosteatosis. Journal of immunology (Baltimore, Md. : 1950) 197, 256265

20. Kahn, S. E. (2003) The relative contributions of insulin resistance and beta-cell dysfunction to the pathophysiology of Type 2 diabetes. Diabetologia 46, 3-19

21. Florez, J. C. (2008) Newly identified loci highlight beta cell dysfunction as a key cause of type 2 diabetes: where are the insulin resistance genes? Diabetologia 51, 1100-1110

22. Mooradian, A. D. (2009) Dyslipidemia in type 2 diabetes mellitus. Nature clinical practice. Endocrinology \& metabolism 5, 150-159

23. Brunzell, J. D., and Ayyobi, A. F. (2003) Dyslipidemia in the metabolic syndrome and type 2 diabetes mellitus. The American journal of medicine 115 Suppl 8A, 24s-28s

24. Barros, R. P., and Gustafsson, J. A. (2011) Estrogen receptors and the metabolic network. Cell metabolism 14, 289-299

25. Kalish, G. M., Barrett-Connor, E., Laughlin, G. A., and Gulanski, B. I. (2003) Association of endogenous sex hormones and insulin resistance among postmenopausal women: results from the Postmenopausal Estrogen/ Progestin Intervention Trial. The Journal of clinical endocrinology and metabolism 88, 1646-1652

26. Tarnopolsky, M. A., and Ruby, B. C. (2001) Sex differences in carbohydrate metabolism. Current opinion in clinical nutrition and metabolic care 4, 521-526

27. Wang, X., Magkos, F., and Mittendorfer, B. (2011) Sex differences in lipid and lipoprotein metabolism: it's not just about sex hormones. The Journal of clinical endocrinology and metabolism 96, 885-893

28. Banos, G., Guarner, V., and Perez-Torres, I. (2011) Sex steroid hormones, cardiovascular diseases and the metabolic syndrome. Cardiovascular \& hematological agents in medicinal chemistry 9, 137-146

29. Mayes, J. S., and Watson, G. H. (2004) Direct effects of sex steroid hormones on adipose tissues and obesity. Obesity reviews : an official journal of the International Association for the Study of Obesity 5, 197-216

30. Tchernof, A., and Despres, J. P. (2000) Sex steroid hormones, sex hormone-binding globulin, and obesity in men and women. Hormone and metabolic research $=$ Hormon- und Stoffwechselforschung $=$ Hormones et metabolisme 32, 526-536

31. Spoletini, I., Vitale, C., Malorni, W., and Rosano, G. M. (2012) Sex differences in drug effects: interaction with sex hormones in adult life. Handbook of experimental pharmacology, 91105

32. Beierle, I., Meibohm, B., and Derendorf, H. (1999) Gender differences in pharmacokinetics and pharmacodynamics. International journal of clinical pharmacology and therapeutics $\mathbf{3 7}$ 529-547

33. Park, Y. M., Pereira, R. I., Erickson, C. B., Swibas, T. A., Kang, C., and Van Pelt, R. E. (2017) Time since menopause and skeletal muscle estrogen receptors, PGC-1alpha, and AMPK. Menopause (New York, N.Y.)

34. Pereira, R. I., Casey, B. A., Swibas, T. A., Erickson, C. B., Wolfe, P., and Van Pelt, R. E. (2015) Timing of Estradiol Treatment After Menopause May Determine Benefit or Harm to Insulin Action. The Journal of clinical endocrinology and metabolism 100, 4456-4462

35. Dutta, S., and Sengupta, P. (2016) Men and mice: Relating their ages. Life sciences 152, 244 248

36. von Eckardstein, A., and Sibler, R. A. (2011) Possible contributions of lipoproteins and cholesterol to the pathogenesis of diabetes mellitus type 2. Current opinion in lipidology $\mathbf{2 2}$ 26-32

37. Kruit, J. K., Brunham, L. R., Verchere, C. B., and Hayden, M. R. (2010) HDL and LDL cholesterol significantly influence beta-cell function in type 2 diabetes mellitus. Current opinion in lipidology 21, 178-185

38. Nesto, R. W. (2005) Beyond low-density lipoprotein: addressing the atherogenic lipid triad in type 2 diabetes mellitus and the metabolic syndrome. American journal of cardiovascular drugs : drugs, devices, and other interventions 5, 379-387

39. Walenbergh, S. M., and Shiri-Sverdlov, R. (2015) Cholesterol is a significant risk factor for nonalcoholic steatohepatitis. Expert review of gastroenterology \& hepatology 9, 1343-1346

40. Ioannou, G. N. (2016) The Role of Cholesterol in the Pathogenesis of NASH. Trends in endocrinology and metabolism: TEM 27, 84-95

41. Tehrani, D. M., Zhao, Y., Blaha, M. J., Mora, S., Mackey, R. H., Michos, E. D., Budoff, M. J., Cromwell, W., Otvos, J. D., Rosenblit, P. D., and Wong, N. D. (2016) Discordance of Low-Density Lipoprotein and High-Density Lipoprotein Cholesterol Particle Versus Cholesterol Concentration for the Prediction of Cardiovascular Disease in Patients With Metabolic Syndrome and Diabetes Mellitus 
(from the Multi-Ethnic Study of Atherosclerosis [MESA]). The American journal of cardiology 117, 1921-1927

42. Baibata, D., Ionescu, G., Petcov, B., and Mancas, S. (2015) Non-High-Density Lipoproteins Cholesterol and Cardio-Metabolic Risk. Maedica 10, 33-38

43. (2002) Third Report of the National Cholesterol Education Program (NCEP) Expert Panel on Detection, Evaluation, and Treatment of High Blood Cholesterol in Adults (Adult Treatment Panel III) final report. Circulation 106, 31433421

44. 44. Hardie, D. G. (2008) AMPK: a key regulator of energy balance in the single cell and the whole organism. International journal of obesity (2005) 32 Suppl 4, S7-12 



\title{
Appendices
}

\author{
Summary \\ Samenvatting \\ 总结 \\ Valorization \\ Curriculum vitae \\ Acknowledgments
}




\section{Summary}

Macrophage stimulating protein (MSP) is a blood plasma protein which is secreted mainly by the liver and exerts its effects by binding to the receptor tyrosine kinase Recepteur d'Origine Nantais (RON). The MSP-RON signaling has been intensively studied as a suppressor during toxic substance-induced inflammation, and is suggested to additionally have a role in the hepatic lipid and glucose metabolism. Given its participation in both inflammation and metabolic dysregulation, MSP emerges as a potential player in the field of metabolic syndrome (MetS). Yet, the knowledge on the regulatory role and treatment potential of MSP in MetS remains very limited. Within this thesis, the effects of MSP, as a novel plasma factor, in the field of MetS, specifically in the context of nonalcoholic steatohepatitis (NASH) and type 2 diabetes mellitus (T2DM), were investigated.

In Chapter 2, a detailed overview of MSP as a key player in inflammation and metabolic homeostasis is provided, and the rational for the central hypothesis is explained.

In Chapter 3, the regulatory role and the molecular mechanism of MSP in the development of inflammation and in lipid metabolism are investigated in in vitro models. MSP was found to inhibit pro-inflammatory cytokine production and lipid accumulation in challenged hepatocytes. We further disclosed that those effects were mediated by the activation of the AMP-activated protein kinase (AMPK) signaling pathway. Furthermore, MSP also significantly suppressed inflammatory response in bone marrow-derived macrophage in an ex vivo model of NASH. Taken together, our data indicate that MSP acts as a key negative regulator of inflammation and of lipogenesis in vitro.

To further investigate the systemic therapeutic effects of MSP in NASH, low density lipoprotein receptor knock out (/d/r-/-) mice, an established NASH mouse model, were treated with recombinant MSP (Chapter 4). While the lipid profile and liver histology remained unaltered, mice treated with MSP demonstrated increased gene expression of pro-inflammatory mediators in the liver. Contrary to our expectations, the short-term administration of MSP did not ameliorate NASH. Within this chapter, we discussed several possible explanations about the contradictive effects of MSP from in vitro to in vivo.

Previously, in cell studies and in animal models, MSP-RON signaling has been shown to suppress glucose production, but no relevant human data are available yet. In Chapter $\mathbf{5}$, possible associations of plasma MSP with metabolic profiles, as well as with glucose tolerance and incidence of T2DM were explored by using a prospective human cohort the Cohort on Diabetes and Atherosclerosis Maastricht (CODAM). Our data showed that MSP was inversely associated with fasting glucose concentrations. However, higher baseline MSP concentrations did not appear to protect against the development T2DM 
over the 7-year follow-up period. Furthermore, MSP was prominently and positively associated with apoB-containing lipoproteins. These findings provide further evidence to the relevance of MSP in the regulation of glucose and lipid metabolism.

Finally, we brought together the results from the individual experimental chapters in Chapter 6, and discussed the clinical potential of MSP in both NASH and T2DM. In addition, an emerging link regarding MSP and sex hormones is formulated. Furthermore, as an interesting association between MSP and low density lipoprotein (LDL) cholesterol was hit upon in the studies of this thesis, possible mechanism about how MSP interacts with LDL cholesterol are discussed. Finally, future perspectives are given as to how the presented work could be followed up.

In summary, the present thesis offers new insights into understanding the regulation and (patho) physiological roles of MSP, as a novel plasma factor, in the field of MetS, and presents perspectives for future research. 


\section{Samenvatting}

Macrofaag stimulerend eiwit (macrophage stimulating protein, MSP) is een eiwit dat voorkomt in de bloedbaan en voornamelijk door de lever daarin wordt uitgescheiden. MSP bindt aan de transmembraan tyrosine kinase receptor genaamd Recepteur d'Origine Nantais (RON), die aanwezig is op verschillende cellen waaronder levercellen en macrofagen. De MSP-RON signaaltransductie cascade is veelvuldig bestudeerd omdat bekend is dat activering ervan de ontstekingsreactie (inflammatie) onderdrukt zoals die bijvoorbeeld optreedt als gevolg van de aanwezigheid van toxische stoffen. Pas recent zijn aanwijzingen verkregen dat MSP - via de MSP-RON signaaltransductie cascade een regulerende rol speelt bij zowel de vet- als de glucosehuishouding in de lever. Omdat MSP dus niet alleen bij ontstekingsreacties maar ook bij het metabolisme is betrokken, wilden wij onderzoeken of MSP een rol speelt bij het zogenoemde 'metabool syndroom' (MetS). Het MetS is een stofwisselingsaandoening die wordt veroorzaakt door het uit evenwicht raken van voedselopname en lichamelijke activiteit, en die leidt tot o.a. obesitas (zwaarlijvigheid) en verstoring van de energiehuishouding in verschillende weefsels. In dit proefschrift onderzochten we de invloed van MSP op verschillende parameters van het MetS, met name in samenhang met niet-alcoholische leververvetting (non-alcoholic steatohepatitis, NASH) en type 2 diabetes mellitus (T2DM).

In Hoofdstuk 2 wordt een overzicht gegeven van onze huidige kennis over MSP in het algemeen en de invloed van MSP op ontstekingsreacties en op de vet- en glucosehuishouding (metabole homeostase). Daarna wordt de centrale hypothese van dit proefschrift in detail toegelicht, met name gericht op de mogelijke toepassing van MSP bij de behandeling van patiënten met metabole ziekten zoals MetS, NASH of T2DM.

In Hoofdstuk 3 wordt een experimentele studie beschreven naar de regulerende rol en het werkingsmechanisme van MSP bij de ontwikkeling van een ontstekingsreactie en veranderingen in de vethuishouding zoals die optreden bij NASH. Voor deze studie is een in vitro model van NASH gebruikt. Aangetoond kon worden dat de door lipopolysaccharide (LPS) of door palmitinezuur in primaire muizenlevercellen geïnduceerde genexpressie van pro-inflammatoire cytokines door MSP wordt geremd. Deze remming verloopt via activering van het AMP-geactiveerde eiwitkinase (AMPK), een bekende 'hoofdschakelaar' voor zowel ontstekingsreacties als voor metabole homeostase. MSP behandeling van de levercellen leidde tot een aanzienlijke vermindering van de door palmitinezuur geïnduceerde vetstapeling en remde de genexpressie van belangrijke enzymen betrokken bij de vet(zuur)aanmaak in deze cellen. Na het met behulp van moleculair-biologische technieken grotendeels verwijderen ('knock-down') van RON waren deze anti-inflammatoire en anti-lipogene effecten van MSP nagenoeg verdwenen. 
Tenslotte hebben we het effect van MSP onderzocht op macrofagen uit het beenmerg. Door behandeling met geoxideerd lage dichtheidslipoproteïne (oxidized LDL, oxLDL) in combinatie met LPS wordt in deze macrofagen de activiteit van AMPK geremd en treedt een flinke ontstekingsreactie op die lijkt op de ontstekingsreactie bij NASH. Deze macrofagen zijn daarmee een goed ex vivo model voor NASH. Na behandeling van deze macrofagen met MSP zagen we een omkering van deze effecten: de AMPK activiteit werd hersteld en de productie en secretie van pro-inflammatoire cytokines werden aanzienlijk geremd. Samengenomen duiden deze bevindingen erop dat MSP, door verhoging van de activiteit van AMPK, werkt als een belangrijke negatieve regulator (remmer) van een ontstekingsreactie en van de vet(zuur)aanmaak (lipogenese).

Om het systemische therapeutische effect van MSP in NASH te onderzoeken hebben we in Hoofdstuk 4 gebruik gemaakt van muizen met een (genetische) deficiëntie van de lage dichtheidslipoproteïne receptor (Idlr knock-out of /dlr-/- muizen). Dit is een veelgebruikt in vivo model voor NASH. De ldlr-/- muizen kregen gedurende 7 dagen òf een standaardvoeding òf een voeding met een verhoogd vet- en cholesterolgehalte (high fat, high cholesterol, HFC). Gedurende de laatste 4 dagen werden ze behandeld met MSP of ter controle met een zoutoplossing. De door de HFC voeding geïnduceerde verhoging van de concentraties cholesterol en triacylglycerolen in plasma werd door behandeling met MSP niet beïnvloed. Het microscopisch beeld van de lever (histologie) was ook niet verschillend tussen de muizengroepen. Echter, in de met MSP behandelde muizen zagen we - in tegenstelling tot onze verwachting - in de lever een verhoogde productie van pro-inflammatoire en pro-apoptotische mediatoren. De korte behandeling met MSP in vivo had dus niet het op grond van de in vitro bevindingen verwachte resultaat en gaf geen vermindering van NASH. In dit hoofdstuk worden mogelijke verklaringen besproken voor deze onverwachte resultaten.

In de literatuur is eerder gerapporteerd dat activering van de MSP-RON signaaltransductie cascade in de lever de glucose productie onderdrukt. Dit is gevonden in studies met celen diermodellen. Bij de mens is dit nog niet bestudeerd. In Hoofdstuk $\mathbf{5}$ is onderzocht of het plasma MSP gehalte is veranderd bij patiënten met diabetes en/of een veranderde zogenoemde glucose tolerantie. Hiervoor is gebruik gemaakt van bloedmonsters van een prospectieve cohortstudie, het Cohort on Diabetes and Atherosclerosis Maastricht (CODAM). In de bloedmonsters is het MSP immunochemisch bepaald, terwijl gegevens over de concentraties glucose en lipiden al beschikbaar waren. Vervolgens is meervoudige lineaire regressive analyse toegepast met MSP als belangrijkste onafhankelijke variabele en verschillende metabole parameters als uitkomstmaat. Een mogelijk verband tussen het plasma MSP gehalte en de prevalentie en incidentie van T2DM is met meervoudige logistische regressive analyse geëvalueerd. Uit deze analyses kwam naar voren dat in het 
CODAM cohort het plasma MSP gehalte omgekeerd is geassocieerd met de nuchtere glucose concentratie. Een hoge MSP uitgangswaarde bleek echter niet te beschermen tegen de ontwikkeling van T2DM gedurende de 7-jaarsperiode van de studie. Daarnaast bleek het plasma MSP gehalte duidelijk positief geassocieerd met de aanwezigheid in plasma van apo-B bevattende lipoproteïnen. Deze nieuwe bevindingen onderstrepen de rol van MSP bij de regulatie van de vet- en glucosestofwisseling.

Tenslotte zijn in Hoofdstuk 6 de resultaten van de verschillende experimentele studies samengebracht en bediscussieerd. Daarbij is speciale aandacht besteed aan de mogelijke toepassing van MSP in de kliniek, met name bij NASH en bij T2DM. Ook is een nieuwe hypothese geformuleerd over het verband tussen MSP en geslachtshormonen. Gezien de gevonden relatie tussen plasma MSP en lage dichtheidslipoproteïne (LDL) is bediscussieerd via welk mechanisme MSP het LDL cholesterol zou kunnen beïnvloeden. Tenslotte is aangegeven hoe in vervolgstudies verder inzicht kan worden verkregen in de rol van MSP bij MetS.

Samenvattend kan gesteld worden dat met de in dit proefschrift beschreven studies veel nieuwe kennis is verkregen over de rol van MSP onder normale en afwijkende (pathofysiologische) omstandigheden, met name ten aanzien van het metabool syndroom (MetS). In vervolgonderzoek kan deze nieuwe kennis worden toegepast bij het vinden van nieuwe behandelingsopties voor het metabool syndroom. 


\section{总结}

巨噬细胞刺激蛋白 (MSP) 是一种主要由肝脏分泌的血浆蛋白。它通过与其受体 (RON) 结合而发挥生物效应。MSP-RON通路已经被研究证实在外源毒性物质引发 的炎症中起到抑制作用。同时, 近期的研究也指出其在肝脏糖脂代谢中的潜在效 应。鉴于其在炎症与代谢中的双重作用, MSP展示出了其在代谢综合征中的潜在 研究价值。但目前此项研究仍属空白。在本论文中, 我们研究了MSP 在代谢综合 征，尤其是非酒精性脂肪性肝炎 (NASH) 及2型糖尿病 (T2DM) 中的作用。

第二章详细地总结和回顾了关于MSP分别在炎症及代谢中的作用。此外，也更深 入地讨论了本论文的中心假说与思想。

第三章中, 我们通过体外模型, 研究了MSP在炎症与脂代谢紊乱中的效应。结果 证实, MSP可以有效地抑制脂毒性引起的炎症及脂质蓄积。并且, 我们发现此效 应由AMP依赖的蛋白激酶 (AMPK) 介导。此外, 在模拟NASH的体外实验模型中, 我们观察到了类似的作用。由此, 我们证明了MSP在体外模型中可对炎症与脂质 生成进行负向调节。

为了进一步证实MSP在治疗 NASH中更系统性的作用, 我们利用基因敲除小鼠建立 了NASH小鼠模型, 并给予小鼠重组MSP蛋白作为治疗方案 (第四章)。结果发 现, MSP治疗并未改变小鼠的血脂及肝脂水平。但是, 我们发现MSP治疗后的小 鼠的肝脏中出现了上调的炎症基因。与我们的预测相反, MSP并没有在NASH的动 物模型中起到有效治疗作用。在此章节中, 我们充分讨论了造成这种体内和体外 模型的矛盾结果的可能原因。

在以往的研究中显示, MSP可以抑制糖的生成。但针对此作用的研究目前只局限 于使用细胞及动物模型, 相关的人群数据仍然空白。在第五章中, 通过对CODAM 数据库的前瞻性队列研究, 我们分析了MSP与人体内各项代谢性指标的关系。数 据显示MSP与空腹血糖水平呈负相关。同时, 我们发现了MSP与总胆固醇以及低 密度脂蛋白胆固醇的强正相关关系。这些研究结果更进一步证实了MSP在人体中 糖脂代谢中的重要作用。

最后, 在第六章中, 我们将以上各个章节的结果汇总分析, 并对MSP对于NASH和 T2DM的临床潜在应用进行了详细讨论。此外, 我们讨论并总结出了与MSP存在潜 在相关性的几种影响因素: 性激素以及低密度脂蛋白胆固醇。最后, 针对目前研 究中待解决的问题, 我们提出了对未来的研究方向的建议。

总的来说, 此论文为MSP在代谢综合征中的病理生理作用提供了新的见解。 


\section{Valorization}

\section{Social and clinical relevance}

Metabolic syndrome (MetS) has become a worldwide health threat. Today, approximately one quarter of the adult world population has MetS. Despite the availability of a number of treatment options that ameliorate specific aspects of MetS, their overall curative effect is unsatisfactory. Moreover, public prevention programs largely failed their targets. Consequently, the prevalence of MetS is still increasing and the burden on healthcare systems and treatment cost is rising dramatically.

Clinical and epidemiologic studies have tightly associated the MetS with non-alcoholic fatty liver disease (NAFLD) - a disease consisting of a variety of steatosis-induced liver pathologies [1]. Non-alcoholic steatohepatitis (NASH) represents the stage that is composed of steatosis and hepatic inflammation, and could lead to irreversible liver damage and sets the stage for further liver injury, like cirrhosis and liver cancer [2]. Currently, the accurately-defined prevalence of NASH remains largely unknown due to the limitation of histological diagnosis. A recent report estimates that around $25 \%$ of the global population is suffering from NAFLD, and the prevalence of NASH among biopsied NAFLD patients has increased to around 60\% [3]. Thus, NASH has become a major publichealth challenge worldwide. In addition, type 2 diabetes mellitus (T2DM), another metabolic disorder which is tightly linked to MetS is investigated in this thesis as well. T2DM affects a large part of the world population and poses a long-term burden to the societies. However, despite a number of attempts in drug development, there is still no effective treatment for NASH. Similarly, the overall curative effects of T2DM are lacking satisfaction and need to be improved.

In this thesis, we proposed macrophage stimulating protein (MSP) as a novel target in the therapeutic strategies of NASH. The novel findings obtained in this thesis show the diversity of the treatment outcome of MSP. Hence, future studies are needed to clarify its therapeutic potential in NASH. Moreover, several clues about the influence factors, e.g. gender and lipid profile, that may impact its therapeutic effects are given by this thesis. These findings suggest that before using MSP as a therapy option, probable factors should be evaluated and some selecting criteria could be made for clinical indications and contraindications. In light of those discoveries, our findings hold significance in optimizing MSP as a clinical target in NASH. In Chapter 5, we determined an inverse association between plasma MSP and glucose. This finding may benefit the accuracy of the prognosis in T2DM, and provides a new hidden therapeutic connection with hyperglycemia. In addition, the newly discovered correlation of low density lipoprotein cholesterol with MSP levels also adds to the motivation of exploring MSP for 
therapeutic use in dyslipidemia. Furthermore, the novel links between MSP with glucose and cholesterol could possibly lead to identification of a new biomarker for T2DM and its complications. Considering the high occurrence of T2DM and the diabetes dyslipidemia $[4,5]$, our findings holds significant promise to its clinical application related to T2DM. As such, our studies could positively affect the economic burden related to NASH and T2DM.

\section{Novelty of the concept}

Within this thesis, we investigated a novel protein - MSP- as a key factor and a potential treatment target in the MetS. Currently, the investigation about MSP is mainly limited to the fields of cancer and inflammation, while the other aspects of this protein are still largely unknown. Hence, this presented work provides novel insights in a more comprehensive view of the functions of MSP. Moreover, while most studies focus on the separate role of MSP in inflammation or lipid/glucose regulation, the current thesis investigates its systemic therapeutic effects in NASH models. We therefore provide the innovative views regarding to the treatment potential of MSP in NASH. In addition, while the investigations about MSP were confined in different cellular or animal models, this current work explores the associations of MSP with the metabolic profile in human population, and uncovers the novel links between MSP with glucose and cholesterols. This innovative study thus provides more direct evidence about the clinical potential of MSP.

\section{Future perspectives \& Potential application}

Findings from this thesis showed that the treatment effect of MSP in NASH is discrepant, and it may be affected by several factors like hormones and lipids. Based on the current findings, several future perspectives regarding to the application of MSP could be given: Firstly, the longer-term treatment effects of MSP in NASH will be worthwhile to explore. Secondly, in view of the potential influence of sexual hormones to the action of MSP, gender difference should be considered when utilizing MSP in clinical practice. Furthermore, multiple factors that may affect the effects of MSP should be further investigated and clarified. Before using MSP as a therapy option, the influence factors are suggested to be evaluated and the selecting criteria could be made for clinical indications and contraindications. For instance, menopausal status might be used as an instruction of dose usage, or considered as selecting criteria. In addition, patients with hypercholesterolemia need carefully evaluation before receiving MSP supplement.

Additionally, regarding to its inverse association with glucose, MSP may be considered as a negative regulator of plasma glucose. Further studies focusing on treatment effects of MSP in T2DM models is worthwhile, and the effect of MSP in particular hepatic glucose 
metabolism should be closely investigated. As an endogenous factor which is constitutively generated in the body, MSP has great advantages to be implemented in clinical application compared to synthetic drugs by virtue of its safe and stable nature. Therefore, the supplement of recombinant MSP may serve as a promising treatment option for T2DM patients.

Taken together, in light of the discoveries described in this thesis, our findings hold significance in optimizing MSP as a clinical target in NASH, and could provide proof-ofprinciple for MSP supplements as an anti-diabetic strategy. 


\section{References}

1. Chalasani, N., Younossi, Z., Lavine, J. E., Diehl, A. M., Brunt, E. M., Cusi, K., Charlton, M., and Sanyal, A. J. (2012) The diagnosis and management of non-alcoholic fatty liver disease: practice Guideline by the American Association for the Study of Liver Diseases, American College of Gastroenterology, and the American Gastroenterological Association. Hepatology (Baltimore, Md.) 55, 2005-2023

2. LaBrecque, D. R., Abbas, Z., Anania, F., Ferenci, P., Khan, A. G., Goh, K. L., Hamid, S. S., Isakov, V., Lizarzabal, M., Penaranda, M. M., Ramos, J. F., Sarin, S., Stimac, D., Thomson, A. B., Umar, M., Krabshuis, J., and LeMair, A. (2014) World Gastroenterology Organisation global guidelines: Nonalcoholic fatty liver disease and nonalcoholic steatohepatitis. J Clin Gastroenterol 48, 467-473
3. Younossi, Z. M., Koenig, A. B., Abdelatif, D., Fazel, Y., Henry, L., and Wymer, M. (2016) Global epidemiology of nonalcoholic fatty liver disease-Meta-analytic assessment of prevalence, incidence, and outcomes. Hepatology (Baltimore, Md.) 64, 73-84

4. Mooradian, A. D. (2009) Dyslipidemia in type 2 diabetes mellitus. Nature clinical practice. Endocrinology \& metabolism 5, 150-159

5. Brunzell, J. D., and Ayyobi, A. F. (2003) Dyslipidemia in the metabolic syndrome and type 2 diabetes mellitus. The American journal of medicine 115 Suppl 8A, 24s-28s 


\section{Curriculum Vitae}

Jieyi Li was born on the 19th of August, 1988 in Henan, China. In September 2006, she was admitted by Zhengzhou University to study Clinical Medicine and there she joined in a seven-year-joint program for a combination of Bachelor and Master study (2006-2013). Since 2011, she performed an internship in Department of Endocrinology and Metabolic Diseases, the 1st Affiliated Hospital of Zhengzhou University. In 2012, she was qualified as a medical practitioner in China. After receiving her Master Degree of Medicine in 2013, she received a scholarship from China Scholarship Council (CSC) and started her scientific career as a PhD student in Molecular Genetics Department of Maastricht University, under close supervision of Prof. dr. R. Shiri-Sverdlov, Prof. dr. J.F.C. Glatz, and Dr. D. Neumann (2013-2017). The topic of her research was focused on the role of macrophage stimulating protein (MSP) in the field of metabolic syndrome. In January 2017, she received a position as a clinician from Tongji hospital in Wuhan, China. With this offer, she will start her training by following the national standardized training protocol in November 2017 and be specialized at Endocrinology in Tongji hospital afterwards. 


\section{List of publications}

1. Li J, Chanda D, Shiri-Sverdlov R, Neumann D. MSP: an emerging player in metabolic syndrome. Cytokine \& growth factor reviews 26, 75-82

2. Chanda $D$, Li J , Oligschlaeger $Y$, Jeurissen ML, Houben T, Walenbergh SM, Shiri-Sverdlov $R$, Neumann D. MSP is a negative regulator of inflammation and lipogenesis in ex vivo models of non-alcoholic steatohepatitis.EMM.2016. Exp Mol Med 48, e258

3. Li J, Chanda D, van Gorp PJ, Jeurissen ML, Houben T, Walenbergh SM, Debets J, Oligschlaeger Y, Gijbels MJ, Neumann D, Shiri-Sverdlov R. Macrophage stimulating protein enhances hepatic inflammation in a NASH model. PloS one 11, e0163843

4. Li J, van Greevenbroek MM, Coumans WA, Chanda D, Jocken JWE, van der Kallen CJ, Stehouwer CD, Schalkwijk CG, Glatz JFC, Shiri-Sverdlov R, Neumann D. Macrophage stimulating protein (MSP) is inversely associated with fasting plasma glucose: The CODAM Study. (Submitted)

5. Jeurissen ML, Walenbergh SM, Houben T, Hendrikx T, Li J, Oligschlaeger Y, van Gorp PJ, Gijbels MJ, Bitorina A, Nessel I, Radtke F, Vooijs M, Theys J, Shiri-Sverdlov R. Myeloid DLL4 does not contribute to the pathogenesis of Non-Alcoholic SteatoHepatitis in Ldlr/- mice. PloS one 11, e0167199

6. Jeurissen ML, Walenbergh SM, Gijbels MJ, Li J, Houben T, Hendrikx T, Oligschlaeger Y, van Gorp PJ, Binder CJ, Donners MM, Shiri-Sverdlov R. Prevention of oxLDL uptake leads to a moderate decrease of atherosclerosis in hematopoietic NPC1-deficient Ldlr/- mice. Atherosclerosis 255, 59-65

7. Chanda D, Oligschlaeger Y, Geraets I, Liu Y, Zhu X, Li J, Nabben M, Coumans W, Luiken JJFP, Glatz JFC, Neumann D. 2-Arachidonoylglycerol reverses inflammation-induced insulin resistance in cardiomyocytes. The Journal of biological chemistry (In press) 


\section{Acknowledgement}

Four years ago, I took my first flight to a completely foreign city - Maastricht - for my PhD study. Although my families and friends fear that it would be a super arduous journey, it turned out that those four years has become one of the happiest times in my life. Now I have to say, Maastricht is like my second home, where I had so much fantastic memories with so many nice people. I feel so lucky to be well surrounded and supported by my family, friends, and colleagues. Hereby, I would like to express my gratitude and my thanks.

My first appreciation goes to my supervision team. Ronit, many thanks for the support and confidence you have always given me. I still remember your warm care during my first few weeks in the department. It really released me from stress and helped me to get into the new environment. Every time I feel confused, no matter it is about the work or life, I know you are always there for me. From you I see a superwoman balancing her career and life perfectly, and being a successful researcher as well as a great mother at the same time. To me, you are not only a great supervisor, but also a life coach.

Jan, thanks for supporting me to apply for the CSC scholarship and accepting me as a member of Molecular Genetics. You are always with kind smiles which make me feel so warm. During our lab chats, your great comments and ideas inspired me a lot. Thanks to your support, I had really wonderful years in our department and I am so proud to be one of the "Molgeners".

To Dietbert, firstly, I would like to thank you for kindly inviting me as a member of your group. It is you who lead me to Maastricht and create this wonderful start for me. You cannot image how excited and grateful when I received your nice offer after my first (and nervous) skype interview. Thanks for always being there for my questions. I feel so relieved that I could talk to you because you will always be able to help me getting out of the mess. Your earnest, erudition and clear logic show me how a real scientist should be. Furthermore, I would like to thank both current and former colleagues in the Department of Molecular Genetics:

My dear paranymph, Yvonne, you are like a big sister to me, although we are around the similar age. In my memory, you are always the one who take care of the others and would like to offer your hands. When I was clueless in searching help in the lab, once I saw you, I know I am safe. When I stayed at home alone during my maternity leave, your nice greetings and mental support made me surrounded with extra love. Thanks for all your warm cares on me. You are always so sweet, just like the many candies and chocolates you brought to the office. Dear Ilvy, my desk neighbor, I was amazed by your 
earnest and passion during working. You are a great colleague who could infect me with your enthusiasm. More than that, you are a good listener, who always made me feel so comfortable to talk, to share. Thanks for the warm memories you gave to me. Wish you good luck in your career! And what is more, enjoy your soccer!

Joost, the memories from you are full of happy laughter! If you do not mind, I would like to nominate you as one of the cutest PIs that I know so far. I admire your open way to express emotions. I still remembered the happiness and excitement in your face when you saw a positive western blot result, and you could not wait to share this with everybody. Thanks for all those happy memories! Willem, my first impression is that you are a serious person. Yes, you do treat the science and research seriously. However, seriousness does not affect the fact that you are a nice person to talk. Despite only few times, I feel very comfortable to chat with you. From you I learned the precise attitude about science, and the way to handle with the tension before the presentation. Also, I would like to thank you for giving me a lot encouragements and supports during our lab chats and journal clubs.

Tom, I enjoy the time working with you. You are so efficient and organized in work. From you I already see a star scientist of tomorrow. I will also miss our interesting and longlasting chats. Good luck with your promotion and I have no doubt that you will make it perfect! Mike, my cute roommate, you are always so nice and patient to help me with the lab protocols, and of course, the Dutch letter translation. I am also impressed by your diligent working. Really hope you find your dream job because you deserve the best! Patrick, thanks for helping me to organize my first animal experiment, showing me the techniques in details, and all kinds of orderings. All the best to your new position! Sofie, Thanks for the good care you gave to me when I just arrived here. You firstly showed me how enjoyable it can be to do the lab work. I also appreciate all kinds of helps you offered me: the techniques, the presentations, the manuscript, and all your great tips. Albert, I admire your powerful thinking and creative scientific ideas. Wish you good luck in your research! And enjoy your Xboxes and PSs! Dip, thanks for your guidance for the first few years. Without you I could not participate in this MSP project and will not be able to accomplish this thesis on time. Marie, I will always remember your sweet smiles and our nice talks, also, your special way to pronounce Junfang's name in Chinese, haha, so cute. Hope you have a bright future in your new career! Miranda, thanks for always being nice and friendly to me! Petra, I really appreciate your kindness in assisting Junfang and me to arrange our promotions. It will be much more difficult without your great experience and help. Thanks to you, we are able to share this memorable day together! Henny, Hanneke, Vivian, Will, Marion, Aomin, Tim, Armand, I enjoyed the moments with you during the lab working, as well as all kinds of activities in our department and thanks to 
you all!

I also got great help from nice people of the other departments and universities: Marleen, I would like to thank you for your guidance and discussion with the statistical analyses. Without your passionate participation and input, the chapter 5 in this thesis could not have been successfully conducted. Mieke and Minh, thanks for being so kind, and I appreciate our nice talks in the coffee corner. Dear Prof. M.K.C. Hesselink, Prof. J.M. Dekker, Prof. D. Lütjohann, and Dr. G.H. Koek, thank you for joining the assessment committee, critically assessing my thesis and granting its approval. Moreover, I would also like to thank China Scholarship Council (CSC) for the financial support granted through my predoctoral fellowship.

Next greetings go to my dear friends, who have accompanied me through this colorful journey and enriched my life.

Hey, David and Sophie, so many thanks to you! My life in Maastricht would not be so wonderful without your participation! I will never forget the happy moments that we shared together: our various Dutch and Chinese dinners; our fantastic trip to Sweden; our special tour in China; and I feel so happy and honored to have you in my wedding ceremony! I really appreciate all the great helps you offer to our new family, especially the precious family crib for Zhiqi. I will miss you so much but I am sure that we will keep in touch. Looking forward to meeting both of you, and of course together with adorable little Floor, again in China!

Frans, thanks so much for picking Junfang and me up in Dusseldorf, when we really need the help. Kiran, Kim, and Victor, I really enjoyed the time that we spent together in Brazil. Anne-Claire and Jules, I have so much happy memories with you in Sweden. Thanks for all you guys, I harvest so many unforgettable moments in my life. Wish you all the best for your future!

辛莹, 亲爱的小师妹, 我们的缘分从五年前的郑州大学就开始了。真的很高兴 你能来到马城, 仿佛我身边又多了一个亲人。你总是那么体贴耐心, 在我被统计 学搞的一头雾水时, 感谢你不厌其烦地帮我理清头绪。在致祺出生后, 你跑前跑 后地照顾，给我们带来了一些难得的闲暇时光。希望你在接下来的日子科研顺 利, 爱情圆满。等到你毕业回国后, 我们再续前缘。张硕，我们的午餐拍档。当 然, 我们之间的交集远不止于这四楼的午餐时光。麻将, 三国杀, 烧烤, 火锅, 科隆, 海德堡, 巴黎……满满的都是我们之间友谊的印迹。你是一个如此新潮的 人, 如此兴趣广泛, 经常会介绍给我们新鲜事物, 带来一些奇思妙想。感谢你, 展示给了我们一个更多可能的世界。希望你和安攀的未来也充满无限可能。华仔 和徐青, 同为河医人, 同乐在马城, 同时迎来了新的家庭小成员, 除了缘分, 我 们还能说什么呢? 难忘我们一同走过的相互扶持的日子。希望你们在最后的一年 
里顺顺利利, 找到心仪的工作。也祝福小玉米健康成长！小庆和轶林, 多亏有了 你们, 我在初进实验室时才不会那么陌生和无助。好怀念之前我们在实验室的欢 声笑语, 谈天说地。现在我们各自开始了新的生活轨迹, 虽然不再聚在一处, 但 各自都在属于自己的幸福之路上奔跑。希望你们的未来都越来越好! 王萍, 萍 姐, 谢谢你经常为我们介绍荷兰的节日文化, 提供给我们各种有用的信息, 让我 们能更好地体会和享受荷兰的生活。也感谢你和开美的热情招待, 每次都可以给 我们带来新的体验。祝福你们享受每一天! 正哥和品睿, 每次打开朋友圈, 都会 被你们各式各样的菜式所惊艳。感谢你们贴心地在我怀孕时送来的爱心午餐, 除 了美食, 我还得到了心中满满的温暖。懂得享受美食的人生才是有乐趣的人生, 希望你们的日子越来越有乐趣! 饶大夫, 你来自南方, 但却习惯了我们用“大夫” 这个北方词汇称呼你。虽然你是医学前辈, 但我们与你相处时却丝毫不觉拘束。 怀念我们一同出行游玩的美好时光。希望你在上海的事业越来越好, 期待以后相 聚交流! 江峰, 我心目中的马城大哥大, 感谢我们曾经在一起谈笑风生的美好时 光。也好高兴看到你在事业上取得好的成绩。期待一切一帆风顺！我们回郑州了 再相聚。于亮, 于老板, 祝贺你顺利找到理想职位! 希望你和梅艳能一直甜甜蜜 蜜下去。张明, 天宇, 活泼的中国小妹妹们, 希望你们在马城的日子能天天开 心。

我亲爱的家人, 我最棒的爸, 感谢你二十几年来为我遮风挡雨, 感谢你努力拼 搏去为给我们提供更好的生长环境, 更感谢你从未停歇的对我的鼓励。没有你当 初的认真执着, 我和俊芳也不会萌生出国读博的想法; 没有你一如既往的支持, 我们也不会一步一步坚持走到今天。有你在我身边, 我感觉安心, 自豪, 幸福。 感谢你, 你是我们家最强大的后盾。妈, 是你一直在用心经营着咱们这个家, 有 了你, 这个家才会如此温暖。妹妹, 我最亲爱的小宝儿, 姐姐一直在努力, 希望 能让你的生活中不再有压力烦恼, 过自己想过的生活, 开心就好。致祺, 我的宝 贝, 此刻你刚刚和爸爸妈妈经历了一场关于奶瓶的战争, 毫无悬念, 你赢了。你 的到来为妈妈的博士生涯画上了圆满的一笔, 也让妈妈在这最后一段紧张准备的 日子中焦头烂额。但是, 你拥有世界上最神奇的笑容, 所有的瘦劳都会随着你的 咯咯一笑而一扫而空。感谢你, 选择我们做了你的父母。感谢你, 带给了我们如 此多如此多的幸福。

最后, 俊芳, 老公, 我生命的另一半。十一年了, 我们一路携手走到了今天。 在这十一年里, 从郑州到马城, 你我像是对方的影子, 从未真正分开过。我早已 习惯了你的每一句语气, 每一个动作, 每一丝眼神。神奇的是, 我们的感情从未 因为习惯而裉色。我想, 这种神奇会继续到下个十一年, 二十二年, 三十三 年……感谢你, 陪在我身边, 无论悲伤或喜悦, 无论顺途与挫折。谨以此书致谢 你, 俊芳, 我的爱人。 
